Stress and Burnout in Canadian Midwives

By

Francis Schryer LeBel

August, 2008. Halifax, Nova Scotia

A Thesis Submitted to

Saint Mary's University, Halifax, Nova Scotia in Partial Fulfillment of the Requirements for the Degree of Masters of Applied Psychology

Copyright Francis Schryer LeBel, 2008

Approved:

Dr. Arla Day

Supervisor

Approved:

Dr. Vic Catano

Committee Member

Approved:

Dr. Lori Francis

Committee Member

Approved: Dr. Michael P. Leiter

External Examiner

Date:

August 29, 2008 


$\begin{array}{ll}\begin{array}{l}\text { Library and } \\ \text { Archives Canada }\end{array} & \begin{array}{l}\text { Bibliothèque et } \\ \text { Archives Canada }\end{array} \\ \begin{array}{l}\text { Published Heritage } \\ \text { Branch }\end{array} & \begin{array}{l}\text { Direction du } \\ \text { Patrimoine de l'édition }\end{array} \\ \begin{array}{l}\text { 395 Wellington Street } \\ \text { Ottawa ON K1A 0N4 } \\ \text { Canada }\end{array} & \begin{array}{l}\text { 395, rue Wellington } \\ \text { Ottawa ON K1A 0N4 } \\ \text { Canada }\end{array}\end{array}$

Your file Votre référence ISBN: 978-0-494-44664-5 Our file Notre référence ISBN: 978-0-494-44664-5

NOTICE:

The author has granted a nonexclusive license allowing Library and Archives Canada to reproduce, publish, archive, preserve, conserve, communicate to the public by telecommunication or on the Internet, loan, distribute and sell theses worldwide, for commercial or noncommercial purposes, in microform, paper, electronic and/or any other formats.

The author retains copyright ownership and moral rights in this thesis. Neither the thesis nor substantial extracts from it may be printed or otherwise reproduced without the author's permission.
AVIS:

L'auteur a accordé une licence non exclusive permettant à la Bibliothèque et Archives Canada de reproduire, publier, archiver, sauvegarder, conserver, transmettre au public par télécommunication ou par l'Internet, prêter, distribuer et vendre des thèses partout dans le monde, à des fins commerciales ou autres, sur support microforme, papier, électronique et/ou autres formats.

L'auteur conserve la propriété du droit d'auteur et des droits moraux qui protège cette thèse. $\mathrm{Ni}$ la thèse ni des extraits substantiels de celle-ci ne doivent être imprimés ou autrement reproduits sans son autorisation.
In compliance with the Canadian Privacy Act some supporting forms may have been removed from this thesis.

While these forms may be included in the document page count, their removal does not represent any loss of content from the thesis.
Conformément à la loi canadienne sur la protection de la vie privée, quelques formulaires secondaires ont été enlevés de cette thèse.

Bien que ces formulaires aient inclus dans la pagination, il n'y aura aucun contenu manquant.

\section{Canada}




\title{
Stress and Burnout in Canadian Midwives
}

by Francis Schryer LeBel

\begin{abstract}
Although there is a recognized need to grow midwifery in Canada, Canadian midwives face a number of unique challenges that may exacerbate their levels of stress and burnout, and negatively influence their experience of work-life balance. Semi-structured interviews were conducted with 6 midwives and 3 subject matter experts to provide context for a valid national survey instrument. I tested the relationship among 6 categories of occupational stressors with strain, burnout, and work-life balance, as well as the buffering role of perceived job control and support variables using a national sample of 233 midwives. Results show that job control, social support, the quality of midwives' relationships, role conflict, and compensation are important predictors of strain, burnout, and work-life balance in Canadian midwives. Results are mixed regarding the buffering role of perceived job control and support variables. These findings have practical implications for Canadian midwives and theoretical implications for occupational stress research.
\end{abstract}

August 29, 2008 


\section{Table of Contents}

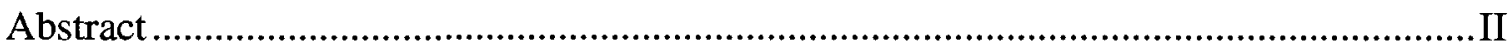

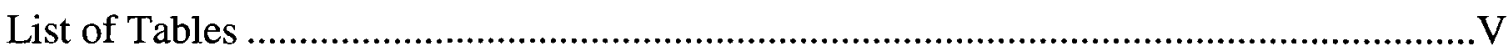

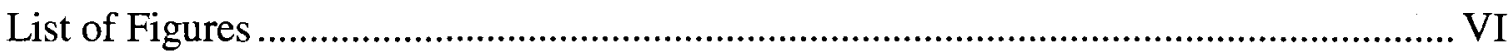

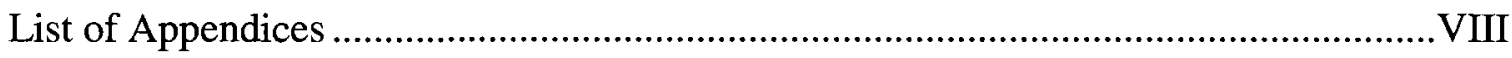

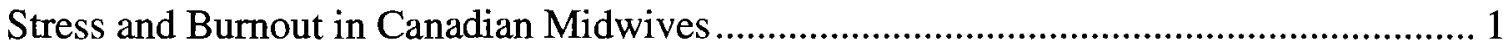

Canadian midwifery in an international context ............................................... 2

Stress, burnout, and work-life balance .............................................................. 6

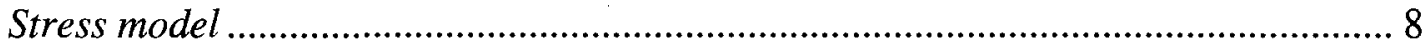

Study 1: Identifying the experiences of Canadian midwives.................................. 22

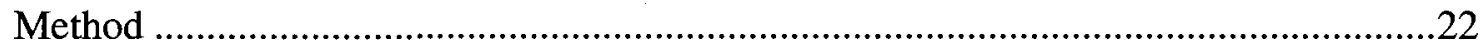

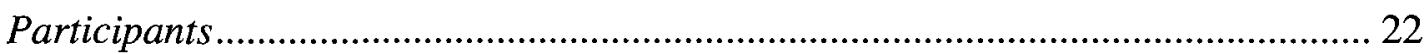

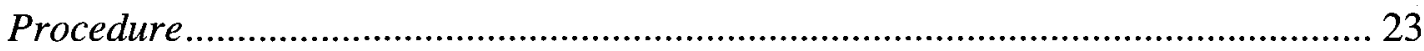

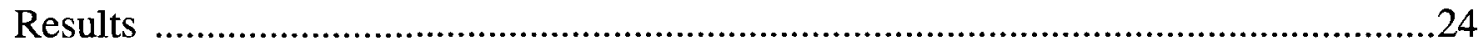

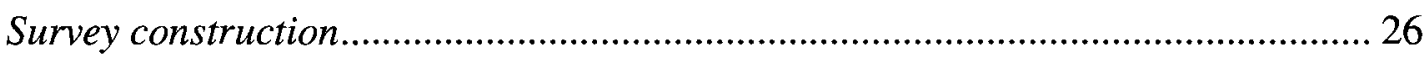

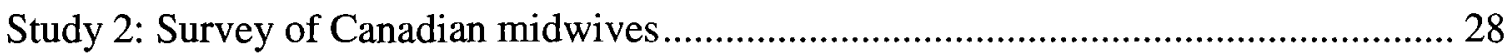

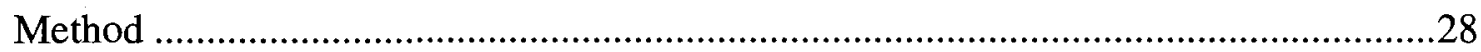

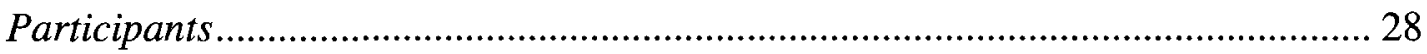

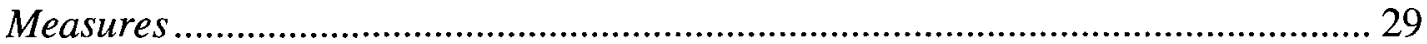

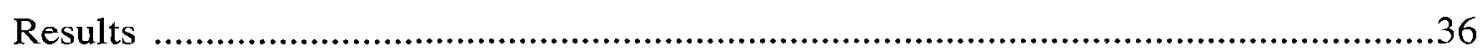

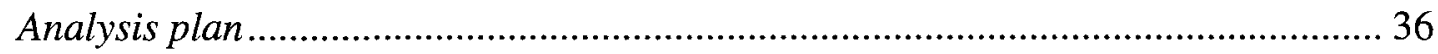

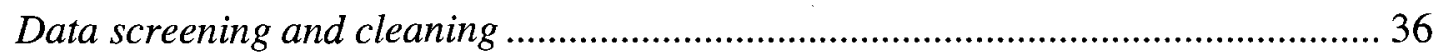

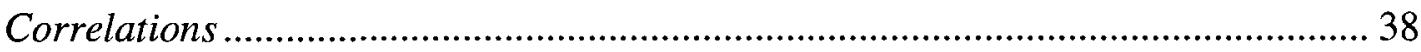




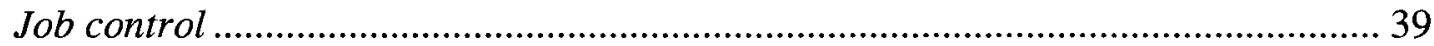

Interpersonal relationships ................................................................................... 40

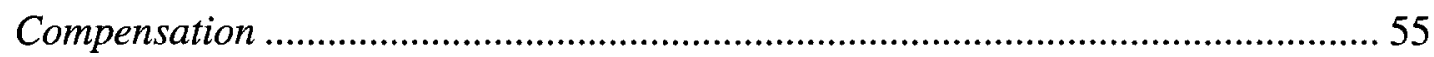

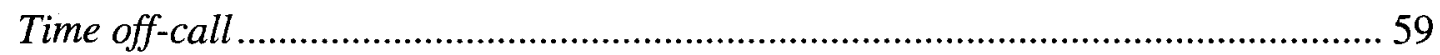

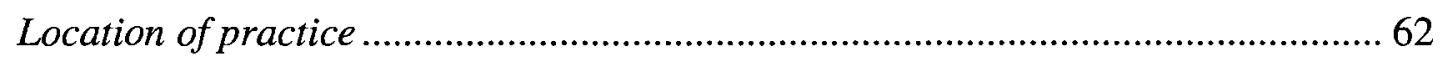

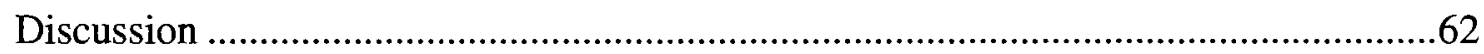

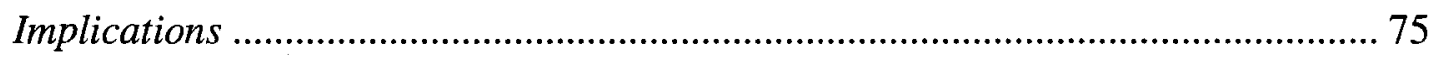

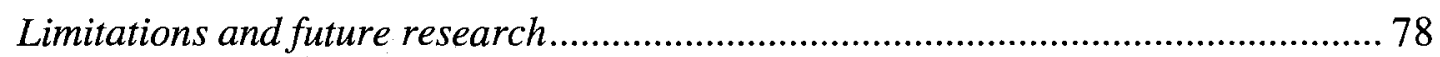

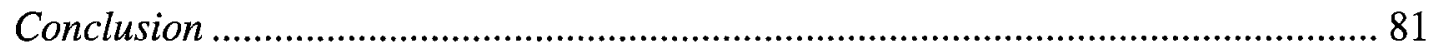

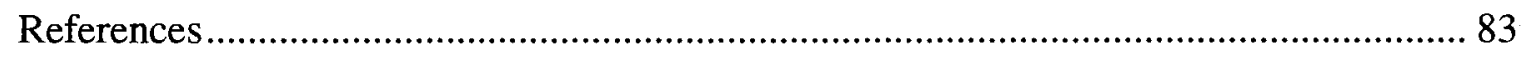




\section{List of Tables}

Table 1. Descriptives and Correlations for Variables Included in Main Analyses

Table 2. Relationship Stressors Predicting Strain, Burnout, and Work-Life Balance; Job Control as a Moderator.

Table 3. Workload Predicting Strain, Burnout, and Work-Life Balance; Job Control and Support as Moderators.

Table 4. Role Conflict Predicting Strain, Burnout, and Work-Life Balance; Job Control and Support as Moderators.

Table 5. Compensation Predicting Strain, Burnout, and Work-Life Balance; Job

Control and Support as Moderators. .58

Table 6 Days Off-Call Predicting Strain, Burnout, and Work-Life Balance; Job Control and Support as Moderators. 


\section{List of Figures}

Figure 1. Interaction between the quality of midwives' relationships with health care professionals and perceived job control on strain.

Figure 2. Interaction between the quality of midwives' relationships with their clients and perceived job control on professional efficacy.

Figure 3. Interaction between the number of difficult births in the last year and perceived job control on cynicism. .48

Figure 4. Interaction between the number of births in the last year and perceived job control on professional efficacy.

Figure 5. Interaction between overwork and social support from midwife colleagues on strain.

Figure 6. Interaction between overwork and social support from midwife colleagues on emotional exhaustion.

Figure 7. Interaction between overwork and organizational support on emotional exhaustion. .52

Figure 8. Interaction between overwork and organizational support on cynicism. ......52

Figure 9. Interaction between midwives' satisfaction with compensation and perceived job control on strain. .56

Figure 10. Interaction between midwives' satisfaction with compensation and social support from midwifery colleagues on emotional exhaustion.

Figure 11. Interaction between midwives' satisfaction with compensation and social support from midwives of colleagues on work-life balance. 
Stress and Burnout VII

Figure 12. Interaction between the number of days midwives are off-call per month and perceived job control on professional efficacy. 


\section{List of Appendices}

Appendix A, Semi-Structured Interview Questions......................................................98

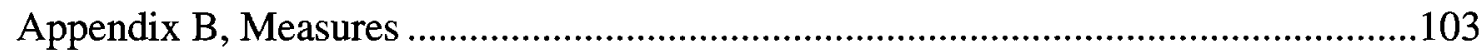

Appendix C, Correlations Between Demographic Variables and Outcome

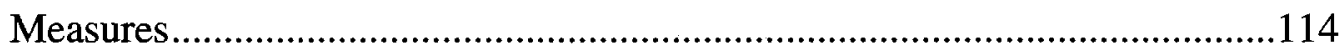


Stress and Burnout in Canadian Midwives

Although Canada boasts a long and storied midwifery tradition (Bourgeault, Benoit, \& Davis-Floyd, 2004), Canadian midwives have only recently begun to operate with similar levels of legitimacy and recognition as midwives the world over. In fact, until the mid 1990s, Canada was the only industrialized nation that did not have regulated midwifery (Bourgeault et al., 2004). However, the emergence of Canadian midwifery is especially timely since both provincial and national organizations involved in the delivery of maternity care have identified possible shortages of maternity care specialists (Ontario Medical Association [OMA], 2006; Society of Obstetricians and Gynaecologists of Canada [SOGC], 2007).

Professional organizations involved with Canadian maternity recognize a need to grow Canadian midwifery (SOGC, 2007). Furthermore, they also recognize that there are special circumstances related to the Canadian midwifery context that could stifle the growth of the profession (Kornelsen, 2003b; OMA, 2006; SOGC, 2007). Specifically, Canadian midwives may have to deal with inadequate remuneration, a limited scope of practice in rural or remote areas, inequity between rural and urban midwives, ambiguous legal status across provinces, and issues of professional recognition or even sometimes outright opposition to their presence (Klein, 2000; Kornelsen, 2003b). These issues may exacerbate stress and burnout in Canadian midwives. Therefore, the goal of this research is to identify and quantify aspects of the Canadian midwifery context that are related to midwives' perceived stress and health outcomes (including psychosocial strain and burnout). 


\section{Canadian midwifery in an international context}

Midwives play a key role in maternal health across many developed countries and their involvement in the birth process is considered the norm in most European countries (Canadian Institute for Health Information [CIHI], 2004). Midwifery has a long and rich history of contributing to maternal health in most of Europe. For example, the registration of midwifery dates back to the early 1900s in the UK, and midwifery education was already well established at the time (Donnison, n.d.). A number of other European countries such as Germany (Scheuermann; 1995) and the Netherlands (DeVries, 2001) boast similarly rich and storied roots to midwifery. The outcome of such a history has been that midwives in Europe have mainly been involved with the health care systems of their respective nations from the beginnings of modernization.

Today, midwives serve an important role in developed nations: They attend roughly $70 \%$ of births in England and $90 \%$ of births in Netherlands, with up to one third of births occurring in the home (CIHI, 2004). The services provided by midwives are cost effective (Anderson \& Davis, 1999; Campbell \& Graham, 2006) and safe (AmelinkVerburg et al. 2008; Johnson \& Davis, 2005). Moreover, in developing countries such as Latin America, Asia, and Africa, educated midwifery plays an active role in the drive to reduce maternal and infant mortality (Campbell \& Graham, 2006; World Health Organization [WHO], 2006). Midwives are also involved in reducing maternal and infant mortality in war torn countries such as Afghanistan (Currie, Azfar, \& Fowler, 2007). Many industrialized nations have large contingents of midwives to serve the maternity care needs of their populations. For example, the UK has 55 midwives per 100,000 population, Australia 57, and the Netherlands 12 (CIHI, 2004, 2006; Canadian Midwifery 
Regulators Consortium [CMRC], 2007; Herschderfer \& Kateman, 2005). Closer to home, in the United-States the American midwife community has had unified representation from the American College of Nurse-Midwives for over 50 years (Williams, 2005) and American midwives attended 10\% of spontaneous vaginal births in 2003 (Bussey, Bell, \& Lydon-Rochelle, 2007). Clearly, midwives are an important part of maternity care world wide, in developing and industrialized nations alike.

The situation of midwifery in Canada is vastly different. Although Canadian midwifery has strong historical roots in both aboriginal and lay traditions, Canada did not have formal regulated midwifery until the 1990s (Bourgeault et al., 2004). In fact, the move to regulate midwifery in Canada began in Ontario and was the result of a lengthy concerted effort to keep midwifery alive in the country. As models of midwifery began to be integrated in health care systems across Canada, midwives faced varying degrees of opposition from professionals in the medical professions (Kornelsen \& Carty, 2004; Vadeboncoeur, 2004). The medical community was concerned about the safety of home births, the adequacy of midwives' training, and their autonomy (Kornelsen \& Carty, 2004; Vadeboncoeur, 2004). In some cases, midwifery's integration was made more difficult due to communication and collaboration problems, as well as territorial struggles over the maternity care landscape (Collin, Blais, White, Demers, \& Desbiens, 2000).

The result is that Canadian midwifery is at a unique point in terms of its development as a profession. It has a long and rich tradition (Bourgeault et al., 2004) and is still in its infancy with regards to regulation and sanctioned practice. However, Canadian midwives are steadily increasing in numbers: In 2003, there were approximately 400 registered practicing midwives (Kornelsen, 2003b). In 2008, there 
were 681 registered and or practicing midwives (T. Occhionero, personal communication, May 07, 2008), which represents approximately 2.2 midwives per 100,000 Canadians. Midwifery legislation has either been passed or is in the process of being passed in most of the Canadian provinces and the provinces of British Columbia and Ontario have extra clauses covering the practice of traditional aboriginal midwifery (CMRC, 2007). National statistics on the use of midwifery are sparse; however, available numbers show that midwives attended $2 \%$ of births nationally in 2002 (Kornelsen, 2003b), and up to 4\% of births in Ontario in 2005 (Perinatal Partnership Program of Eastern and Southeastern Ontario [PPPESO], 2005).

The re-introduction of midwifery in a Canada is particularly timely. Recently, the Ontario Medical Association (OMA) voiced concerns about perceived shortages of pediatricians, neonatologists, and of obstetrical nurses (OMA, 2006). At the national level, the Society of Obstetricians and Gynaecologists of Canada (SOGC) has drawn attention to a recent dip in the Canadian OECD ranking in maternal and newborn health (Haymes, 2007; SOGC, 2006). That is, based on the most recent OECD numbers (2005), Canada ranked $21^{\text {st }}$ in infant mortality and $11^{\text {th }}$ for maternal mortality (ranking $6^{\text {th }}$ of 7 among G7 countries); Conversely, in 1990, Canada was one of the top performing countries internationally (ranking $6^{\text {th }}$ and $2^{\text {nd }}$ respectively; Human Resources and Social Development Canada [HRSDC], 2008; SOGC, 2006). Specifically, the SOGC is concerned with the disparity in quality of maternal care options between rural and urban Canada and called for a national birthing strategy (SOGC, 2006).

The SOGC also acknowledges a generalized shortage of maternity care workers, including not only obstetricians and nurses, but also midwives and other specialists (e.g., 
ultrasound specialists, dieticians, and social workers; SOGC, 2007). Moreover, according to the SOCG (2007), the current Canadian midwife population is not sufficient to replace obstetricians and family doctors who are leaving maternity care. Therefore, the newly minted Canadian midwife profession, the established medical professions, and the Canadian public all have an important stake in increasing the share of maternity care accounted for by midwives.

Overall, the unique position of Canadian midwifery as a profession is a result of the convergence of the issues described above. Specifically, regulated midwifery in Canada is still relatively new but the profession itself has a rich history in the country (Bourgeault et al., 2004). There is also demand to grow midwifery in response to an expressed need for more midwives in maternity care (e.g., SOGC, 2007). However, the relative novelty of midwifery in institutionalized maternity care in Canada can be a source of tension between midwives and other health care professionals (Blais \& Joubert, 2000; Klein, 2000; Kornelsen \& Carty, 2004; Vadeboncoeur, 2004). For example, early evaluations of the integration of midwifery in Quebec was characterized by a lack of knowledge about midwifery in other health care providers, a certain territoriality and distrustful attitude over perceived invasion of the maternal care landscape, and disparities in caregivers' professional cultures (Collin et al., 2000). The struggle of midwives to establish themselves as legitimate caregivers strangely echo the tenor of challenges faced by British midwives nearly a century ago (Donnison, n.d.).

Midwifery stakeholders have identified a number of other critical issues that need to be addressed to achieve sustainable growth in Canadian midwifery and help midwives contribute more effectively to the Canadian health care system (Kornelsen, 2002; 
Kornelsen 2003a). Midwives who practice in rural areas typically deal with difficulties in accessing specialists and services as compared to midwives working in or around urban areas (Ramsey, 2002; Kornelsen, 2003b). Midwives may also have to contend with inadequate remuneration, inflexible practice models, and the difficulties of working oncall for long periods of time (Hird, 2002; Kornelsen, 2003b). As a combination, these circumstances may create a set of working conditions that will contribute to increased stress and burnout, and poor experiences of work-life balance.

\section{Stress, burnout, and work-life balance}

Stress has long been a focal point of organizational research (Kelloway \& Day, 2005). Researchers define psychological stress as an individual's reaction to environmental characteristics that are perceived as negative or taxing (Lazarus \& Folkman, 1984) and tend to use the term interchangeably with psychological strain and job strain (e.g., de Croon, Sluiter, Blonk, Broersen, \& Frings-Dresen, 2004; Lazarus \& Folkman 1984). The environmental characteristics that may or may not be perceived as negative are known as stressors (Lazarus \& Folkman, 1984). For example, a possible stressor in midwifery may involve a lack of access to certain medical tests. If this situation is perceived as negative by the midwife, it will be perceived as stressful. This experienced psychological stress may manifest in terms of psychological, physiological, and behavioural strain outcomes (Lazarus \& Folkman, 1984). Because there are a relatively large number of working conditions that have been described as potential occupational stressors, researchers tend to discuss occupational stressors in terms of a 
framework of six general categories including job control, workload, and work scheduling (Kelloway \& Day, 2005; Sauter, Murphy, \& Hurrell, 1990).

Prolonged exposure to stressors in the workplace can lead to a specific negative reaction known as burnout, which is broad concept that was initially explored in professions involved with the provision of health services (Maslach \& Jackson, 1981; Maslach, Schaufeli, \& Leiter, 2001). However, research has now broadened the scope of burnout to include a number of caring and non-caring occupations (Maslach, et al., 2001). Although the definition of burnout has been fluid over the years, there appears to be agreement that burnout is expressed in terms of emotional exhaustion, cynicism, and a reduced sense of professional efficacy (or personal accomplishment; Maslach \& Jackson, 1981; Maslach, et al, 2001).

The more recent theoretical conceptualizations of burnout have been articulated in terms of job-person fit (Maslach \& Leiter, 1997; Maslach et al., 2001). More specifically, Maslach et al. (2001) theorize that burnout develops as a result of a chronic mismatch between the expectations of a given employee or professional and the conditions experienced in the workplace. Essentially, the greater the gap between the person and the work demands the greater the likelihood of burnout (Maslach \& Leiter, 1997; Maslach et al., 1997). Maslach et al. (2001) have noted six likely areas of work life as the main sources of mismatch leading to burnout (e.g., control, reward, community), many of which are analogous to similar categories presented in a common framework of workplace stressors (Kelloway \& Day, 2005; Sauter, Murphy, \& Hurrell, 1990). Therefore, employees or professionals who chronically experiences these mismatches are more likely to suffer from burnout and then more likely to suffer from the negative 
consequences of burnout (in terms of job performance and ill health; Maslach et al., 2001).

Exposure to workplace stressors may also have a significant impact on one's experience of work-life balance (e.g., Barnes-Farrell et al., 2008; Johansson, 2002). However, the work-life balance literature is somewhat more divergent in how the construct is operationalized (Guest, 2002). Some scholars focus on the concept of strict balance (Greenhaus, Collins \& Shaw, 2003), others are more interested in reciprocal interference from work to home and from home to work (Peeters, Montgomery, Bakker, \& Schaufeli, 2005), some tend to focus on work-family conflict (Greenhaus \& Beutell, 1985), and others broaden the concept to include leisure activities (Dex \& Bond, 2005; Small \& Riley, 1990). Regardless of the perspective, the common thread is the need to reconcile the demands of one's work life with one's expectations for one's non-work life (or home life, or family life). The results of work interference on non-work life can include both physical and psychological symptoms of anxiety (Small \& Riley, 1990), and possibly burnout (Peeters et al., 2005) and sleep disturbances (Tucker, Dahlgren, Akerstedt, \& Waterhouse, 2008).

\section{Stress model}

Using the occupational stress literature helps to organize the concerns identified in the Canadian midwifery context (e.g., working relationships, work scheduling) in terms of probable stressors and how these stressors may relate to outcomes such as burnout, strain, and work-life balance. The occupational stress literature typically identifies six groups of workplace stressors: 1) Job Content \& Control; 2) Interpersonal 
relationships; 3) Workload and work pace; 4) Role Stressors; 5) Career concerns; and 6) Work Scheduling (see for example, Kelloway \& Day, 2005; Sauter et al., 1990).

1) Job Content and Control. The lack of control over important aspects of one's job, type of work, and workplace has been well established as a workplace stressor, (e.g., Karasek, 1979). Job control may involve having control over the predictability of work, the scheduling of work, and the amount of work (Dwyer \& Ganster, 1991). Job control is a relevant stressor within the context of Canadian midwifery because evidence from international midwifery suggests that midwives do tend to feel less autonomy than their nurse colleagues (Carlisle, Baker, Riley, \& Dewey, 1994) and they may experience high unpredictability of work and little control over the scheduling and amount of work they do each day or week (e.g., Bakker et a1., 1996; Harworth-Brockman, 2002; Hird, 2002).

Research has consistently shown a relationship between a lack of job control and manifestations of physiological and psychological strain (Elsass \& Veiga, 1997; Liu, Spector, \& Jex, 2005). Similarly, research also supports links between higher job control and more positive outcomes such as job satisfaction, commitment, and involvement (Spector, 1989). Moreover, according to the mismatch framework of burnout (Maslach et al., 2001), a mismatch in control in which one's access to resources or one's level of authority are insufficient to complete tasks effectively is likely to lead to reduced professional efficacy. Finally, there is evidence that workload and work scheduling, the control of which is important to the concept of job control (Dwyer \& Ganster, 1991), are also important to peoples' experiences of work-life balance (Johansson, 2002; Tausig \& Fenwick, 2001). Therefore, I hypothesize that: 
Hypothesis 1: Midwives' experience of higher job control will be associated with lower strain, lower burnout, and higher work-life balance.

The relationship between job control and situations of high work demands is at the core of what is known as the job demands-control model (Karasek, 1979). Karasek (1979) initially proposed that the negative effects of job demands would interact with job control whereby the most strain is experienced in a low-control high-demand situation. In a sense, higher job control can negate some of the effects of certain job stressors whereby high control tends to result in a weaker or null relationship between demands and negative outcomes (Dwyer \& Ganster, 1991; Ganster, Fox, \& Dwyer, 2001). Therefore, midwives' experience of higher job control may moderate the relationship between other workplace stressors (i.e., workload, work scheduling, role conflict) and the outcome measures (i.e., strain, burnout, and work-life balance). The specific moderation hypotheses will be discussed along with the respective workplace stressors.

2) Interpersonal Relationships. Ideally, workplace relationships should be a source of social support and task support (Sauter et al., 1990). However, poor workplace relationships are well known stressors (Kelloway \& Day, 1995; Sauter et al., 1990). Evidence suggests that workplace relationships will be relevant predictors of stress in the context of Canadian midwifery especially with regards to midwives' relationships with other health care professionals (Klein, 2000; Kornelsen \& Carty, 2004; Vadeboncoeur, 2004). Also, research evidence suggests that midwives tend to have poorer experiences of support and have difficulty trusting colleagues (Deery, 2005; Kirkham \& Stapleton, 2000). 
Interpersonal conflict at work has been related to a number of negative outcomes such as physical and psychosocial manifestations of strain (Frone, 2000; Spector \& Jex, 1998), work disability among women (Appleberg, Romanov, Heikkilä, Honkasalo, \& Koskenvuo, 1996), and poor personal outcomes such as depression and lower self-esteem (Frone, 2000). Moreover, interpersonal relationships in the workplace, studied under the guise of workplace social support, are also generally related to lower levels of workplace stressors (Viswesvaran, Sanchez, \& Fisher, 1999).

Workplace relationships as potential stressors would best be described in terms of a mismatch in community under the mismatch architecture of burnout (Maslach et al., 2001). According to Maslach et al. (2001) a mismatch in the sense of community occurs when one loses their connection to the people they work with either through isolation or through chronic conflict with others in the workplace. Such a loss undermines the experience of social support and of shared ties and group values with others at work. The negative affect generated by poor working relationships, as with that generated by role stressors, also has the potential to spillover into non-work life (Small \& Riley, 1990; Williams \& Alliger, 1994) and negatively affect work-life balance. Therefore, I hypothesize that:

Hypothesis 2a: Poor workplace relationships with other midwives, clients, and health care professionals will be associated with higher strain, higher burnout, and lower work-life balance.

Hypothesis 2b: Midwives' experience of high social support from midwifery colleagues and from their midwifery organization will be associated with lower strain, lower burnout, and higher work-life balance. 
Hypothesis 2c: Perceived job control will moderate the relationship between quality of midwives' workplace relationships and strain, burnout, and work-life balance. Specifically, at high levels of perceived job control outcomes should be more positive regardless of the quality of relationships. At lower levels of job control midwives will have generally poorer outcomes and the low-control, poorrelationship midwives will tend to have the worst outcomes. Research evidence also shows that social support can have a buffering effect against workplace stressors (Frese, 1999; Russel, Altmaier, \& van Velzen, 1987; Viswesvaran et al., 1999). That is, at low levels of social support the relationships between stressors and strain reactions are stronger and higher levels of social support reduce the strength of potential stressors above (Viswesvaran et al., 1999) and according to the job demands-control-support model (Johnson \& Hall, 1988) more negative outcomes are expected for the low-support higher stress midwives. Therefore, midwives' experience of social support (from colleagues and organizational) may moderate the relationship between other workplace stressors (i.e., workload, work scheduling, role conflict) and the outcome measures (i.e., strain, burnout, and work-life balance). The specific moderation hypotheses will be discussed along with the respective workplace stressors.

3) Workload and Work Pace. Ideally, workload demands should match and not exceed the abilities of the employee (Sauter et al., 1990). However, anecdotal evidence from Canadian midwives (Harworth-Brockman, 2002; Hird, 2002) and research with Dutch midwives (Bakker et al., 1996) suggests that excessive workloads and exceeding work capacity are important stressors in midwives' experience of burnout. Furthermore, 
according to the authors of the Dutch study it may be "difficult to translate the findings into a cure" (Bakker et al., 1996; p. 180). Reviews of the experience of stress in other caring professions confirm that workload is likely to be a relevant stressor (Coyle, Edwards, Hannigan, Fothergill, \& Burnard, 2005; Edwards, Burnard, Coyle, Fothergill, \& Hannigan, 2000).

The experience of being overworked is a type of stressor that has been regularly linked to both psychological and physiological strain (for a brief review see Kelloway \& Day, 2005). Also, according to the mismatch framework of burnout (Maslach et al., 2001), a chronic mismatch in workload is expected to be an antecedent of burnout, especially for the emotional exhaustion dimension. Finally, workload has been also been commonly identified as an indicator of poor work-life balance, a distinction that is not only limited to actual workload, but also to perceived workload (Adebayo, 2006; Dex \& Bond, 2005; Johansson, 2002; Kodz et al., 2003). Therefore, I hypothesize that: Hypothesis 3a: Higher indications of objective workload such as the number of births attended and the average length of a midwife's workweek will be associated with higher strain, higher burnout, and lower work-life balance. Hypothesis 3b: Midwives' perceptions of being overworked will be associated with higher strain, higher burnout, and lower work-life balance after controlling for the effects of objective workload variables.

As discussed above, there is evidence that both perceived job control and social support may buffer against the negative effects of workplace stressors. More specifically, according to the job demands-control model (Karasek, 1979) and the job demandscontrol support model (Johnson \& Hall, 1988) low control and high demands as well as 
low support and high demands should be associated with the worst outcomes. Moreover, in a recent test of the interactions of the job demands-resources model researchers found that autonomy, an important aspect of perceived job control, and social support from moderated the relationship of job demands to two of the three dimensions of burnout (emotional exhaustion and cynicism; Bakker, Demerouti, \& Euwema, 2005). Again the more negative outcomes were in the situations where resources (i.e., autonomy and social support) were lacking and demands were high. Therefore I hypothesize that:

Hypothesis 3c: Perceived job control will moderate the relationship between workload stressors and strain, burnout, and work-life balance. Specifically, at high levels of perceived job control, outcomes will be more positive regardless of the level of workload. At lower levels of job control midwives will have generally poorer outcomes, and the low-control, high-workload midwives will tend to have the worst outcomes.

Hypothesis $3 d$ : Social support (from colleagues and organization) will moderate the relationship between objective and subjective workload and strain, burnout, and work-life balance. Specifically, at high levels of social support, outcomes will be more positive regardless the level of workload. At lower levels of social support, midwives tend to have poorer outcomes, and the low-support, highworkload midwives will tend to have the worst outcomes.

Research evidence suggests that perceived workload and objective workload are qualitatively different as they relate to possible stressors. For example, perceived workload may be more related to perceived control than objective workload even though they both interact with control to predict health care costs (Ganster, Fox, \& Dwyer, 
2001). I am testing for the effects of different qualities of workload by giving measures of objective workload priority over subjective measures to give them more explanatory power because interventions on objective measures of workload are more straightforward (e.g., reduced client load).

4) Role Stressors. Roles and duties in the workplace should be well defined and conflicts in job expectations should be avoided (Sauter et al., 1990). Role stressors occur when an employee or professionals must deal with conflicting demands possibly because of ambiguous definitions of responsibilities (i.e., role ambiguity) or because of conflicting sets of demands (i.e., role conflict; Kelloway \& Day, 2005). Again, there is evidence that role stressors will be relevant in evaluating the antecedents of strain in the Canadian midwifery context. For example, Zimmer (2005) describes a situation where ambiguity in assigned roles can lead to stressful interactions between midwives and nurses. Moreover, research in the British midwifery context found that role stressors are significant contributors to midwives' experience of stress (Carlisle et al., 1994).

Role stressors have been linked to increased strain outcomes in the research literature (e.g., Day \& Livingstone, 2001). Role stressors also probably fall under the rubric of mismatches in control within the mismatch framework of burnout (Maslach et al, 2001). That is, Maslach et al. (2001) conceptualised one aspect of mismatches in control as a mismatch in the amount of authority and associated responsibilities. The conflict between an employee's role as a function of their authority and their role as a function of their responsibilities is thought to be an antecedent of burnout, especially for the professional efficacy dimension. 
The relationship of workplace role conflict to work-life balance is less clear in as much as problems in work-life balance are themselves problems between work roles and non-work roles (e.g., Greenhaus \& Beutell, 1985). The work-life balance theme of mood spillover can be used to ascertain how workplace role stressors might have an impact on midwives' experiences of work-life balance. Research on mood spillover shows that negative affect experienced at work can carry over and negatively effect non-work life including spousal relationships and leisure time (Small \& Riley, 1990; Williams \& Alliger, 1994), resulting in poorer experiences of work-life balance. Therefore, I hypothesize that:

Hypothesis 4a: High role conflict will be associated with higher strain, higher burnout, and a lower experience of work-life balance.

The job demands-control (-support) models (Johnson \& Hall, 1988; Karazek, 1979) predict that the more negative outcomes as a result of exposure to stressors will be in the situations where there is either low control or low support in combination with high demands. There is some research evidence of the role of job control as a moderator between role conflict and burnout (Frenet, Guay, \& Senécal, 2004). However, the evidence is somewhat ambiguous because the measure of role conflict was aggregated with other work demand measures, therefore a clear test may be required. Regarding the possible moderating role of support variables, a recent meta-analysis of research with regards to social support shows that social support has a direct effect and a moderating effect on the stressor-strain relationship (Viswesvaran, 1999). Numbers compiled indicate a small though significant role of social support as a moderator with role conflict stressors (Viswesvaran, 1999). Therefore I hypothesize that: 
Hypothesis $4 b$ : Perceived job control will moderate the relationship between midwives' role conflict and strain, burnout, and work-life balance. Specifically, at high levels of perceived job control outcomes will be more positive regardless of the level of role conflict. At lower levels of job control midwives will have generally poorer outcomes and the low-control, high-role conflict midwives will tend to have the worst outcomes.

Hypothesis 4c: Social support (from colleagues and organization) will moderate the relationship between role conflict and strain, burnout, and work-life balance. Specifically, at high levels of social support, outcomes will be more positive regardless the level of role conflict. At lower levels of social support, midwives will tend to have poorer outcomes, and the low-support, high-role conflict midwives will tend to have the worst outcomes.

5) Career Concerns. Ideally, there should be no ambiguity with regards to the safety of one's career (Sauter et al., 1990). However, career concerns typically come from three different sources: job insecurity, work safety, and effort-reward imbalance (Kelloway \& Day, 2005). The effort-reward imbalance aspect of career concerns may be especially relevant to Canadian midwifery. Effort-reward imbalance describes a state of working where one's efforts are high and the associated rewards are low (Siegrist, 1996). In the Canadian midwifery context, such career concerns may be reflected in the observations that in at least some cases midwives' remuneration is inadequate (Kornelsen, 2003b). Moreover, the remuneration and practice models of Canadian midwifery may make it difficult for midwives who wish to practice part-time (Knox, 
2002; Leibau, 2002), possibly forcing midwives to chose between career and family (which is a potential indicator of poor work-life balance).

Maintaining an effort-reward imbalanced work state over longer periods can lead to negative health consequences (Siegrist, 1996). Furthermore, the rewards imbalance aspect of career concerns is almost completely analogous to the rewards mismatch described by Maslach et al. (2001) as an antecedent of burnout, especially with regards to the professional efficacy dimension. Both Siegrist (1996) and Maslach et al. (2001) noted the negative potential that results from a lack of recognition of the value of one's work by others. This state of negative affect as either an antecedent of burnout or as part of the reward-imbalance model has the potential to spillover onto non-work life (Small \& Riley, 1990; Williams \& Alliger, 1994). Therefore, I hypothesize that:

Hypothesis 5a: Midwives' dissatisfaction with financial compensation will be associated with higher strain, higher burnout, and lower work-life balance. Hypothesis 5b: Perceived job control will moderate the relationship between midwives' dissatisfaction with compensation and strain, burnout, and work-life balance. Specifically, at high levels of perceived job control outcomes will be more positive regardless of midwives' satisfaction with their compensation. At lower levels of job control midwives will have generally poorer outcomes, and the low-control, low-satisfaction midwives will tend to have the worst outcomes. Hypothesis 5c: Social support (from colleagues and organizational) will moderate the relationship between midwives' dissatisfaction with their compensation and strain, burnout, and work-life balance. Specifically, high levels of social supports should result in more positive outcomes regardless or satisfaction. At lower levels 
of social supports midwives will tend to have poorer outcomes and the lowsupport, low-satisfaction midwives will tend to have the worst outcomes.

6) Work Scheduling. Ideally, work scheduling should allow professionals to meet the demands of their non-work life (Sauter et al., 1990). However, some Canadian midwives are concerned that the requirements of working on-call are difficult to deal with (e.g., Hird, 2002). There is ample research that shows that employees who work non-standard hours tend to experience more emotional exhaustion, more job stress, and a higher incidence of psychosomatic health problems (e.g., headaches, upset stomach, etc.), and higher overall burnout (Appleton, House, \& Dowell, 1998; Demir, Ulusoy, \& Ulusoy, 2003; Jamal, 2004). Research in other health professions also shows that working on-call is related to higher incidence of psychological symptoms (e.g., Appleton, House, \& Dowell, 1998; Nicol \& Botterill, 2004).

It is not clear where work scheduling would fall under the mismatch architecture of burnout (Maslach, 2001). However, common conceptions of perceived job control (Dwyer \& Ganster, 1991) include an aspect about the predictability of work and control over when work starts and ends. As such, it would be fair to assume that issues in work scheduling are in fact mismatches in control as described by Maslach et al. (2001) and are an antecedent of burnout, especially with regards to professional efficacy. Finally, research evidence also suggests that those employees who work non-standard hours tend to have a poorer experience of work life balance (Barnes-Farrell et al., 2008; Tausig \& Fenwick, 2001). Overall, we can expect that the days midwives are not on-call to be less stressful and less intrusive to midwives' experience of work-life balance than the days midwives are on-call. As outlined at a midwifery conference: "Flexible work conditions, 
adequate time off call, and vacation time from the pager, are key to a balanced lifestyle" (Hird, 2002, p. 114). Therefore, I hypothesize that:

Hypothesis $6 a$ : The number of days midwives are off-call will be associated with lower strain, lower burnout, and higher work-life balance.

Hypothesis 6b: Perceived job control will moderate the relationship between the number of days midwives are off call and strain, burnout, and work-life balance. Specifically, at high levels of perceived job control, outcomes will be more positive regardless of the number of days midwives are off-call. At lower levels of job control, midwives will have generally poorer outcomes, and the low-control, low-number of days off-call midwives will tend to have the worst outcomes. Hypothesis 6c: Social support (from colleagues and organization) will moderate the relationship between the number of days midwives are off-call and strain, burnout, and work-life balance. Specifically, at high levels of social support, outcomes will be more positive outcomes regardless the number of days midwives are off-call. At lower levels of social support, midwives will tend to have poorer outcomes, and the low-support, low-number of days off-call midwives will tend to have the worst outcomes.

It is possible to use the number of days worked off-call as a measure of workload rather than work scheduling. However, the state of being on-call for work refers to a property of scheduling that is unpredictable. One may work the same average number of hours week to week, but a stable Monday to Friday daytime work routine is qualitatively different than a workweek where one may be called in the middle of the night one day 
and mid afternoon the next day. That difference in quality is what makes the numbers of days a midwife is off-call a measure of work scheduling stressors.

Location of Practice. In addition to the workplace stressors groups outlined in the research literature (Sauter et al., 1990), there are concerns that certain disparities between urban and rural midwives may be a source of occupational stress. Disparities in the availability of resources or access to specialists may exist between midwives who practice in rural areas and those who practice in or around urban areas (Ramsey, 2002; Kornelsen, 2003b). It is also likely that midwives practicing in urban areas have more frequent contact with potentially hostile working environments as a result of ambiguous or poor relationships with health care professionals (Kornelsen \& Carty, 2004;

Vadeboncoeur, 2004). Therefore, it is reasonable to expect that there will be differences in negative outcomes based on location of practice.

Hypothesis 7a: The effect of midwives' location of practice on strain, burnout, and work-life balance, is mediated by the quality of midwives' relationships with health care professionals.

Hypothesis $7 b$ : The effect of midwives' location of practice on strain, burnout, and work life-balance, is mediated by midwives' access to resources.

Overall, by using this framework of workplace stressors and applying it to what we know of the Canadian midwifery context it becomes apparent that there is a clear case to look at the experience of stress, burnout, and work-life balance of Canadian midwives. The existing literature on Canadian midwifery gives us a very good idea of which stressors will be relevant. However, much of the information available about Canadian midwives is descriptive or essentially amounts to personal accounts (e.g., Hird, 2002). 
Some of the research on international midwifery can serve to supplement or confirm which stressors may be relevant in Canadian midwifery (e.g., Carlisle et al., 1994). However, the particularities of Canadian midwifery justify the need to perform research specific to the Canadian context.

Study 1: Identifying the experiences of Canadian midwives

The first part of the study involved conducting interviews aimed at identifying the key issues related to Canadian midwives' experience of stress and wellbeing in the workplace. The purpose of these interviews was to clarify and contextualize the theorized workplace stressors and inform the development of a national survey. The interviews also ensure that the specific experiences of the midwifery population were adequately covered, thus providing evidence of content validity.

\section{Method}

\section{Participants}

Interview participants were recruited on a voluntary basis through contacts within the midwifery profession. Participants were offered a gift card at a book store as compensation for their time. The interviews were conducted with midwives $(n=6)$ as well as subject matter experts (SMEs; $n=3$ ). The midwives interviewed were at different points in their career, such that I was able to get input from more and less experienced perspectives on midwifery. The SMEs interviewed included a doula, an expert involved in advocacy for midwives, and a former midwife now working at the administrative levels of a midwifery education program. Interview participants were from Ontario $(n=$ 6) and Nova Scotia $(n=3)$, providing us with some perspective from a province where 
midwives have been legislated for a number of years (i.e., Ontario) and from a province where regulation is still in progress (i.e., Nova Scotia).

\section{Procedure}

Interview questions were designed to explore aspects that are important to the experiences of stress in the work lives of midwives and also aspects that midwives felt contributed to their wellbeing. The semi-structured interview included open ended general questions ("Think of a work day in the past month that was particularly stressful. Why was that particular day stressful?") and more specific questions ("Specifically with regards to your work with your clients, think of a recent client interaction that went particularly well. What individual or personal factors, if any, made it go well?"). A separate but similar script was used to interview SMEs. Again questions were designed to explore aspects of midwives' stress as well as aspects of midwives' wellbeing. The SME interview script also used both general and specific questions (interview question are attached in Appendix A).

The semi-structured interviews were conducted over the phone or in person. All interviews were recorded digitally after receiving consent from the participant. Questions were asked in the same order in every case. Participants were allowed as much time as they desired to answer the questions and finish expressing their thoughts. Efforts were made to keep the answers on topic and participants were prompted to think of more distant examples when they struggled with finding an answer.

The recordings were reviewed and inductively parsed for general themes. General themes were identified from a first interview. Themes were then revised and added to upon the analysis of the remaining interviews. The unit of analysis for themes was the 
completed thought or idea within a question. The themes were then clustered into meaningful categories. The categories and themes were then assigned nominal importance ratings based on how many individual participants brought them up and based on how many times in general the themes were discussed as answers to questions (one frequency point maximum per answer). These frequencies were used to provide the researcher with a general guide to confirm which themes were thought to be most important and which additional themes should be flagged for inclusion in the survey.

\section{Results}

The contents of the interviews provided support for the importance of the previously discussed six categories of workplace stressors (Kelloway \& Day, 2005; Sauter et al., 1990).

Job content and control. Interview participants brought up concerns about the scheduling of work and the unpredictability of work. For example, an interview participant described a typical stressful situation where you might have booked a full day of client visits but also have a client who may be giving birth imminently. Participants also discussed stressful situations related to a lack of control over the resources of midwifery (e.g., access to specialists and access to special tests). Moreover, the general theme of perceived job control was present as a supporting theme as interviewees discussed other possible stressors.

Interpersonal relationships. The responses of interview participants supported the importance of interpersonal relationships in the experience of stress of Canadian midwives. Comments supported the importance of both organizational support (e.g., 
"...having a college that is more concerned with the wellbeing of its members would be very useful.") and social support (e.g., "The people who found it fascinating that I could be called away at any moment became more and more important in my social life."). Interview participants also described a number of situations in which poor working relationships with clients, other midwives, and health care professionals, could be a significant source of stress (e.g., "The environment that we work in as health care practitioners is very hostile. Midwifery is looked on as alternative health care as opposed to as a strong part of a health care team").

Workload. Interview participants' responses also implicated workload as a likely stressor for Canadian midwifery. For example, respondents specified that having a manageable workload that enabled them to provide effective care was very helpful in reducing their experience stress. Conversely, an interview participant described a situation where she experienced stress because her workload, including taking care of a new registrant, supervising an apprentice, and hiring two support staff who had recently left the office, had become difficult to manage, keeping her from giving all the necessary focus to her clients. Moreover, some respondents mentioned that their workload and stress were increased because of a frequent need to do extra unpaid work, because they had to work unreasonably long hours (even within the context of a birth), or because other midwives in their practice didn't carry their fair share of the load.

Role conflict. Respondents described a number of situations implicating role stressors as important contributors to their experience of stress. Specifically, respondents mentioned the difficulties that arise in their interactions with medical professionals when 
there are differences in professional opinion and problems when authority and jurisdiction are unclear (e.g., "I was asked to perform a task that is not my role.").

Compensation. The compensation aspect of career concerns was brought up with regards to midwives who are paid a fee per course of care. Specifically, the concerns is that the amount received per course may be low compared to the amount of care provided over a long period (e.g., a fee of $\$ 2,500$ for seven months of pre- post-natal care including child birth and home visits) and that in areas where the fee per course is not set by regulation (e.g., Nova Scotia) it can become very difficult to sustain a family practicing as a midwife.

Time off-call. Interview respondents also described a number of situations where work scheduling issues were a source of stress. For example, one interviewee claimed that "Because of the long hours and the very short periods off-call you can lose connection with a lot of your friends." The general consensus was that although for some it is possible to adapt and live healthily with very little time off-call, the long periods oncall and short recuperation periods are a very meaningful stressor (e.g., "Periods of being on-call $24 / 7$ with very little time off, you're always functioning at a very high anxiety level.").

Survey construction

The contents of the interviews also served to review scales to be used in an eventual survey instrument. An initial core of established measures were selected to assess stressors that had been clearly identified in the interviews for which there were measures available (e.g., Role Conflict, House, Schuler, \& Levanoni, 1983; Rizzo, House, \& Lirtzman, 1970). The items contained in these scales were reviewed with SMEs 
experienced in scale development (SMEs included graduate students and a faculty member). The revision process had a number of goals: (1) To increase the face validity and content validity of these scales with regards to midwifery as a profession by tweaking the language of certain items; (2) To reduce the overall length of the survey by removing scale items not relevant to midwifery issues; (3) To minimize common method variance and further reduce the length of the survey by reducing overlap between scales where possible.

Another core of items was developed to address stressors specific to midwifery as raised in the interview. For example, a series of items were developed to assess the quality of working relationships between midwives and their midwifery colleagues, other health professionals, and their clients. These items were also reviewed by the same group SMEs with experience in scale development. Furthermore, where it may have been unclear how the items in some scales would yield interpretable factors, the items were evaluated with sorting tasks and revised further.

The completed survey was then reviewed by one of the midwifery SMEs who had participated in the first part of the research. The feedback served to reduce the number of total items and give a final few modifications to the language of a number of items. The resulting survey package was specifically tailored to the Canadian midwifery context, made every effort to be short while still covering most of the issues that appeared to be important to Canadian midwives' stress and wellbeing, and included measures that were vetted by a number of SMEs with experience in scale development. 
Study 2: Survey of Canadian midwives

The second part of this research effort was to conduct a national survey of the Canadian midwife population to delineate the key components of stress and wellbeing for the profession and support the validity of the framework of occupational stressors for Canadian midwives. The construction of this survey was guided by the content gleaned from the interviews conducted in the first step. However, because midwifery is a very complex profession as practiced in Canada (e.g., prenatal care, clinic visits, home visits, postnatal care, and births in homes, hospitals, and birthing centres) many of the established workplace measures are inadequate for immediate use with midwives. Moreover, some of the issues raised in the interviews were so specific to the Canadian midwifery context that items needed to be created to address these concerns.

\section{Method}

The survey was hosted online through the Survey Monkey service, which allowed participants to complete the survey at their convenience and relatively free of hassles. Participants were also informed that a paper-and-pencil version of the survey could be mailed to them if they had a preference for that format.

\section{Participants}

Participants for the survey were contacted through an e-mail mailing list maintained by the Canadian Association of Midwives (CAM) with a message explaining the purpose of the research and offering two prizes of $\$ 75$ as a participation incentive. The recruitment message was in both official languages and explained that a French version of the survey was not available (e.g., French versions of measures would have 
had to be properly back translated and validated) but asking French speaking participants who are fluent in English to consider participating in the survey. In one case where there was a reasonable expectation that a number of practicing midwives were not registered with the CAM (i.e., Manitoba), midwives were also contacted through their provincial association thereby expanding the pool of contacted midwives to $N=689$.

A total of 233 midwives responded to the survey for a response rate of $33.9 \%$. All midwives were women, and their average age was 40.5 years-old. Most were married or common law (70.0\%), and practiced in urban areas (70.4\%). Most of the respondents were from Ontario (63.7\%), British Columbia (21.1\%), and Quebec (6.7\%). The midwives who responded had an average of 9.3 years of experience (ranging from 3 months to 42 years), and $27.4 \%$ had experience working as midwives in other countries for an average of 5.8 years.

\section{Measures}

Many of the measures used in this study were modified for use with midwives or designed specifically for this study. See Appendix B to consult the measures.

Demographics. Participants were asked to indicate their age, marital status, number of children, tenure, the province in which they practice, and if they practice in an urban or rural setting. Participants were also asked to indicate which setting was more typical for their practice of midwifery.

Workload. Participants were asked to answer a number of questions about their typical workload. Specifically, participants were asked to provide an estimate of how many hours they work per week by providing an estimate in hours, and to provide an 
estimate of the number of births they attend per year, the number of home births, and the number of difficult births they had worked through.

Scheduling. With the expectation that midwives who have more time off-call have a more balanced, less stressful lifestyle (Hird, 2002), participants were asked to indicate the average number of days per month they were typically off-call.

\section{Established Scales}

$J o b$ control. Perceived job control was assessed using applicable items from the perceived job control scale (Dwyer \& Ganster, 1991). Respondents answered on a 5-point scale $(1=$ Very little $; 5=$ Very $m u c h)$ to items assessing their perceptions of control at work (e.g., "How much control do you have over how you do your work?"). Higher scores indicate higher perception of job control. The scale was reduced from 22 to 14 items and, where necessary, minor wording adjustments were made to enhance the face validity of the scale for the midwife population. For example, "How much control do you have over the amount you earn at your job" was reworded to "... earn as a midwife" and the item "How much control do you have over how quickly or how slowly you have to work" was dropped because pacing was not an especially relevant aspect of control as a midwife. The scale had a Cronbach's alpha of $\alpha=.87$, and item-total correlations ranged from $r=.38$ to $r=.75$ in this study.

Role conflict. Role conflict was assessed using applicable items from the Role Conflict and Role Ambiguity Scale (House, Schuler, \& Levanoni, 1983; Rizzo, House, \& Lirtzman, 1970). Respondents answered on a 7-point Likert scale (1 = Strongly disagree; $7=$ Strongly agree $)$ to indicate their level agreement to items assessing their experience of role conflict in the workplace (e.g., "I am involved in situations in which there are 
Stress and Burnout 31

conflicting requirements"). Higher scores indicate a higher perception of role conflict. Five items were retained that are especially applicable to midwifery. For example, the item "My boss always accepts my work" was dropped because it taps into a workplace dynamic not especially relevant to midwifery. The wording of items was for the most part unchanged. The scale had a Cronbach's alpha of $\alpha=.77$, and item-total correlations ranged from $r=.39$ to $r=.69$ in this study.

Organizational Support. Organizational support was assessed using applicable items from the Survey of Perceived Organizational Support (SPOS; Eisenberger, Huntington, Hutchison, \& Sowa, 1986). Respondents answered on a 7-point Likert scale $(1=$ Strongly disagree $; 7=$ Strongly agree $)$ to indicate their level agreement to items assessing their experience of organizational support (e.g., "The organization strongly considers my goals and values"). Higher scores indicate a higher perception of organizational support. Six items were retained that are especially applicable to midwifery. For example, the item "The organization tries to make my job as interesting as possible" was dropped because it is not relevant to the practice of midwifery. The wording of items was for the most part unchanged. However, because the representation of midwifery varies between provinces, survey participants were asked to respond to the items while considering the support from the organization most responsible for supporting them in their province. The scale had a Cronbach's alpha of $\alpha=.90$, and itemtotal correlations ranged from $r=.64$ to $r=.84$ in this study.

Social support. Social support was assessed using the Social Support Scale (Day, Parker, \& Keyes, 1998). Respondents answered on a 7-point Likert scale ( 1 = Strongly disagree; $7=$ Strongly agree) to indicate their level agreement to items assessing their 
experience of social support (e.g., "I can count on these people to listen to my problems"). Respondents used the scale's six items to rate their perceptions of social support originating from midwife colleagues. Higher scores indicate a higher (more positive) perception of social support. The scale had a Cronbach's alpha of $\alpha=.88$, and item-total correlations ranged from $r=.59$ to $r=.77$ in this study.

Measures specifically designed for this study

Several scales were created specifically for this survey based on the data collected in the semi-structured interviews to identify factors that were potentially linked to midwives' stress and wellbeing.

Access to resources. Access to resources was assessed using eight items, and respondents answered on a 7-point Likert scale $(1=$ Strongly disagree $; 7=$ Strongly agree) to indicate their level of agreement with each item about their access to resources (e.g., "I can consult directly with specialists as required by my practice"). One of the items in the scale (i.e., "The medical facilities I deal with face staff shortages.") had an exceptionally low item-total correlation of $r=.11$. Although hospital staff are clearly important resources for midwives, who need to be well supported when working in a hospital, staff shortages are clearly unrelated to the other resources of midwifery. In fact, acting on staff shortages is outside of the purview of midwifery as an organized profession. As such, when looking at the effects of resources that item will be left out and tested separately. The seven remaining items of the resources scale have a Cronbach's alpha of $\alpha=.72$, and item-total correlations ranged from $r=.32$ to $r=.61$ in this study. The integrity of the scale was assessed with a principal components analysis. Results show that the single-factor solution was adequate: all items loaded on the theorized factor 
with loadings ranging from .46 to .83 . The single factors explain $41 \%$ of the total scale variance.

Working relationships. The quality of midwives' working relationships was assessed using 10 items, and respondents answered on a 7-point Likert scale $(1=$ Strongly disagree $; 7$ = Strongly agree) to indicate their level of agreement with each item about the quality of their working relationships (e.g., "My working relationships with other health care professionals are collaborative"). The scale assesses the quality of midwives' working relationships using three subscales: (a) Health care professionals, (b) Other midwives, (c) Clients. Higher scores indicate more positive relationships. The health professionals subscale had a Cronbach's alpha of $\alpha=.85$, and item-total correlations ranged from $r=.58$ to $r=.78$, the midwives subscale $\alpha=.77$, and item-total correlations ranged from $r=.57$ to $r=.74$, and the clients subscale $\alpha=.66$, and item-total correlations ranged from $r=.37$ to $r=.65$. The integrity of the scale was assessed with a principal components analysis with promax rotation. Results show that the three-factor solution was adequate: all items loaded on their theorized factor with loadings ranging from .69 to .94 . The three factors explain $70 \%$ of the total scale variance.

Overwork. Midwives' perception of being overworked was assessed using five items, and respondents answered on a 7-point Likert scale $(1=$ Strongly disagree $; 7=$ Strongly agree) to indicate their level of agreement with each item about their experiences working as midwives (e.g., "I often have to do extra unpaid work"). Higher scores indicated a higher perception of being overworked. This scale had a Cronbach's alpha of $\alpha=.72$, and item-total correlations ranged from $r=.41$ to $r=.63$ in this study. The integrity of the scale was assessed with a principal components analysis. Results 
show that the single factor solution was adequate: all items loaded on the single factor with loadings ranging from .61 to .80 . The single factor explains $48 \%$ of the total scale variance.

\section{Outcome measures}

Burnout. The MBI-GS (Maslach, Jackson, \& Leiter, 1996) was selected to measure the burnout outcome. This measure is designed to have more general application than the original MBI and has show to have a stable factor structure across many occupation groups (Bakker, Demerouti, \& Shaufeli, 2002). The original MBI scale focuses on the demands posed by the provider-client relationship (Bakker et al., 2002). Therefore, in this situation where we expect midwives' experience of burnout to be related to factors that go beyond their personal relationship with clients (e.g., job control, relationships with health care professionals, personality variables) the MBI-GS more appropriate.

Respondents answered on a 7 -point scale $(0=$ Never $; 6=$ Everyday) to indicate how often they experience the state or situation described in each item (e.g., "I feel emotionally drained from my work"). The scale assesses burnout using three subscales: (a) exhaustion; (b) cynicism; (c) professional efficacy. Higher scores indicate higher selfreported exhaustion, cynicism, and professional efficacy. The exhaustion subscale had a Cronbach's alpha of $\alpha=.91$, and item-total correlations ranged from $r=.74$ to $r=.81$, cynicism $\alpha=.85$, and item-total correlations ranged from $r=.40$ to $r=.77$, and professional efficacy $\alpha=.75$, and item-total correlations ranged from $r=.41$ to $r=.61$ in this study. 
Strain. The Symptoms Checklist (Bartone, Ursano, Wright, \& Ingraham, 1989) was retained to assess manifestations of psychological, behavioural, and physical strain. This measure has previously been used to operationalize reactions to general stressors and workplace stressors (e.g., Day \& Livingstone, 2001; Day, Therrien, \& Carroll, 2005; Soderstrom, Dolbier, Leiferman, \& Steinhardt, 2000).

Respondents answered on a 6-point scale $(0=$ Never; $5=$ Always $)$ to items assessing how frequently they experience symptoms (e.g., "Trouble sleeping"). The 20item symptoms checklist assesses the occurrence of psychological, behavioural, and physiological strain symptoms. Higher scores indicate higher overall incidence of symptoms. The scale had a Cronbach's alpha of $\alpha=.89$, and item-total correlations ranged from $r=.29$ to $r=.70$ in this study.

Work-life balance. Work-life balance was assessed using the Work-Life Integration Scale (Cannon, Morrow, Knight, \& Day, 2008). This scale was retained over other choices because it embraces a broader focus rather than a narrower work-family perspective and because it focuses on the successful integration of work and non-work rather than the conceptually more difficult concept of balance.

Four especially applicable items were retained to asses the work-life balance of midwives. Respondents answered on a 7 -point Likert scale $(1=$ Strongly disagree $; 7=$ Strongly agree) to indicate their level of agreement with statements about their experience of work-life balance (e.g., "I am happy with the way I divide my time among work, family, and my personal life"). Higher scores indicate a higher (more positive) perception of work-life balance. The scale had a Cronbach's alpha of $\alpha=.92$, and itemtotal correlations ranged from $r=.76$ to $r=.86$ in this study. 


\section{Results}

Analysis plan

Most of the hypotheses will be tested with simple regression or hierarchical regression. When testing for moderation, the variable(s) of interest were entered at the first step, the moderator was entered at the second step so as not to occlude the relationship of the variable of interest to the outcome, and the interaction terms were entered at the third step. Moderated hierarchical regressions were performed using standardized scores as per Aiken and West (1991). The simple slopes for significant interactions were plotted and tested also according to the guidelines provided by Aiken and West (1991). Finally, the mediation analysis for Hypothesis 7 was performed following the guidelines suggested by Baron and Kenny (1986).

Data screening and cleaning

A number of survey participants had missing data points for some scales. To remedy the situation, scale and subscale scores were computed in each case where the participant had answered at least $75 \%$ of the items. The data were also screened for extreme outliers and impossible answers (e.g., average work week of 360 hours) eliminating $n=8$ responses.

According to the general guidelines discussed in Tabachnick and Fidell (2007, p.123), the listwise sample sizes are sufficient to provide adequate power for the majority of analyses. That is, with the exception of one set of analyses, the largest analyses in the present study have 11 predictors (i.e., analyses involving workload variables) and a sample size of at least $n=159$, which is above the minimum sample sizes of $n=115$ to $n$ $=138$ would be called for to test individual predictors and multiple correlation. Likewise, 
Stress and Burnout 37

the set of analyses with the lowest sample size (i.e., analyses involving midwives' time off-call) have at least $n=149$, which is well above the sample sizes of $n=90$ to $n=109$ called for by Tabachnick and Fidell (2007). However, one set of analyses (i.e., the hierarchical regressions testing the moderation of social support variables on workload; $n$ $=156$ to 159 ) has 17 predictors (because of the large number of interaction terms) and suffers from reduced power to test multiple correlation but still has sufficient power to test individual predictors (Tabachnick \& Fidell, 2007, call for sample sizes of $n=186$ and $n=121$ respectively).

With the relatively large number of outcome variables, hypotheses, and predictors, the relatively large number of tests raises the concern of committing Type 1 errors. The real concern is specifically with the number of interaction terms, with little variance left to be accounted for by interactions at the later hierarchical steps and a large number of tests there is the potential for significant interactions to be spurious. However, hierarchical regression may lack power in detecting moderation (Aguinis \& StoneRomero, 1997; Evans, 1985; McClelland \& Judd, 1993). Therefore, I assessed the power (post-hoc) for the hierarchical regression with the workload variables which had the largest number of tested interactions using an online power calculator (Soper, 2008). Results indicated that power at $\alpha=.05$ ranged from .74 to .40 for analyses involving perceived job control, and from .71 to .48 for analyses involving the support variables at the steps including the interaction terms (fourth steps). As such, it appears that power is reduced enough at the interaction steps, and the effect sizes small enough, that Type 2 errors might be more of a concern. 
Stress and Burnout 38

Also, some of the outcome variables (i.e., cynicism and professional efficacy) are fairly skewed leading to less favourable indicators with regards to assumptions of normality. The analyses were performed with both transformed and unaltered variables and compared. The results were largely equivalent although the main effects explained slightly more variance with the transformed variables (approximately $1 \%$ more variance explained). Therefore I opted to carry on with the unaltered variables.

\section{Correlations}

The means, standard deviations and correlations among the variables used in the main analyses are presented in Table 1 . The emotional exhaustion and cynicism dimensions of burnout were highly intercorrelated, and they had a smaller negative relationship with professional efficacy, supporting theory and past research (Maslach et al., 2001; Maslach, 2003). Moreover, emotional exhaustion was strongly related to strain, which is also expected by burnout theory (Maslach et al., 2001; Maslach, 2003). Strain also showed the expected negative relationships with professional efficacy and the proposed moderator variables. Work-life balance had a strong negative relationship with strain, emotional exhaustion, and cynicism, and a moderate relationship with professional efficacy. Among the hypothesized stressor variables, the number of days midwives are off-call was unrelated to any outcome, or any of the other moderators or stressors. Also, midwives' average workweek, their perceptions of overwork, and the number of difficult births attended over the last year were the only workload variables consistently associated with outcomes (i.e., strain, burnout, work-life balance). However, of the workload variables only overwork was related to professional efficacy, and neither the number of births or home births attended over the last year was associated with any outcomes. 
Prior to conducting the regression analyses, the need to perform analyses while controlling for the effects of demographic or practice variables was assessed by examining the zero order correlations between the demographic variables and the outcome variables (see Appendix C). There were small correlations between midwives' age $(r=-.18, p<.05)$ and emotional exhaustion, and between practice setting (i.e., if a midwife identified as principally practicing in a hospital setting and emotional exhaustion $(r=.21, p<.01)$. The analyses were run both with and without these two control variables: Although a few levels of significance change, there were no substantive differences in the results. More specifically, the significance of the vast majority of main effects remained unchanged and two of the interactions that were significant at the $\alpha=$ .05 level were no longer significant ostensibly because of a slightly reduced sample size (i.e., some of the participants who had otherwise complete data did not indicate their age or main practice setting). Therefore, the analyses without controlling for age or hospital practice are presented.

Job control

Hypothesis 1, which stated that job control would be associated with strain, burnout, and work-life balance, was tested with simple regression. Perceived job control was entered as the first and only component individually to predict each outcome. Perceived job control significantly predicted strain $\left(\beta=-.43, R^{2}=.18, p<.001\right)$, emotional exhaustion $\left(\beta=-.54, R^{2}=.29, p<.001\right)$, cynicism $\left(\beta=-.42, R^{2}=.17, p<\right.$ $.001)$, professional efficacy $\left(\beta=.31, R^{2}=.09, p<.001\right)$, and work-life balance $(\beta=.42$, $\left.R^{2}=.18, p<.001\right)$ 
Interpersonal relationships

The research hypotheses involving interpersonal relationship variables were tested through simple regression (Hypothesis $2 b$ ) and moderated hierarchical regression (see Table 2; Hypothesis 2a and Hypothesis 2c). The hypothesis that workplace relationship stressors would significantly predict the outcome variables (Hypothesis 2a) was tested by entering the workplace relationship variables at the first step of a moderated regression. As a group, workplace relationship stressors were significantly associated with the hypothesized outcome variables $\left(R^{2}\right.$ ranged from .08 to $\left..16, p<.001\right)$. Relationship stressors accounted for the most variance in strain $\left(R^{2}=.15, p<.001\right)$ and cynicism $\left(R^{2}=\right.$ $.16, p<.001)$ and the least variance in professional efficacy $\left(R^{2}=.09, p<.001\right)$. 


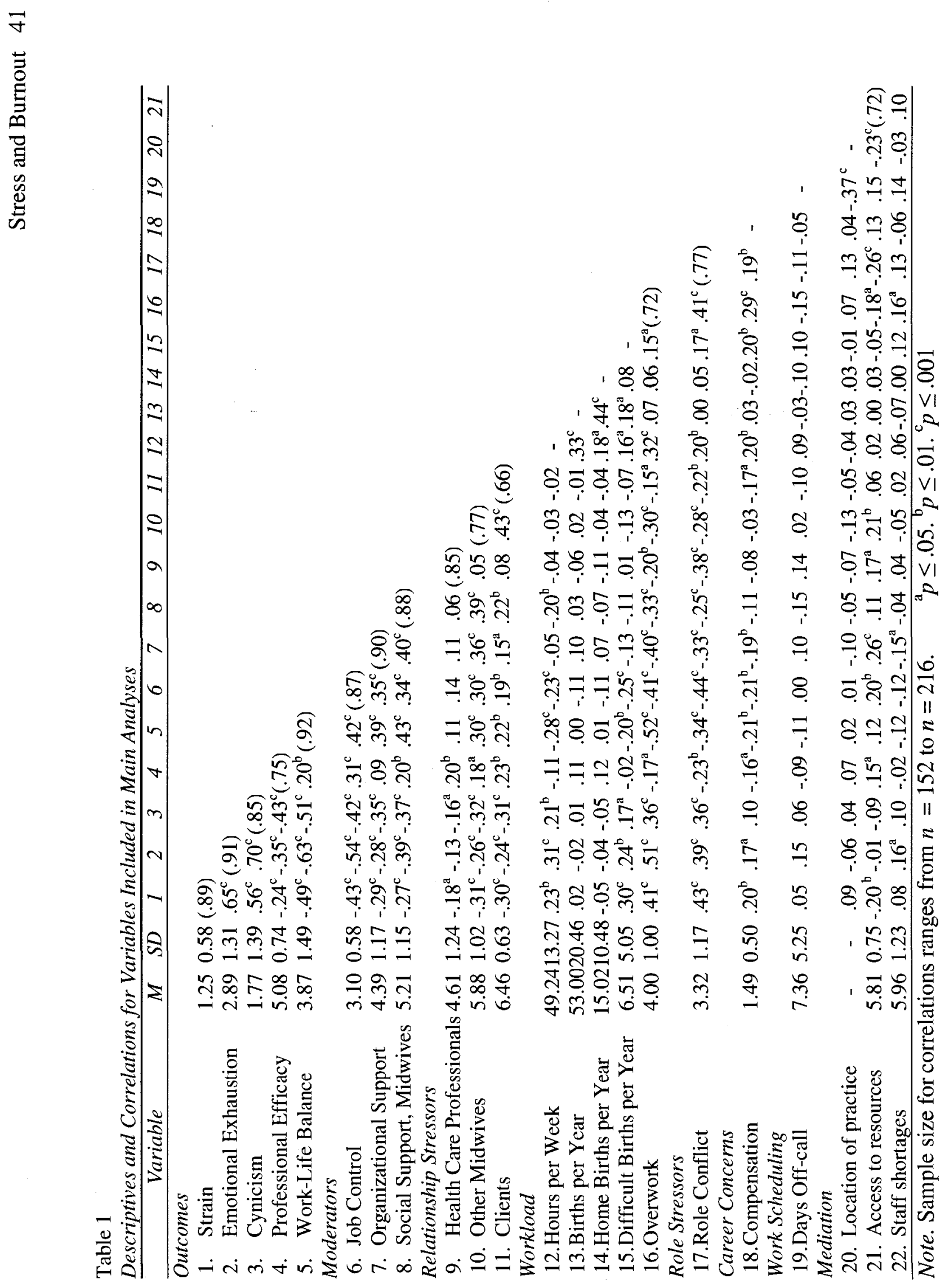


However, the quality of midwives' relationships with other midwives was the sole significant predictor for emotional exhaustion $(\beta=-.19, p<.05)$ and work-life balance $(\beta=.25, p<.001)$. Perceived job control was entered at the second step and accounted for incremental variance in all outcomes $\left(\Delta R^{2}\right.$ ranged from .05 to $\left..22, p<.001\right)$.

The interaction terms were entered at the third and final steps. Although none of the interaction steps provided a significant increment of variance two individual interactions were significant: the interaction between perceived job control and quality of midwives' relationships with health care professionals on strain $(\beta=-.15, p<.05)$, and the interaction between perceived job control and the quality of midwives' relationships with their clients on professional efficacy $(\beta=-.16, p<.05)$. More specifically, at low reported job control, midwives tended to have higher strain regardless of the quality of midwives' relationships with health care professionals $(\beta=$ $.02, n s$; see Figure 1). However, at higher reported job control midwives tended to have less overall strain and their strain tended to be significantly reduced as the quality of their relationships with heath care professionals tended to improve $(\beta=-.25, p<.01$;). Likewise, at high reported job control midwives tended to have higher professional efficacy regardless of the quality of their relationships with their clients $(\beta=.01, n s$; see Figure 2). However, at lower reported job control midwives tended to have lower professional efficacy and their professional efficacy tended to be significantly reduced as the quality of their relationships with clients tended to deteriorate $(\beta=.33, p<.01)$.

The hypothesis that the social support variables would predict strain, burnout, and work-life balance was tested by using a simple regression in which social support from other midwives and organizational support were entered simultaneously 
(Hypothesis $2 \mathrm{~b}$ ). The social support variables jointly accounted for a significant amount of variance in all outcome variables ( $R^{2}$ ranged from .05 to $.25, p<.05$ ). Midwives' social support from other midwives was a unique predictor for all five outcomes $(\beta$ ranged from -.18 to $.34, p<.05$ ). Organizational support was a significant predictor of strain, cynicism, and work-life balance ( $\beta$ ranged from -.21 to $.26, p<.01$ ), but not of emotional exhaustion $(\beta=-.14, n s)$ or of professional efficacy $(\beta=.01, n s)$.

Table 2

Relationship Stressors Predicting Strain, Burnout, and Work-Life Balance; Job Control as a Moderator

\begin{tabular}{|c|c|c|c|c|c|c|c|c|c|c|}
\hline \multirow[b]{2}{*}{ Variable } & \multicolumn{2}{|c|}{ Strain } & \multicolumn{2}{|c|}{$\begin{array}{l}\text { Emotional } \\
\text { Exhaustion }\end{array}$} & \multicolumn{2}{|c|}{ Cynicism } & \multicolumn{2}{|c|}{$\begin{array}{l}\text { Professional } \\
\text { Efficacy }\end{array}$} & \multicolumn{2}{|c|}{$\begin{array}{l}\text { Work-Life } \\
\text { Balance }\end{array}$} \\
\hline & $\beta$ & $\Delta R^{2} R^{2}$ & $\beta$ & $\Delta R^{2} R^{2}$ & $B$ & $\Delta R^{2} R^{2}$ & $\beta$ & $\Delta R^{2} R^{2}$ & $\beta$ & $\Delta R^{2} R^{2}$ \\
\hline 1. Relationship stressors & & $.15^{\mathrm{c}} .15^{\mathrm{c}}$ & & $.10^{c} .10^{c}$ & & $.16^{\mathrm{c}} \cdot 16^{\mathrm{c}}$ & & $.09^{c} .09^{c}$ & & $.10^{c} .10^{c}$ \\
\hline $\begin{array}{l}\text { With health care } \\
\text { professionals }\end{array}$ & $-.16^{\mathrm{a}}$ & & -.11 & & -.13 & & $.18^{\mathrm{a}}$ & & .09 & \\
\hline With other midwives & $-.21^{\mathrm{t}}$ & & $-.19^{a}$ & & $-.23^{b}$ & & .10 & & $.25^{\mathrm{c}}$ & \\
\hline With clients & $-.19^{a}$ & & -.14 & & $-.19^{\mathrm{a}}$ & & $.18^{\mathrm{a}}$ & & .09 & \\
\hline 2. Moderator & & $.11^{\mathrm{c}} .25^{\mathrm{c}}$ & & $.22^{\mathrm{c}} \cdot 32^{\mathrm{c}}$ & & $.09^{\mathrm{c}} .25^{\mathrm{c}}$ & & $.05^{\mathrm{c}} \cdot 15^{\mathrm{c}}$ & & $.12^{\mathrm{c}} .22^{\mathrm{c}}$ \\
\hline Perceived job control & $-.34^{c}$ & & $-.50^{\circ}$ & & -.33 & & $.24^{\mathrm{c}}$ & & $.36^{\mathrm{c}}$ & \\
\hline 3. Interaction terms & & $.02 .28^{\mathrm{c}}$ & & $.00 .32^{\mathrm{c}}$ & & $.01 .26^{\mathrm{c}}$ & & $.03 .18^{\mathrm{c}}$ & & $.01 .23^{\mathrm{c}}$ \\
\hline $\mathrm{JC} *$ Health care & $-.15^{\mathrm{a}}$ & & -.01 & & -.05 & & -.07 & & .07 & \\
\hline JC *Midwives & -.04 & & -.03 & & .05 & & .11 & & -.07 & \\
\hline JC * Clients & .06 & & -.03 & & .08 & & $-.16^{\mathrm{a}}$ & & .06 & \\
\hline
\end{tabular}

Note. Sample size ranges from $n=182$ to $n=184$.

${ }^{\mathrm{a}} p \leq .05 ;{ }^{\mathrm{b}} p \leq .01 ;{ }^{\mathrm{c}} p \leq .001$. 


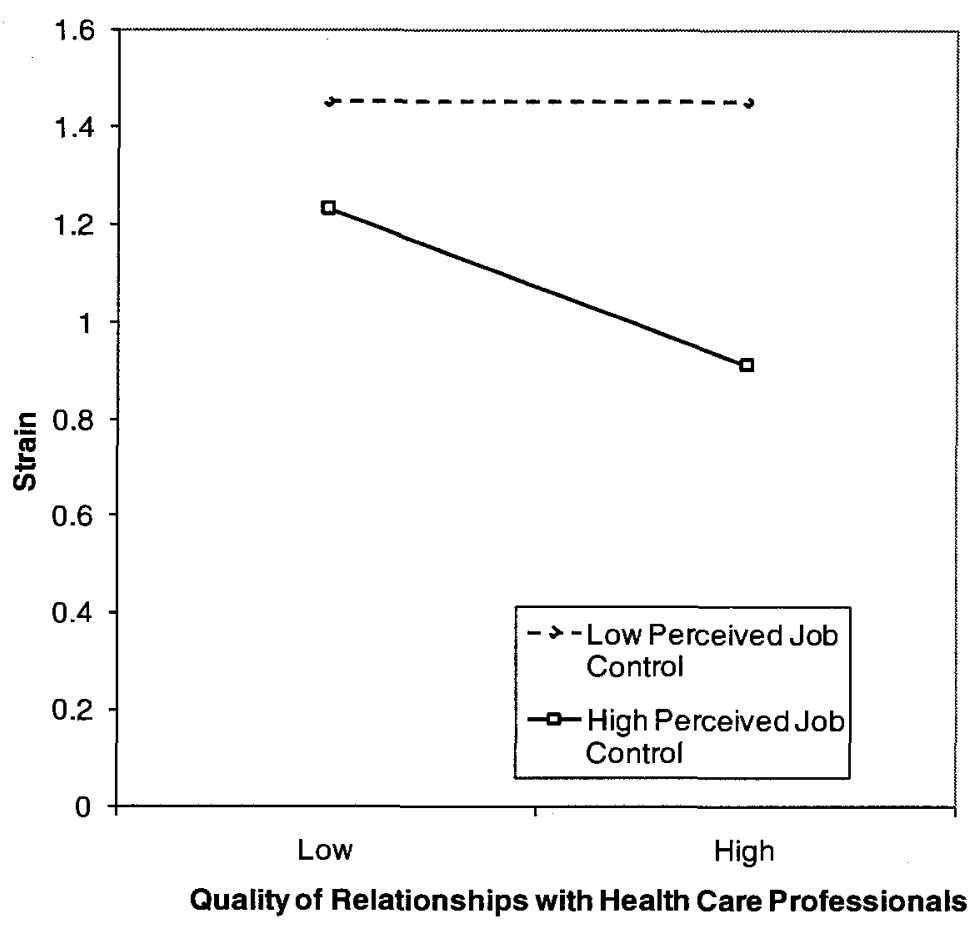

Figure 1. Interaction between the quality of midwives' relationships with health care professionals and perceived job control on strain.

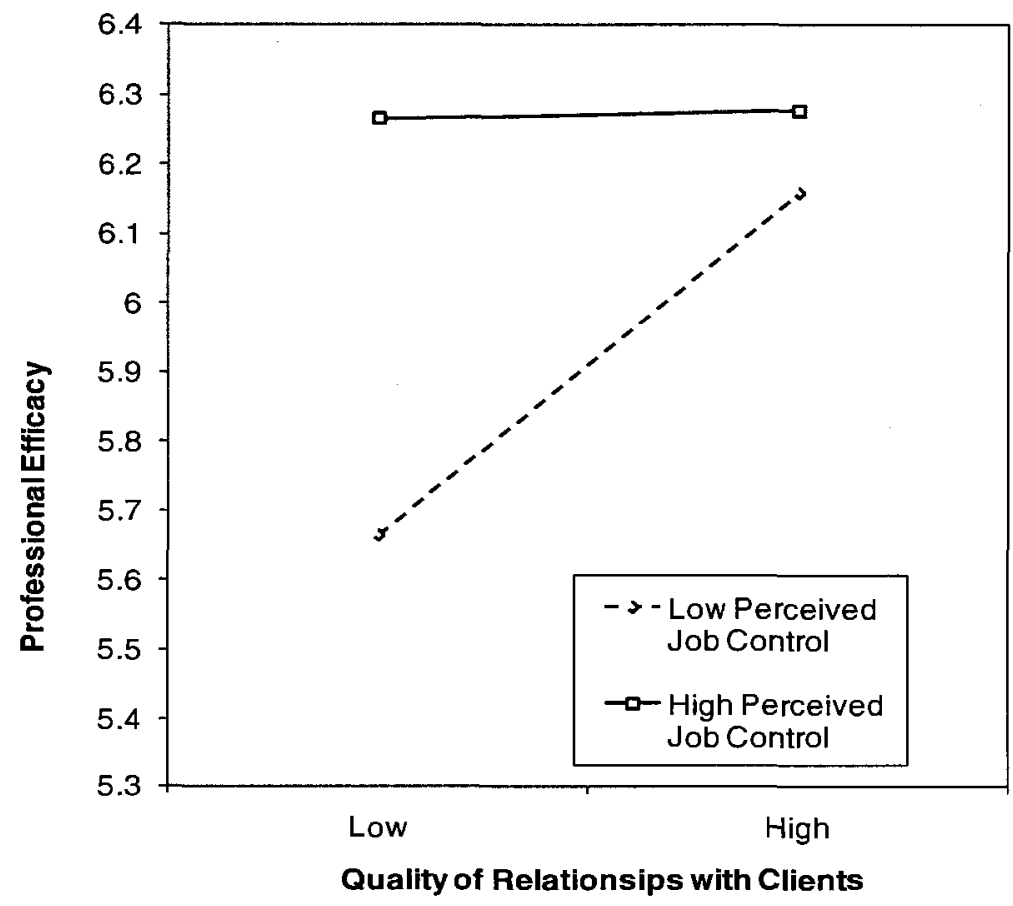

Figure 2. Interaction between the quality of midwives' relationships with their clients and perceived job control on professional efficacy 


\section{Workload}

The hypotheses for the workload stressors were tested through hierarchical regression (see Table 3). The objective workload measures were entered together at the first steps of regression. The objective workload variables were significant predictors of all outcomes with the exception of for professional efficacy. The number of difficult births over the last year uniquely predicted $\operatorname{strain}(\beta=.28, p<.001)$, emotional exhaustion $(\beta=.20, p<.01)$, and work-life balance $(\beta=-.18, p<.05)$. Also, the average length of the workweek both uniquely predicted strain $(\beta=20, p<.05)$, emotional exhaustion $(\beta=.31, p<.001)$, cynicism $(\beta=.18, p<.05)$, and work life balance $(\beta=$ $.27, p<.001)$.

The measure of overwork was entered at the second steps of the regression (as per Hypothesis 3b). As seen in Table 3, midwives' perception of being overworked significantly predicted increments in all the outcome variables, with the exception of professional efficacy, after controlling for the effects of objective measures of workload ( $R^{2}$ ranged from .09 to $.21, p<.001$ ). Midwives' perception of overwork accounted for considerable incremental variance in strain $\left(\Delta R^{2} .21, p<.001\right)$ and work-life balance $\left(\Delta R^{2} .21, p<.001\right)$.

The moderator variables were entered at the third steps in separate analyses for job control and support, followed by the interaction terms at the fourth and final steps. After controlling for the workload variables, perceived job control still accounted for significant incremental variance in all the outcome variables $\left(\Delta R^{2}\right.$ ranged from .03 to .12 $p<.01)$, with the most additional variance accounted for in emotional exhaustion $\left(\Delta R^{2}=\right.$ $.12, p<.001)$ and professional efficacy $\left(\Delta R^{2}=.10, p<.001\right)$, and the least in work-life balance $\left(\Delta R^{2}=.03 . p<.01\right)$. Separately, after controlling for the workload variables, the 
Stress and Burnout 46

Table 3

Workload Predicting Strain, Burnout, and Work-Life Balance; Job Control and Support as Moderators

\begin{tabular}{|c|c|c|c|c|c|c|c|}
\hline & & Strain & & $\begin{array}{l}\text { hotional } \\
\text { haustion }\end{array}$ & Cynicism & $\begin{array}{l}\text { Professional } \\
\text { Efficacy }\end{array}$ & $\begin{array}{c}\text { Work-Life } \\
\text { Balance }\end{array}$ \\
\hline Variable & $\beta$ & $\Delta R^{2} R^{2}$ & $\beta$ & $\Delta R^{2} R^{2}$ & $B \Delta R^{2} R^{2}$ & $\beta \Delta R^{2} R^{2}$ & $\beta \Delta R^{2} R^{2}$ \\
\hline 1. Objective workload & & $.13^{\mathrm{c}} .13^{\mathrm{c}}$ & & $.14^{\mathrm{c}} .14^{\mathrm{c}}$ & $.07^{\mathrm{a}} \cdot 07^{\mathrm{a}}$ & $\begin{array}{ll}.03 & .03\end{array}$ & $.11^{\mathrm{c}} .11^{\mathrm{c}}$ \\
\hline Births per year & -.10 & & $-.12^{\mathrm{a}}$ & & .02 & .11 & .09 \\
\hline Home births & -.08 & & -.02 & & -.07 & .07 & .00 \\
\hline Difficult births & .28 & & $.20^{\mathrm{b}}$ & & .05 & -.04 & $-.18^{\mathrm{a}}$ \\
\hline Average work week & .20 & & $.31^{\mathrm{c}}$ & & $.18^{\mathrm{a}}$ & -.15 & $-.27^{1}$ \\
\hline 2. Subjective workload & & $.13^{\mathrm{c}} .26^{\mathrm{c}}$ & & $.21^{\mathrm{c}} .35^{\mathrm{c}}$ & $.09^{\mathrm{c}} .16^{\mathrm{c}}$ & $.01 \quad .05$ & $.21^{\mathrm{c}} .32^{\mathrm{c}}$ \\
\hline Overwork & .38 & & $.48^{\mathrm{c}}$ & & $.33^{\mathrm{c}}$ & -.13 & $-.48^{l}$ \\
\hline Job Control & & & & & & & \\
\hline 3. Moderator & & $.05^{\mathrm{c}} .31^{\mathrm{c}}$ & & $.12^{\mathrm{c}} .47^{\mathrm{c}}$ & $.09^{\mathrm{c}} .25^{\mathrm{c}}$ & $.10^{\mathrm{c}} .15^{\mathrm{c}}$ & $.03^{\mathrm{b}} \cdot 35^{\mathrm{c}}$ \\
\hline Job control & -.26 & & $-.39^{\mathrm{c}}$ & & $-.34^{\mathrm{c}}$ & $.36^{\mathrm{c}}$ & $.20^{\mathrm{b}}$ \\
\hline 4. Interaction Terns & & $.02 .34^{\mathrm{c}}$ & & $.01 .48^{\mathrm{c}}$ & $.05 .30^{\mathrm{c}}$ & $.04 .19^{c}$ & $.02 .37^{\mathrm{c}}$ \\
\hline $\mathrm{JC} *$ Births & .01 & & .07 & & .14 & $-.21^{\mathrm{a}}$ & .15 \\
\hline JC $*$ Home Births & -.04 & & -.09 & & -.09 & .02 & -.08 \\
\hline $\mathrm{JC} *$ Difficult Births & -.02 & & .06 & & $-18^{a}$ & -.05 & -.04 \\
\hline $\mathrm{JC} *$ Work week & -.12 & & -.12 & & -.06 & .14 & .02 \\
\hline $\mathrm{JC} *$ Overwork & -.04 & & .05 & & -.12 & .04 & .09 \\
\hline
\end{tabular}

Support

3. Moderator

$\begin{array}{lllll}.04^{\mathrm{a}} .30^{\mathrm{c}} & .04^{\mathrm{b}} .40^{\mathrm{c}} & .09^{\mathrm{c}} .25^{\mathrm{c}} & .03 & .07\end{array}$

$\begin{array}{llllll}\text { Colleague Support } & -.11 & -.21^{\mathrm{b}} & -.22^{\mathrm{b}} & .18^{\mathrm{a}} & .26^{\mathrm{c}} \\ \text { Org. Support } & -.14 & -.04 & -.19^{\mathrm{a}} & .00 & .14\end{array}$

4. Interaction terns

$.06 .36^{\mathrm{c}}$

$04.44^{\mathrm{c}}$

$.04 .29^{\mathrm{c}}$

.06 .13

$.03 .46^{\mathrm{C}}$

$\mathrm{Col} *$ Births

$-.07$

.07

$-.02$

$-.14$

.04

$\mathrm{Col} *$ Home Births $\quad-.10$

$-.10$

$-.05$

.06

$-.08$

$\mathrm{Col} *$ Difficult Births .01

$-.08$

.07

$-.03$

$-.11$

$\mathrm{Col} *$ Work week $\quad-.12$

$-.18$

$\mathrm{Col} *$ Overwork $\quad .23^{\mathrm{a}}$

$.25^{\mathrm{a}}$

$-.17$

.15

.03

Org * Births

$-.03$

.17

$-.03$

.00

Org * Home Births $\quad-.01$

$-.02$

.07

$-.07$

.07

Org * Difficult Births $\quad-.15$

.01

.02

$-.06$

.03

Org* Work week $\quad-.05$

.13

$-.07$

.06

.12

Org * Overwork $\quad-.08$

$-.16^{\mathrm{a}}$

.09

$-.01$

$-.07$

$-.20^{\mathrm{a}}$

.19

.10

Note. Sample size ranges from $n=159$ to $n=172$ for analyses involving job control and from $n=156$ to $n=159$ for analyses involving support; Results for steps 1 and 2 from the analyses with job control. $\quad{ }^{\mathrm{a}} p \leq .05 ;{ }^{\mathrm{b}} p \leq .01 ;{ }^{\mathrm{c}} p \leq .001$. 
support variables jointly accounted for significant increments in variance in all the outcome variables with the exception of professional efficacy $\left(\Delta R^{2}\right.$ ranged from .04 to $.09 p<.05)$ with the most additional variance accounted for in cynicism $\left(\Delta R^{2}=.09, p<\right.$ $.001)$ and work-life balance $\left(\Delta R^{2}=.09, p<.001\right)$, and the least in strain $\left(\Delta R^{2}=.04, p<\right.$ $.05)$ and emotional exhaustion $\left(\Delta R^{2}=.04, p<.01\right)$.

Although the interaction steps failed to account for a significant amount of incremental variance, some of the interaction terms were significant. There was a significant interaction between the number of difficult births midwives experienced over the last year and perceived job control on cynicism $(\beta=-.18, p<.05)$, and there was a significant interaction between the total number of births in the last year and perceived job control on professional efficacy $(\beta=-.21, p<.05)$. In both cases, control buffered the negative impact of the stressors. That is, midwives who tended to report lower perceived job control tended to have higher cynicism, regardless of the number of difficult births per year $(\beta=-.08, n s$; see Figure 3$)$. However, at higher reported job control midwives tended to report lower overall cynicism and their cynicism tended to be reduced as they attended fewer difficult births $(\beta=-.20, p<.05)$. Likewise, midwives who tended to report higher perceived job control tended to have a higher sense of professional efficacy regardless of the number of births per year $(\beta=-.14, n s$; see Figure 4). However, at lower reported job control midwives tended to have lower overall professional efficacy and their professional efficacy tended to be reduced as they tended to attend fewer births per year $(\beta=.29, p<.05)$. 


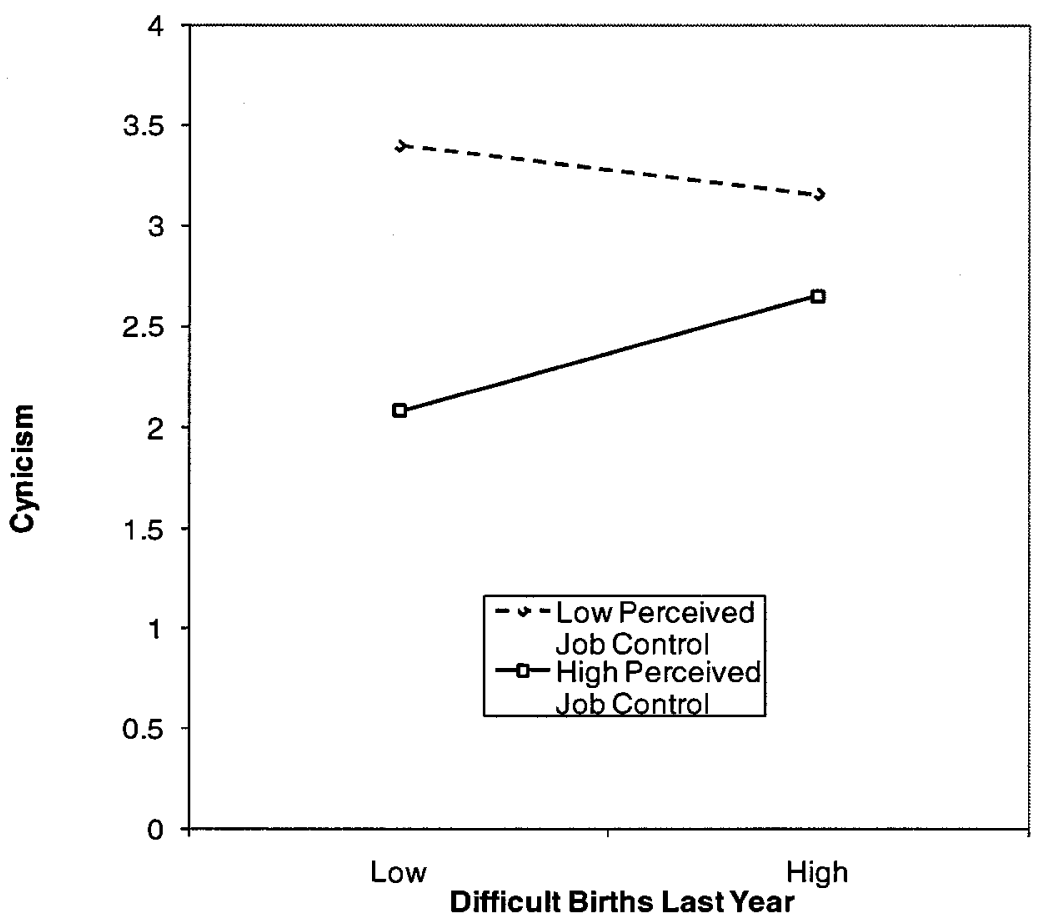

Figure 3. Interaction between the number of difficult births in the last year and perceived job control on cynicism.

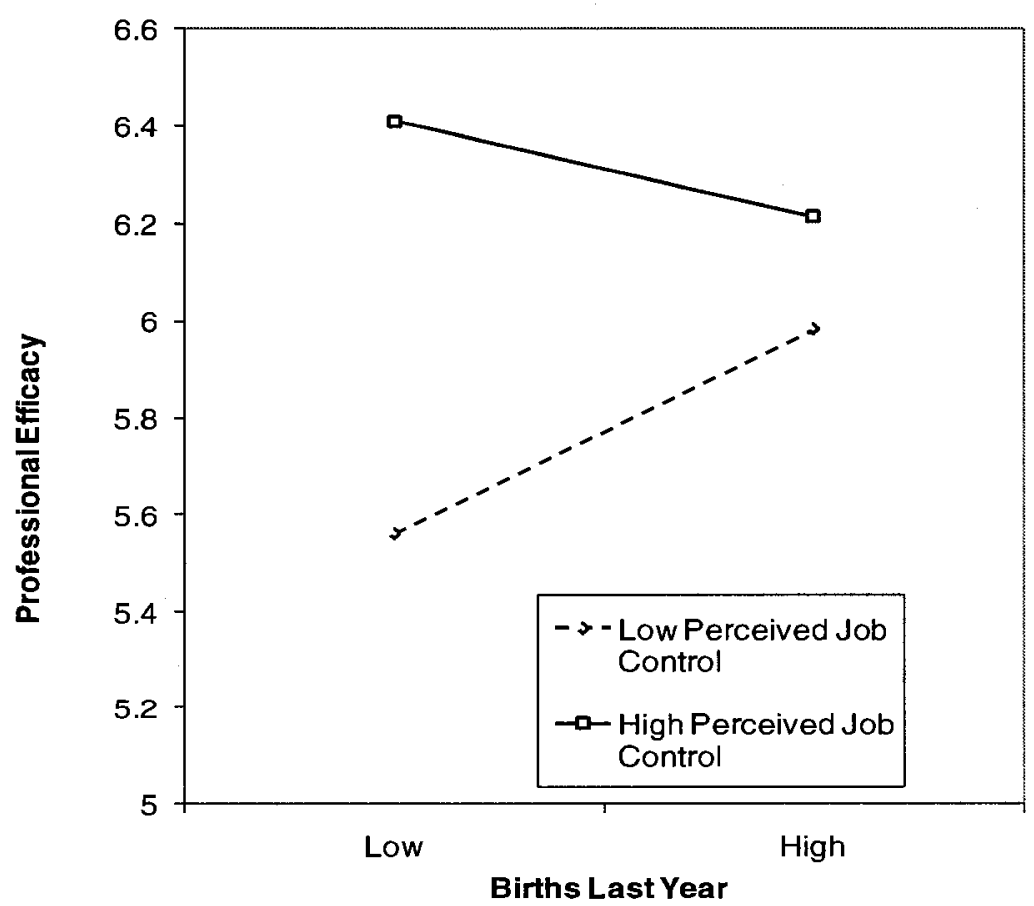

Figure 4. Interaction between the number of births in the last year and perceived job control on professional efficacy. 
There were also significant interactions between midwives' experience of social support from colleagues and midwives' perceptions of being overworked on strain $(\beta=$ $.23, p<.05)$ and on emotional exhaustion $(\beta=.25, p<.05)$. Both interactions had a similar shape, where midwives who reported high support from colleagues tended to have better outcomes at low levels of overwork, and there was no significant difference between reported levels of support at high levels of overwork. More specifically, at high levels of support from colleagues there was a significant positive relationship between midwives' experience of overwork and strain $(\beta=.53, p<.001$; see Figure 5). However, at lower levels of reported support there was no relationship between midwives experience of overwork and strain $(\beta=.18, n s)$. Moreover, at high levels of overwork there was no significant difference between the high-support and low-support from colleagues midwives on strain, $t(138)=.73, n s$, whereas at lower levels of overwork, midwives who reported higher levels of social support from colleagues had significantly lower strain than those who had lower levels of support, $t(138)=-2.38, p<.05$.

Likewise, at high levels of support from colleagues, there was a significant positive relationship between midwives' experience of overwork and emotional exhaustion $(\beta=.62, p<.001$; see Figure 6). However, at lower levels of reported support the relationship between midwives experience of overwork and emotional exhaustion was weaker $(\beta=.25, p<.01)$. Moreover, at high levels of overwork there was no significant difference between the high-support and low-support from colleagues midwives on emotional exhaustion, $t(139)=.47, n s$, whereas at lower levels of overwork, midwives who reported higher levels of social support from colleagues had 
Stress and Burnout 50

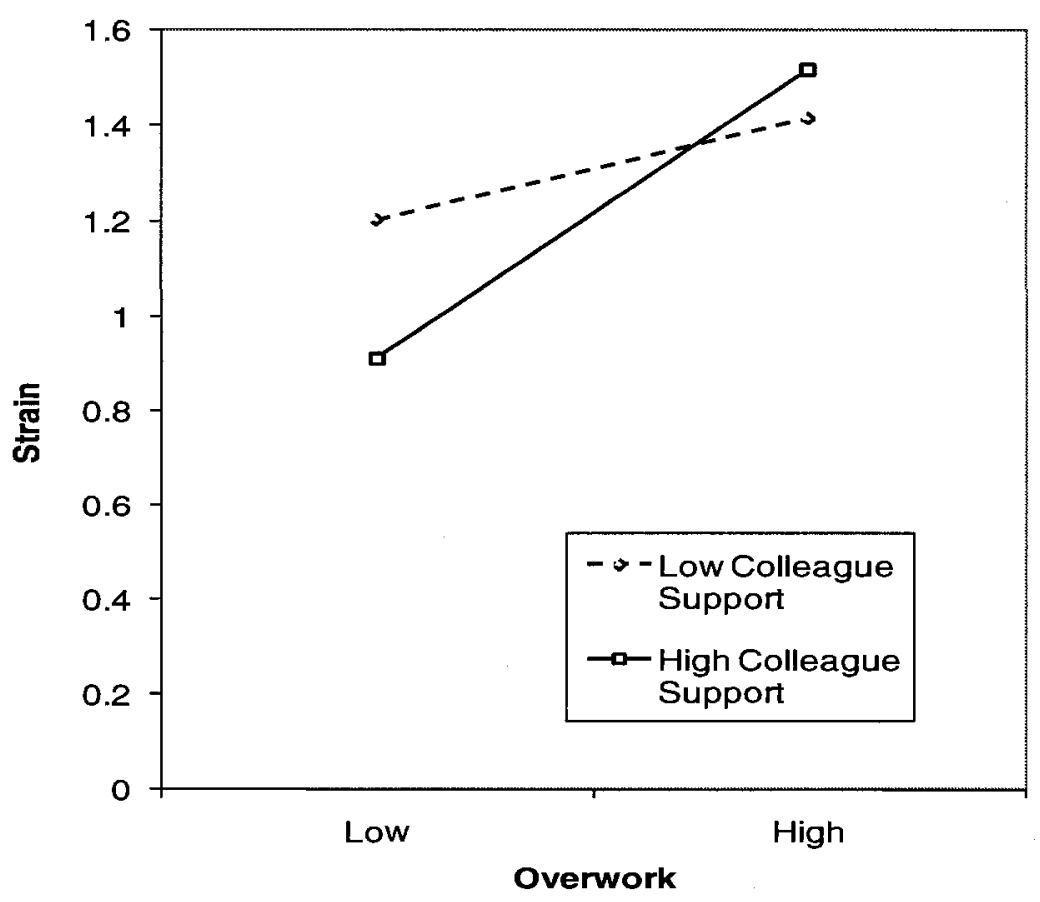

Figure 5. Interaction between overwork and social support from midwife colleagues on strain.

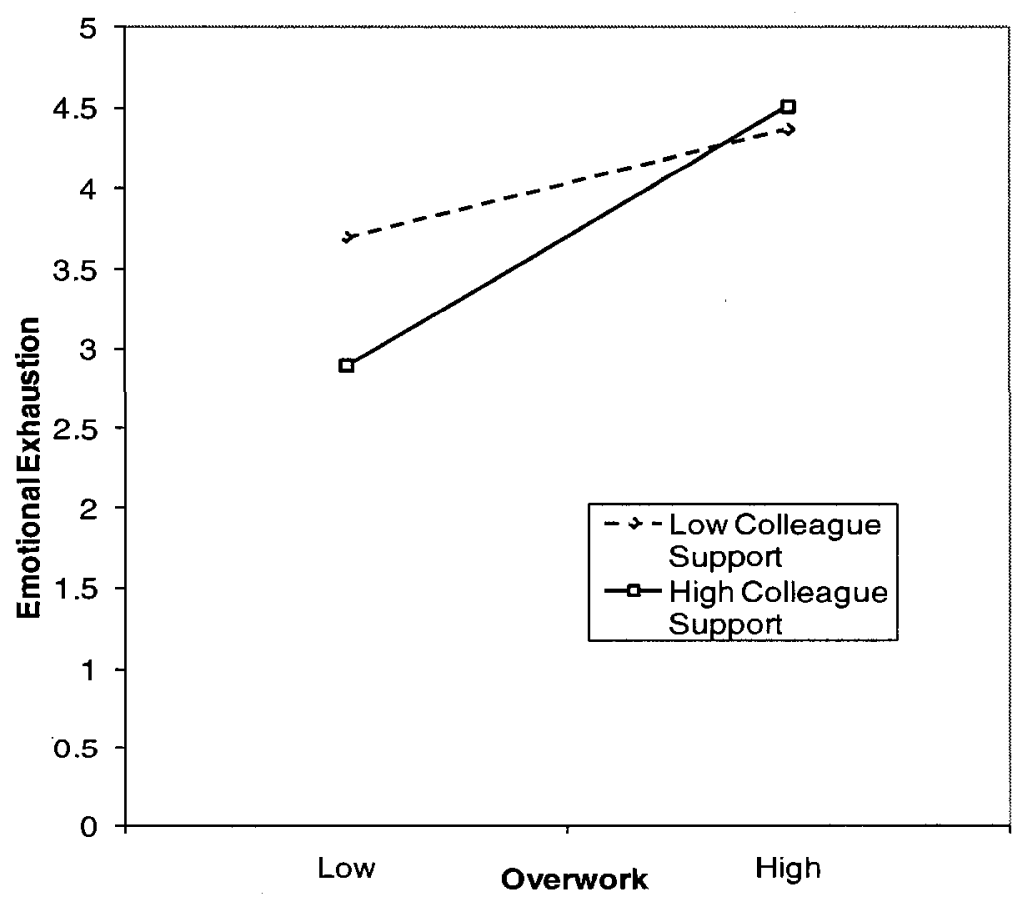

Figure 6. Interaction between overwork and social support from midwife colleagues on emotional exhaustion. 
significantly lower emotional exhaustion than those who had lower levels of support, $t(139)=-3.10, p<.01$

There were also significant interactions between midwives' experience of organizational support and midwives' perceptions of being overworked on emotionalexhaustion $(\beta=-.16, p<.05)$ and cynicism $(\beta=-.20, p<.05)$. Both interactions had a similar shape, where the low organizational support midwives tended to have poorer outcomes at high levels of overwork, and there was no significant difference between high and low organizational support midwives at low levels of overwork. More specifically, at low levels of organizational support there was a significant positive relationship between midwives' experience of overwork and emotional exhaustion $(\beta=.59, p<.001$; see Figure 7). However, at higher levels of organizational support, the relationship between midwives experience of overwork and emotional exhaustion was weaker $(\beta=.28, p<.05)$. Moreover, at low levels of overwork there was no significant difference between the high and low overwork midwives on emotional exhaustion, $t(139)=.70, n s$, whereas at higher levels of overwork, midwives who reported lower levels of organizational support had significantly higher emotional exhaustion than those who had higher levels of support, $t(139)=-2.04, p<.05$.

Likewise, at low levels of organizational support there was a significant positive relationship between midwives' experience of overwork and cynicism $(\beta=.40, p<.01$; see Figure 8). However, at higher levels of organizational support, there was no relationship between midwives experience of overwork and cynicism $(\beta=.01, n s)$. Moreover, at low levels of overwork, there was no significant difference between the 
Stress and Burnout 52

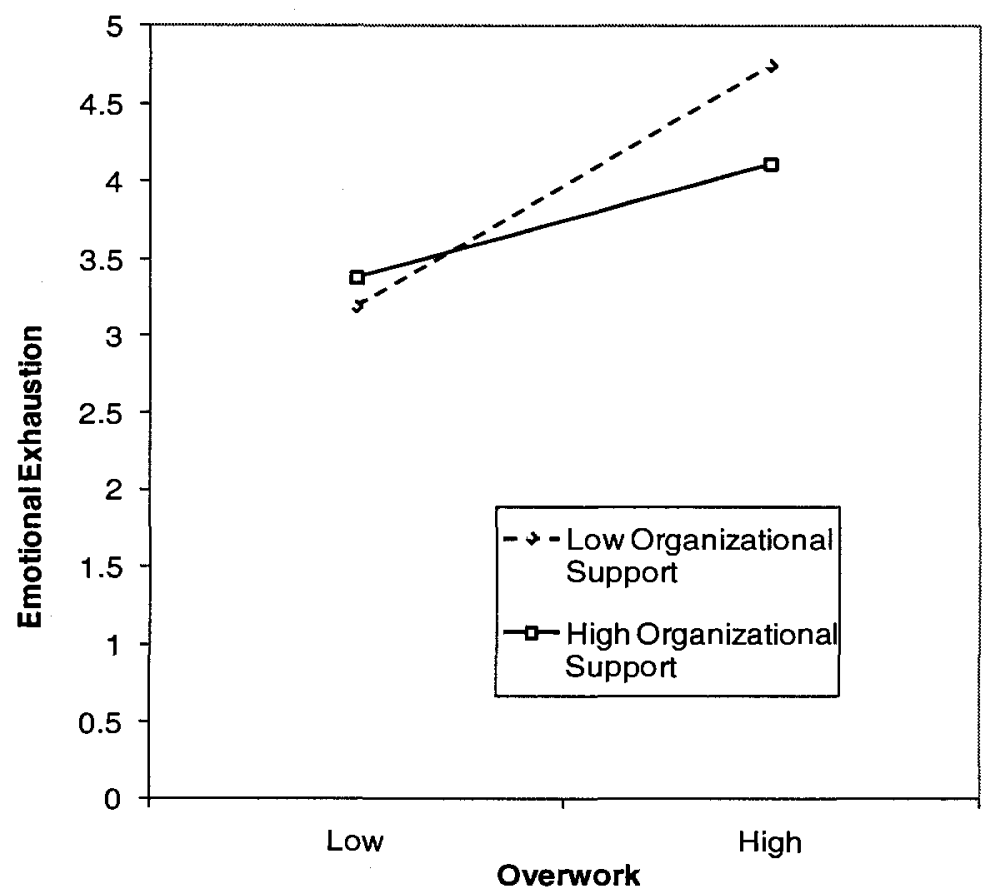

Figure 7. Interaction between overwork and organizational support on emotional exhaustion.

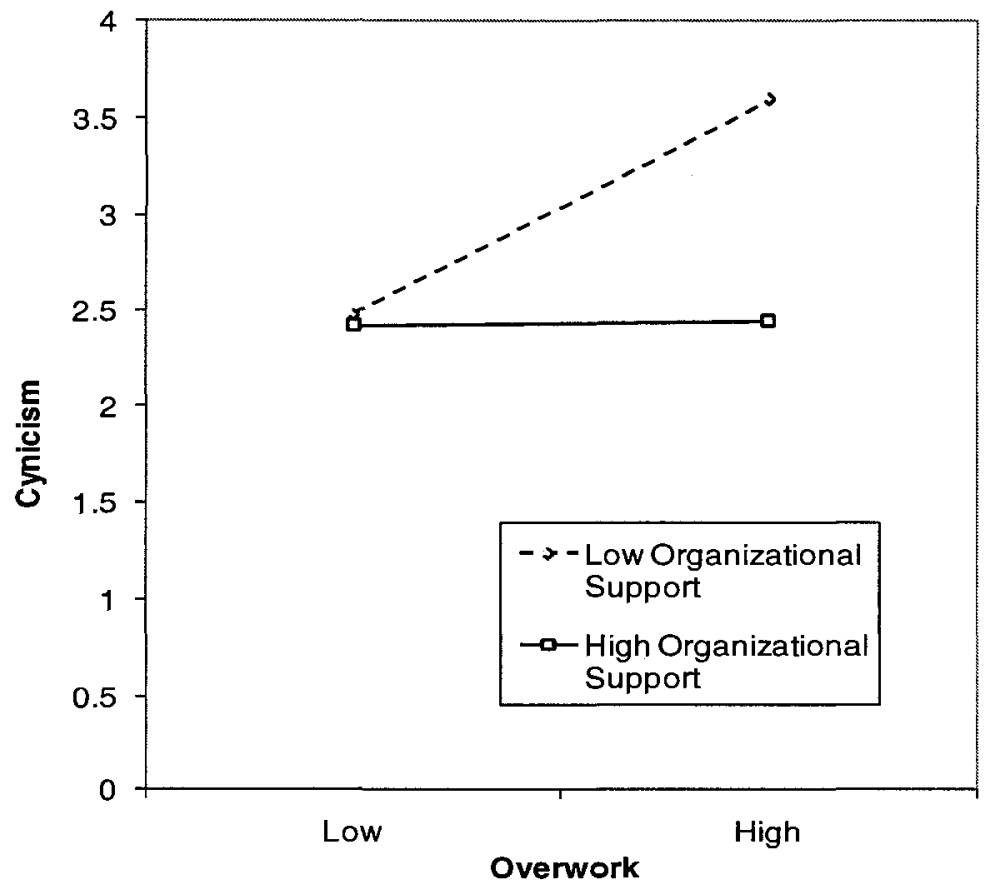

Figure 8. Interaction between overwork and organizational support on cynicism. 
Stress and Burnout 53

high and low overwork midwives on cynicism, $t(139)=.17, n s$, whereas at higher levels of overwork, midwives who reported lower levels of organizational support had significantly higher cynicism than those who had higher levels of support, $t(139)=-$ $3.11, p<.01$. Role conflict

The hypotheses for role conflict were tested through hierarchical regressions (see Table 4). The role conflict variable was entered at the first step of regression and predicted significant variance for all five outcome measures $\left(R^{2}\right.$ ranged from .05 to .18 , $p<.01)$. Role conflict tended to predict the most variance in strain $\left(R^{2}=.18, p<.001\right)$ and emotional exhaustion $\left(R^{2}=.15, p<.001\right)$, and the least in professional efficacy $\left(R^{2}\right.$ $=.05, p<.01)$.

The moderator variables were entered at the second steps in separate analyses for job control and support. Perceived job control accounted for significant incremental variance in all the outcome variables $\left(\Delta R^{2}\right.$ ranged from .05 to $\left..17, p<.001\right)$, with the most incremental variance accounted for in emotional exhaustion $\left(\Delta R^{2}=.17, p<.001\right)$, and the least in professional efficacy $\left(\Delta R^{2}=.05, p<.001\right)$ and strain $\left(\Delta R^{2}=.07, p<\right.$ .001). The support variables jointly accounted for significant incremental variance in all the outcome variables with the exception of professional efficacy $\left(\Delta R^{2}\right.$ ranged from .04 to $.16, p<.05$ ) with the most incremental variance accounted for in work-life balance $\left(\Delta R^{2}=.16, p<.001\right)$ and the least in strain $\left(\Delta R^{2}=.04, p<.05\right)$. The interaction terms were entered at the third steps in separate analyses for job control and support. However, none of the interaction steps or interaction terms was significant (Hypothesis $4 \mathrm{~b}$ and Hypothesis $4 \mathrm{c})$. 
Table 4

Role Conflict Predicting Strain, Burnout, and Work-Life Balance; Job Control and Support as Moderators

\begin{tabular}{|c|c|c|c|c|c|c|c|c|c|c|}
\hline & \multicolumn{2}{|c|}{ Strain } & \multicolumn{2}{|c|}{$\begin{array}{l}\text { Emotional } \\
\text { Exhaustion }\end{array}$} & \multicolumn{2}{|c|}{ Cynicism } & \multicolumn{2}{|c|}{$\begin{array}{l}\text { Professional } \\
\text { Efficacy }\end{array}$} & \multicolumn{2}{|c|}{$\begin{array}{c}\text { Work-Life } \\
\text { Balance }\end{array}$} \\
\hline Variable & $\beta$ & $\Delta R^{2} R^{2}$ & $\beta$ & $\Delta R^{2} R^{2}$ & $\beta$ & $\Delta R^{2} R^{2}$ & $\beta$ & $\Delta R^{2} R^{2}$ & $\beta$ & $\Delta R^{2} R^{2}$ \\
\hline 1. Role Stressors & & $.18^{\mathrm{c}} .18^{\mathrm{c}}$ & & $.15^{\mathrm{c}} .15^{\mathrm{c}}$ & & $.13^{\mathrm{c}} .13^{\mathrm{c}}$ & & $.05^{\mathrm{b}} .05^{\mathrm{b}}$ & & $.12^{c} .12^{c}$ \\
\hline Role Conflict & $.43^{\mathrm{c}}$ & & $.39^{c}$ & & $.36^{\mathrm{c}}$ & & $-.23^{\mathrm{b}}$ & & $-.34^{\mathrm{c}}$ & \\
\hline \multicolumn{11}{|l|}{ Job Control } \\
\hline 2. Moderator & & $.07^{\mathrm{c}} .25^{\mathrm{c}}$ & & $.17^{\mathrm{c}} .32^{\mathrm{c}}$ & & $.08^{\mathrm{c}} \cdot 21^{\mathrm{c}}$ & & $.05^{\mathrm{c}} \cdot 10^{\mathrm{c}}$ & & $.09^{c} \cdot 21^{c}$ \\
\hline Job Control & $-.30^{c}$ & & $-.46^{\mathrm{c}}$ & & $-.32^{c}$ & & $.26^{\mathrm{c}}$ & & $-.34^{\mathrm{c}}$ & \\
\hline 3. Interaction terms & & $.01 .26^{\mathrm{c}}$ & & $.01 .32^{c}$ & & $.00 .21^{\mathrm{c}}$ & & $.00 .10^{c}$ & & $.00 .21^{c}$ \\
\hline JC $*$ Role Conflict & -.10 & & -.07 & & .03 & & -.04 & & .05 & \\
\hline \multicolumn{11}{|l|}{ Support } \\
\hline 3. Moderator & & $.04^{\mathrm{a}} .22^{\mathrm{c}}$ & & $.09^{c} .25^{c}$ & & $.10^{\mathrm{c}} \cdot 23^{\mathrm{c}}$ & & $.03 .07^{\mathrm{b}}$ & & $.16^{c} \cdot 29^{c}$ \\
\hline Colleague Support & -.13 & & $-.29^{c}$ & & $-.24^{c}$ & & $.18^{\mathrm{a}}$ & & $.30^{\mathrm{c}}$ & \\
\hline $\begin{array}{l}\text { Organizational } \\
\text { Support }\end{array}$ & -.12 & & -.06 & & $-.17^{\mathrm{a}}$ & & -.04 & & $.20^{\mathrm{b}}$ & \\
\hline 4. Interaction terms & & $.01 .23^{\mathrm{c}}$ & & $.01 .26^{\mathrm{c}}$ & & $.00 .24^{\mathrm{c}}$ & & $.00 .07^{\mathrm{a}}$ & & $.01 .30^{\mathrm{c}}$ \\
\hline Col * Role Conflict & -.01 & & -.11 & & -.06 & & .01 & & .03 & \\
\hline Org ${ }^{*}$ Role Conflict & -.07 & & .03 & & .01 & & -.04 & & .09 & \\
\hline
\end{tabular}

Note. Sample size ranges from $n=182$ to $n=199$ for analyses involving perceived job control and from $n=179$ to $n=183$ for analyses involving support; Results for step 1 from the analyses with perceived job control.

${ }^{\mathrm{a}} p \leq .05 ;{ }^{\mathrm{b}} p \leq .01 ;{ }^{\mathrm{c}} p \leq .001$. 


\section{Compensation}

The hypotheses for compensation were tested through hierarchical regression (see Table 5). The satisfaction with compensation variable was entered at the first steps of regression. Results show that the reported adequacy of compensation was a significant predictor of $\operatorname{strain}\left(R^{2}=.04, p<.01\right)$, emotional exhaustion $\left(R^{2}=.03, p<\right.$ $.05)$, professional efficacy $\left(R^{2}=.03, p<.05\right)$, and work-life balance $\left(R^{2}=.05, p<.01\right.$; Hypothesis 5a). The moderator variables were entered at the second steps in separate analyses for job control and support. Perceived job control accounted for significant incremental variance in all the outcome variables $\left(\Delta R^{2}\right.$ ranged from .08 to $\left..26, p<.001\right)$ with the most incremental variance accounted for in emotional exhaustion $\left(\Delta R^{2}=.26, p\right.$ $<.001)$ and the least in professional efficacy $\left(\Delta R^{2}=.08, p<.001\right)$. The support variables also jointly accounted for incremental variance in all the outcome variables $\left(\Delta R^{2}\right.$ ranged from .04 to $.22, p<.05$ ), with the most incremental variance accounted for in work-life balance $\left(\Delta R^{2}=.22, p<.001\right)$ and the least in strain $\left(\Delta R^{2}=.09, p<.001\right)$ and professional efficacy $\left(\Delta R^{2}=.04, p<.05\right)$.

The interaction terms were entered at the third step of the regressions in separate analyses for perceived job control and for the support variables. The interactions between perceived job control and adequacy of compensation on $\operatorname{strain}(\beta=.22, p<.05)$ and on cynicism $(\beta=.21, p<.05)$ were significant (see Table 5). At higher reported job control, midwives tended to experience lower overall strain regardless of the adequacy of their compensation $(\beta=.03, n s$; see Figure 9). However, at lower job control midwives tended to report higher overall strain and midwives who felt that their compensation was adequate tended to report significantly less strain than those who felt 
it was inadequate $(\beta=-.26, p<.01)$. Although the interaction between job control and compensation on cynicism was significant, neither of the slopes was significantly different from zero, therefore the interaction was not interpretable.

Although none of the interaction steps were significant, the interactions involving midwives' social support from colleagues with adequacy of compensation on emotional exhaustion $(\beta=.24, p<.05)$ and on work-life balance $(\beta=.21, p<.05)$ were significant. In both cases, at higher reported levels of support from colleagues midwives tended to have lower overall emotional exhaustion and higher overall work-life balance regardless of the reported adequacy of midwives' compensation $(\beta=.05, n s$; see Figure 10) or work-life balance $(\beta=.-.04, n s$; see Figure 11). However, at lower levels of reported support from colleagues midwives who felt that their compensation was

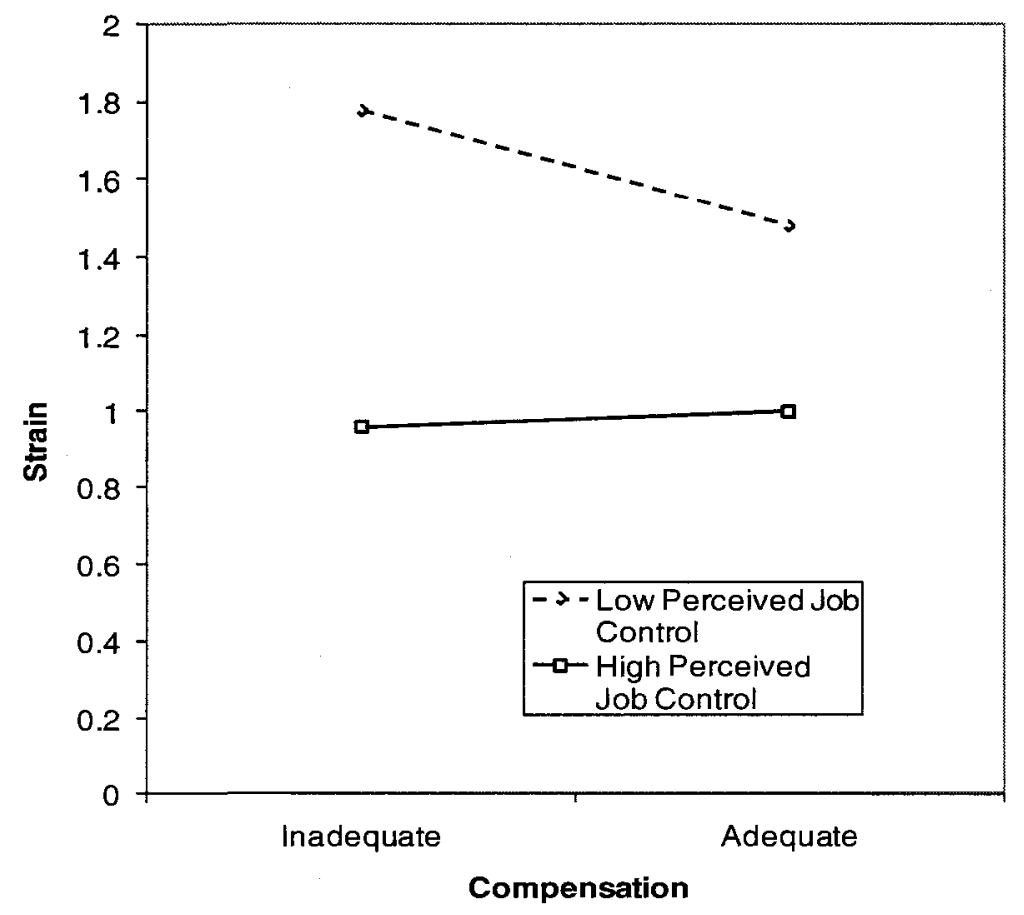

Figure 9. Interaction between midwives' satisfaction with compensation and perceived job control on strain. 
Stress and Burnout 57

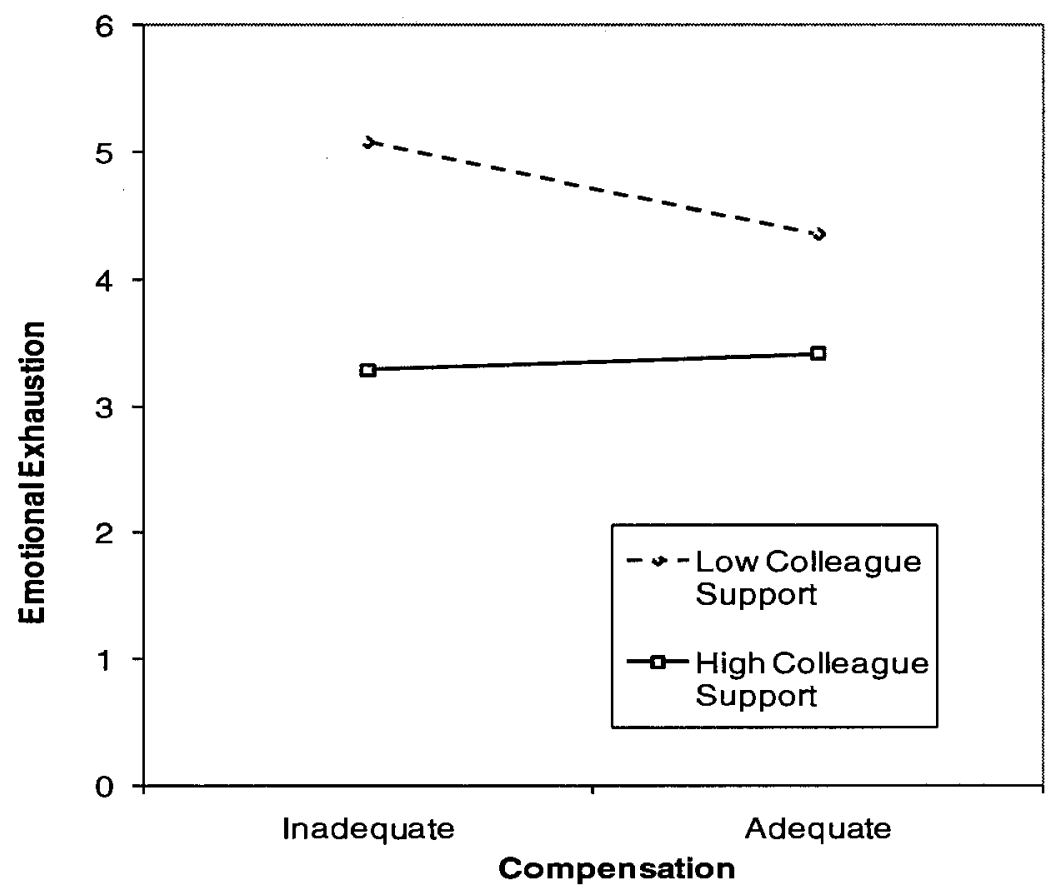

Figure 10. Interaction between midwives' satisfaction with compensation and social support from midwifery colleagues on emotional exhaustion.

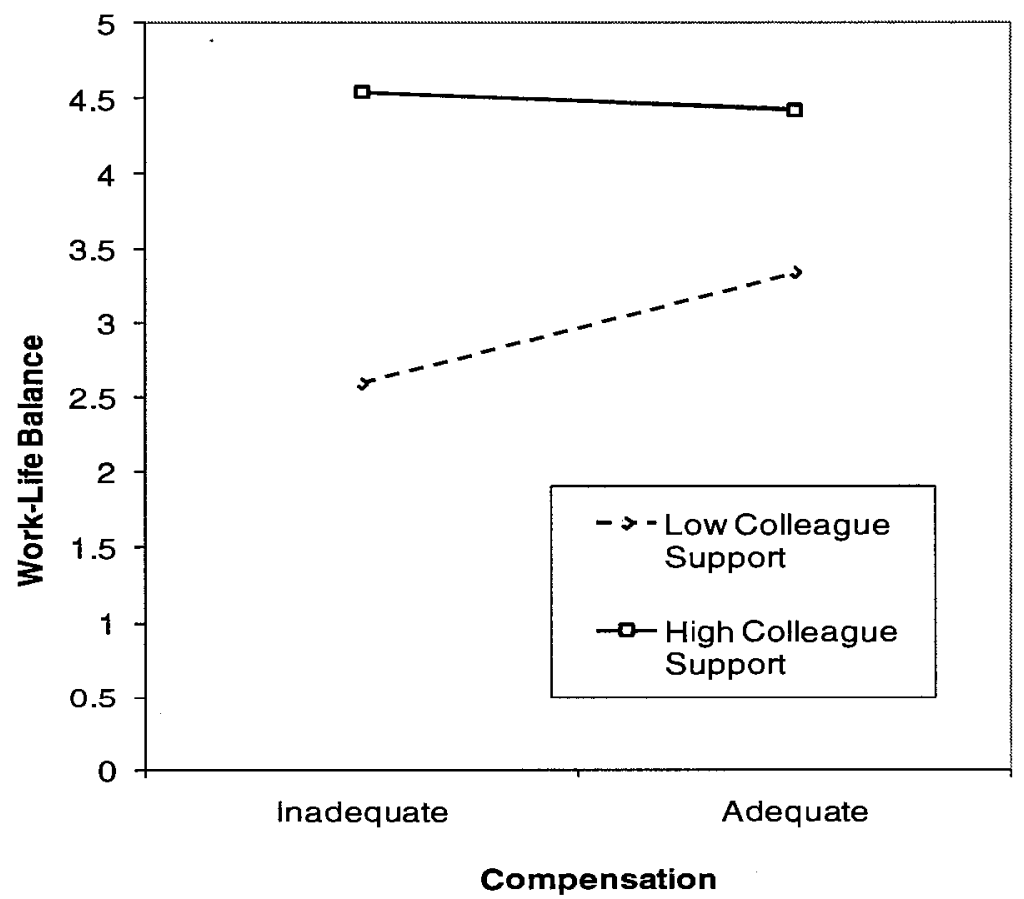

Figure 11. Interaction between midwives' satisfaction with compensation and social support from midwives of colleagues on work-life balance. 
Table 5

Compensation Predicting Strain, Burnout, and Work-Life Balance; Job Control and Support as Moderators

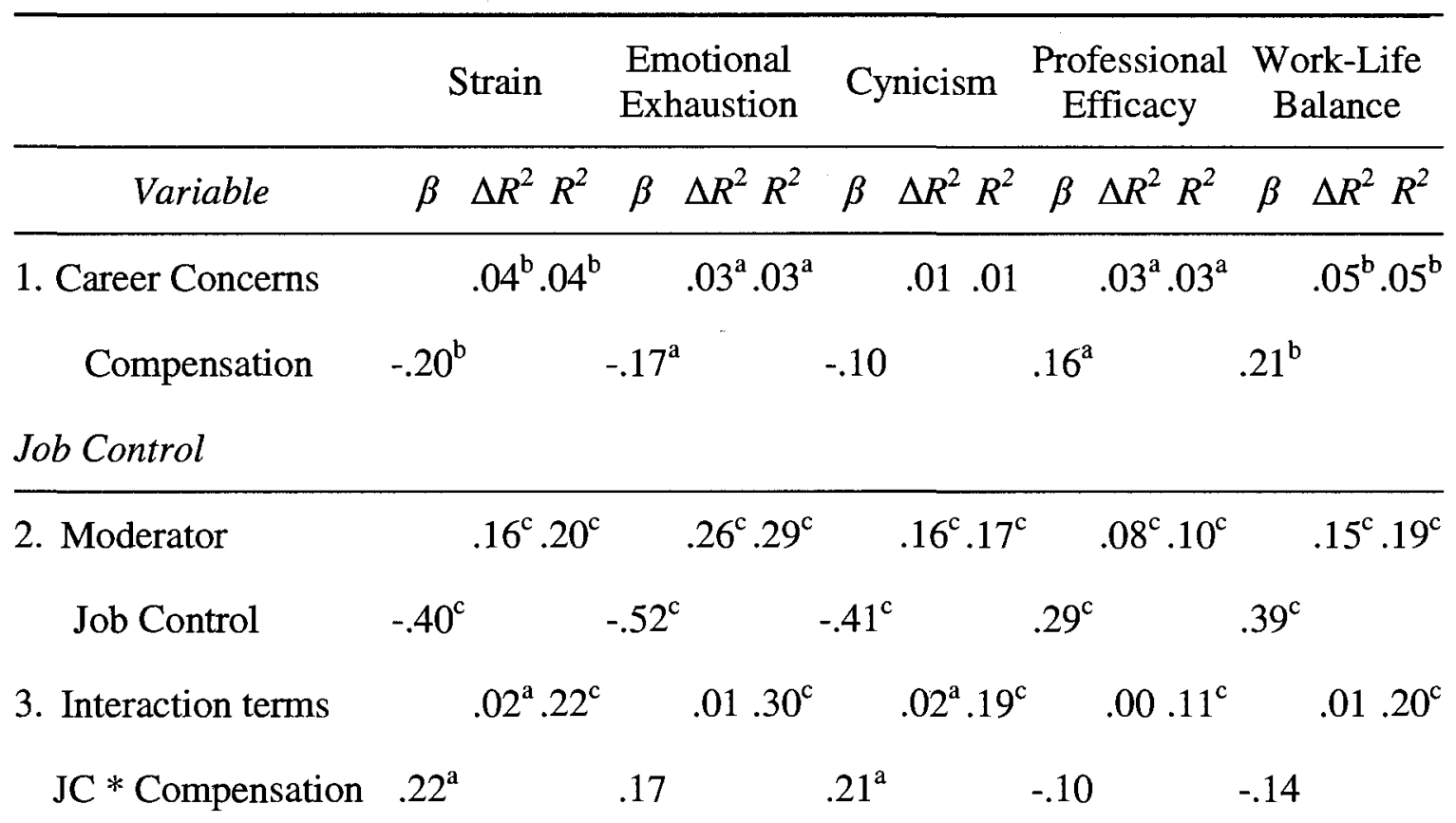

Support

2. Moderator

Support from

Colleagues

Organizational

Support

3. Interaction terms

Colleagues *

Compensation

Organization * Compensation

$$
.09^{c} .13^{c}
$$$$
.15^{\mathrm{c}} .18^{\mathrm{c}}
$$$$
.17^{\mathrm{c}} \cdot 18^{\mathrm{c}}
$$$$
.04^{\mathrm{a}} .07^{\mathrm{b}}
$$$$
.22^{c} .26^{c}
$$$$
-.18^{\mathrm{a}}
$$

$-.33^{\mathrm{c}}$

$-.28^{\mathrm{c}}$

$.20^{\mathrm{a}}$

$.34^{\mathrm{c}}$

$$
-.19^{\mathrm{a}}
$$

$-.12$

$-.23^{\mathrm{b}}$

$-.01$

$.24^{\mathrm{c}}$

$$
.01 .14^{\mathrm{c}}
$$

$.02 .20^{\mathrm{c}}$

$.01 .19^{\mathrm{c}}$

$.00 .08^{\mathrm{a}}$

$.02 .28^{\mathrm{c}}$

Note. Sample size ranges from $n=180$ to $n=196$ for analyses involving perceived job control and from $n=177$ to $n=181$ for analyses involving support; Results for step 1 from the analyses with perceived job control.

${ }^{\mathrm{a}} p \leq .05 .{ }^{\mathrm{b}} p \leq .01 .{ }^{\mathrm{c}} p \leq .001$. 
inadequate tended to have significantly higher emotional exhaustion $(\beta=-.28, p<.01)$ and significantly lower work-life balance $(\beta=.25, p<.05)$.

Time off-call

The hypotheses that the number of days midwives are off-call were tested through hierarchical regression (see Table 6). The number of days midwives are off-call per month was entered at the first steps of regression. Results show that the number of days midwives are off-call per month does not significantly predict any of the outcome measures. The moderator variables were entered at the second steps in separate analyses for job control and support. Perceived job control accounted for significant incremental variance in all the outcome measures $\left(\Delta R^{2}\right.$ ranged from .09 to $\left..33, p<.001\right)$, with most incremental variance accounted for in emotional exhaustion $\left(\Delta R^{2}=.33, p<.001\right)$ and the least in professional efficacy $\left(\Delta R^{2}=.09, p<.001\right)$. The support variables jointly accounted for incremental variance in all the outcome variables with the exception of professional efficacy ( $\Delta R^{2}$ ranged from .14 to $\left..28, p<.001\right)$, with the most incremental variance accounted for in work-life balance $\left(\Delta R^{2}=.28, p<.001\right)$ and the least in strain $\left(\Delta R^{2}=.14, p<.001\right)$ and emotional exhaustion $\left(\Delta R^{2}=.18, p<.001\right)$.

The interaction terms were entered at the third steps of the regressions in separate analyses for perceived job control and for the support variables. Perceived job control did significantly moderate the relationship of the number of days midwives are off-call to professional efficacy $(\beta=.25, p<.001)$. At higher reported job control midwives tended to have a higher overall sense of professional efficacy regardless of the number of days they were off-call $(\beta=.12, n s$; see Figure 12$)$. However, at lover reported job control midwives tended to have a lower overall sense of professional efficacy and their 
sense of professional efficacy tended to be significantly reduced as their number of days off-call increased $(\beta=-.29, p<.01)$. The interaction was expanded on post-hoc by comparing the zero-order correlations between the number of days a midwife is off-call and the other measures of objective workload for those who scored below the median on perceived job control. Results show that there was no relationship between the number of days off-call per month and average work week, the number of births per year, or the number of difficult births per year. However there was a significant negative relationship between the number of home births per year and the number of days off-call for the lower perceived control midwives $(r=-.25, p<.05)$ not present in the higher reported perceived control midwives $(r=.07, n s)$. Finally, the moderator hypothesis for the

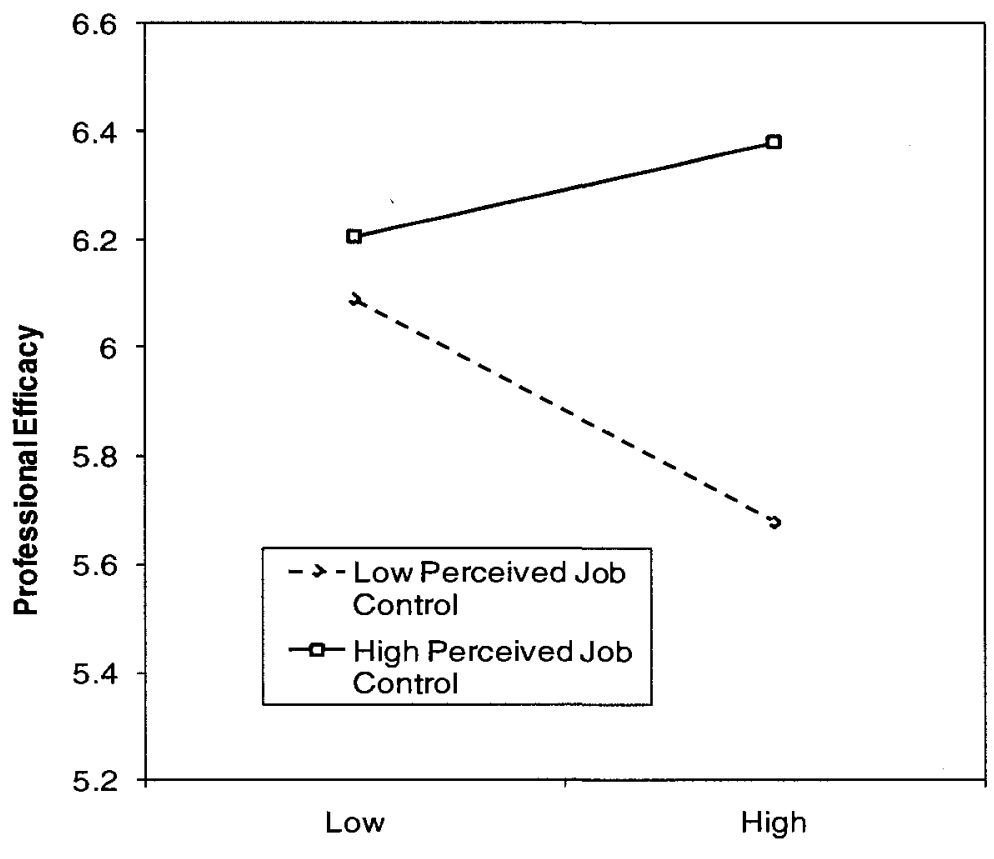

Number of Days Off-Call per Month

Figure 12. Interaction between the number of days midwives are off-call per month and perceived job control on professional efficacy. 
Table 6

Days Off-Call Predicting Strain, Burnout, and Work-Life Balance; Job Control and Support as Moderators

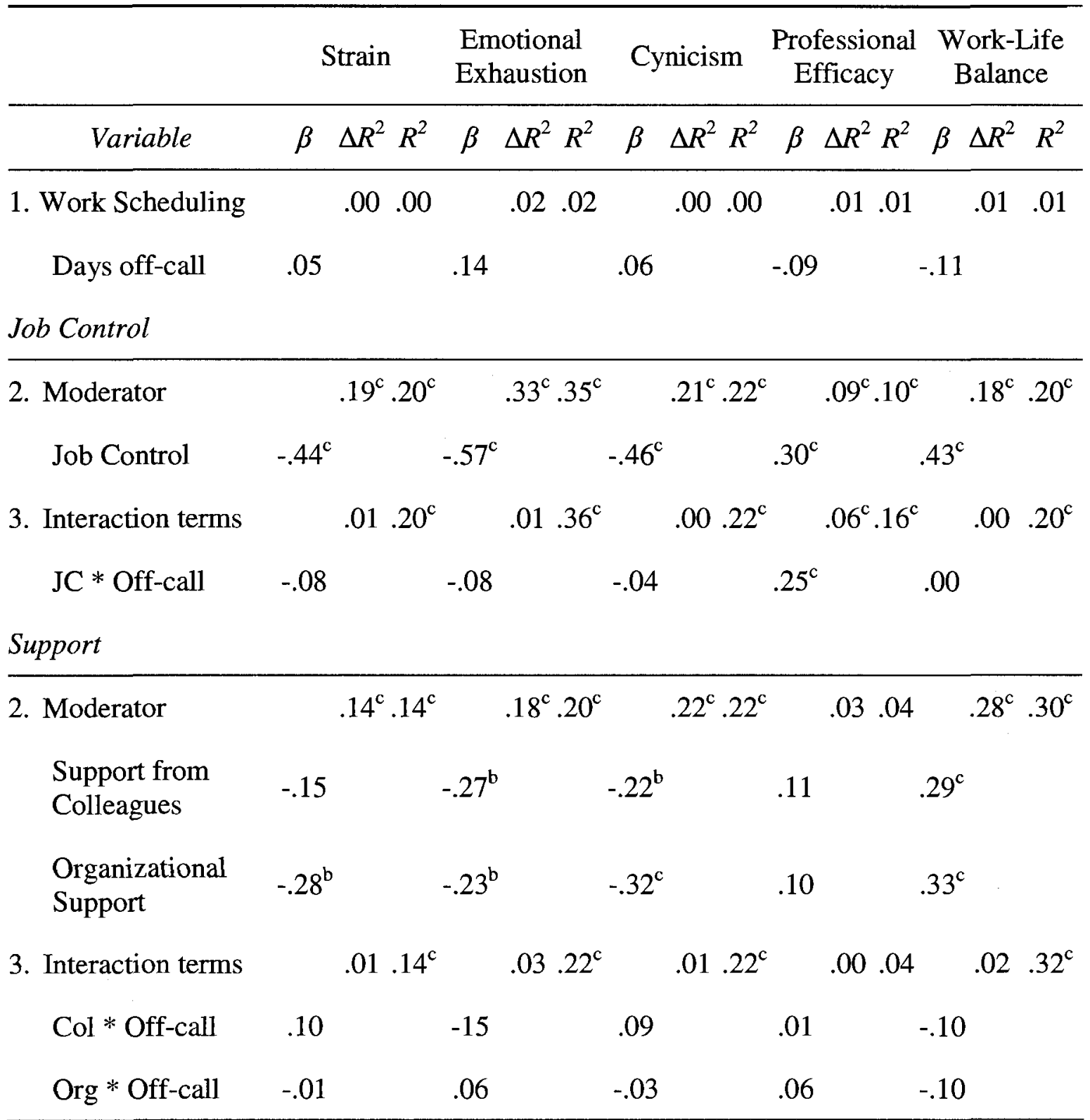

Note. Sample size ranges from $n=152$ to $n=167$ for analyses involving perceived job control and from $n=149$ to $n=153$ for analyses involving support; Results for step 1 from the analyses with perceived job control.

${ }^{\mathrm{a}} p \leq .05 .{ }^{\mathrm{b}} p \leq .01 .^{\mathrm{c}} p \leq .001$. 
support variables (Hypothesis 6c) was not supported: none of the interaction steps or interaction terms was significant.

\section{Location of practice}

The mediation hypotheses for midwives' location of practice (Hypothesis 7a and Hypothesis $7 b$ ) were tested by first reviewing the zero-order correlations (Baron \& Kenny, 1986). However, there was no significant relationship between location of practice and any of the outcome variables ( $r$ ranged from .02 to $.09, n s$; see Table 1 ), which indicates that mediation cannot occur. Moreover, there is no apparent relationship between midwives' location of practice and the quality of their relationships with health care professionals. However, there is a significant relationship between midwives' location of practice and access to resources $(r=-.23, p<.001)$, such that midwives in rural areas tend to report less access to resources. A post-hoc review of the correlations between individual items of the resources scale and midwives' location of practice reveals significant correlations for three specific items. Midwives who operate in rural practice tend to report less access to the latest tests as required by practice standards ( $r=$ $-.28, p<.01)$, less access to counselling services $(r=-.17, p<.05)$, and less access to the means of protecting themselves from legal action $(r=-.15, p<.05)$.

\section{Discussion}

The goal of this study was to identify and quantify the key aspects related to Canadian midwives' perceives stress and health outcomes. Stressors covering the six categories of a popular framework of occupational stress (Kelloway \& Day, 2005; Sauter et al., 1990) were tested. Five of the six stressor categories were significant predictors of strain, burnout, and work-life balance in Canadian midwives. The present 
Stress and Burnout 63

study also tested for, and found, partial evidence of a moderating effect for perceived job control, social support from colleagues and organizational support. The pattern of significant interactions was such that the moderating variables generally had positive main effects. Some of the interactions involving job control highlighted the importance of high job control in reducing the deleterious effects of high levels of stressors or improving outcomes at lower levels of stressors, and some of the interactions involving the support variables suggested that organizational support may be more important when midwives have a high feeling of overwork and social support from colleagues may be more important when midwives have a low feeling of overwork.

Moreover, the relevance of the stressors was confirmed a priori through a series of semi-structured interviews with Canadian midwives and subject matter experts. Relevant measures of stressors were selected and modified when necessary to increase their face validity and content validity with regards to the Canadian midwifery context. Other measures were designed specifically for use within this study. Therefore, the present study was able to describe the relevant stressors for Canadian midwives while being mindful of the complexities of Canadian midwifery.

Job Control

Results showed that job perceived job control was a very important predictor of strain, all subscales of burnout, and work-life balance for Canadian midwives, thus supporting Hypothesis 1 . These results were in agreement with a relatively large body of research showing the importance of job control as a stressor (Johnson \& Hall, 1988; Karasek, 1979). Even when job control was entered after controlling for the other stressors (when testing for moderation), it remained a significant predictor, which 
indicates, at the very least, that the effect of perceived job control was not fully mediated by any one other stressor category. In other words, perceived job control played an important role with regards to midwives' experience of strain, burnout, and work-life balance, above and beyond other workplace stressors tested in this study.

For the most part the moderating hypotheses regarding job control (Hypotheses $2 c, 3 c, 4 b, 5 b, 6 b)$ were not supported, in that the interactions failed to account for a significant increase in variance. However, mixed results with regards to the buffering role of perceived job control are not entirely unexpected (van der Doef \& Maes, 1999). Moreover several interaction steps did account for meaningful amounts of variance (e.g., above 1\%; Evans, 1985) and included betas that were significant. A number of researchers have discussed the overall lack of power for detecting moderation in field research and have suggested that it would be somewhat irresponsible to assume that no interaction exists when no significant results are found (Aguinis \& Stone-Romero, 1997; Evans, 1985; McClelland \& Judd, 1993). Evans (1985) even suggested that interaction terms which account for at least $1 \%$ of variance explained could be considered significant. In our analyses the interactions involving perceived job control all originated from hierarchical blocs where the incremental variance explained was greater than $1 \%$ (e.g., the interaction between the quality of midwives' relationships with their clients and job control on professional efficacy, see Table 2). Dismissing these interaction terms as inconsequential despite their failure to achieve significance at the hierarchical level may be ill-advised.

Therefore, I interpreted all interactions that had significant betas. Perceived job control had significant moderating effects with interpersonal stressors, workload, 
compensation, and scheduling (i.e., the number of days midwives are off-call). A number of the interactions had the expected shape whereby high job control midwives tended to have more positive outcomes than low job control midwives and the midwives reporting lower control and higher levels of a given stressor tended to have the poorest outcomes (e.g., Figure 2 and Figure 9). However the interaction between perceived job control and the number of days midwives were off-call suggests that the relationship of workplace stressors to professional efficacy was not straightforward. Specifically, in that interaction midwives who reported lower perceived control and more days off-call (i.e., low-stressor) tended to have the lowest professional efficacy. A similar relationship is apparent in the interaction between job control and the number of births per year where the low job control midwives had significantly reduced professional efficacy as they attended fewer births per year (see Figure 4).

I surmised that the lower professional efficacy of midwives with more days offcall and lower perceived job control would be characteristic of a midwife who perhaps simply does not work as much weekly or does not attend as many births, thereby being disconnected from a source of professional accomplishment. I explored this possibility by drawing out the zero-order correlations between the number of days midwives were off-call and the other measures of objective workload for those midwives who scored below the median on perceived job control. The post-hoc exploration exposed a negative correlation between the number of home births per year and the number of days off-call for the lower perceived control midwives whereby midwives who have a high number of days off-call and lower perceived job control tend to attend fewer home births. The 
implication of this relationship is that perhaps home births are critical to the actualization of professional efficacy in Canadian midwives.

\section{Interpersonal relationships}

Two clusters of interpersonal relationship items were tested for main effects on strain burnout and work-life balance. The first group consisted of the three subscales assessing the quality of midwives' relationships with health care professionals, other midwives, and clients. As hypothesized, midwives' working relationships jointly predicted strain, all three subscales of burnout, and work-life balance, thus supporting Hypothesis 2a. However, the predictive pattern across the scales and subscales was quite different: evidently midwives' different working relationships predicted different aspects of their experience of occupational stress.

The quality of midwives' relationships with health professionals was significantly associated with strain and professional efficacy such that poor relationships with other health care professionals were associated with increased strain and a reduced sense of professional efficacy. This pattern relationships with outcome variables was similar to the one observed for midwives' access to resources, which were also related only to strain and professional efficacy (see Table 1). Burnout theory suggests that issues of inefficacy tend to arise more from issues dealing with the resources whereas exhaustion and cynicism will result from overload and social conflicts (Maslach et al., 2001; Malsach, 2003). As such, it may be that midwives' ability to maintain good relationships with other health care professionals is more important as a means of securing a resource with which to be more effective, as opposed to being a source of social conflict. 
On the other hand, the quality of midwives' relationships with other midwives was significantly associated with strain, emotional, exhaustion, cynicism, and work-life balance. That is to say, relationships between midwives appeared to be more important with regards to midwives' experiences of conflict and overload in the workplace (Maslach et al., 2001; Maslach, 2003). The quality of midwives' working relationships with other midwives was the only one of the three types of relationships assessed that was significantly associated with emotional exhaustion and work-life balance. Ultimately, midwives do not work in isolation: $96.8 \%$ of midwives who responded to the survey reported practicing with at least one or more other midwives. As such, midwives who share a practice also share incoming case loads, administrative concerns, and a number of other aspects of day to day work life. Naturally poor relationships with midwives would then increase day to day conflict and the associated emotional exhaustion as a basic stress response (Maslach, 2003). Also, the relatively high correlation $(r=.43, p<.001)$ between social support from midwives and work-life balance underlines the importance of other midwives in a given practice at enhancing the quality of non-work life of practice partners in what some describe as a very difficult mode of practice (e.g. Hird, 2002).

Midwives' relationships with their clients were also significantly associated with stain, cynicism, and professional efficacy. In general, midwives' relationships with their clients are overwhelmingly positive ( $M=6.46, S D=.63$ on a 7-point scale). However, poor relationships with clients are potentially devastating. As one survey respondent commented: "I had a very devastating interaction with a client that I felt robbed me of my "innocence" and has impaired my ability to trust clients and form satisfying 
relationships, which has greatly impacted both my motivation at work and my sense of fulfillment and place in my community." The comment illustrates how poor client interactions can lead to cynicism by means of cognitively distancing oneself from the actual work as theorised in Maslach et al. (2001). Overall, the quality of workplace relationships is clearly important to Canadian midwives' experience of strain, burnout, and work-life balance.

The support variables also jointly predicted stain, burnout, and work-life balance, thus supporting Hypothesis $2 \mathrm{~b}$. Still, between social support from colleagues and organizational support the pattern of associations was different. Midwives' experience of social support from midwifery colleagues was significantly associated with all the outcomes, whereas organisational support was significantly associated with strain, cynicism, and work-life balance. We see again with regard to emotional exhaustion the role of potential chronic day to day stressors (e.g., poor experience of support from colleagues) being important as a predictor of emotional exhaustion.

Midwives' relationships with other midwives and the social support they get from midwifery colleagues are conceptually close variables. To confirm that their roles with regards to predicting emotional exhaustion and work-life balance were indeed independent I tested for mediation using a Sobel test using an online test calculator (Preacher \& Leonardelli, 2001). The test was non-significant in both cases confirming independent relationship. Therefore, conceptually the quality of midwives' relationships with other midwives (e.g., elements of collaboration and respect) was probably related to work-life balance through the spillover of negative affect (Small \& Riley, 1990; 
Williams \& Alliger, 1994) and social support from midwife colleagues would relate to work-life balance as a type resource.

The moderating hypotheses were not supported in the case of social supports (from colleagues or organizational; Hypotheses 3d, 4c, 5c, 6c). However, the lack of a significant buffering effect was not entirely unexpected given the mixed results of previous research (van der doef \& Maes, 1999, Viswesvaran et al., 1999). As with job control, a number of interaction terms were significant and interpretable despite the fact that the hierarchical blocs they were included in failed to account for significant incremental variance (Evan, 1985). The support variables both had significant interactions with midwives' perception of being overworked and negative outcomes. The results regarding social support for colleagues were somewhat mixed. The pattern of moderation for social support from midwifery colleagues on the relationship of overwork to strain and emotional exhaustion (Figures 5 and 6) showed a stronger effect for midwives with higher levels of reported support, which was not expected for moderation by a support variable (Viswesvaran et al., 1999). Moreover, at high levels of overwork there was no significant difference between the high and low support midwives on strain and emotional exhaustion where as per the demands-control-support model (Johnson \& Hall, 1988) we would expect the low-support midwives to score higher. The benefit of high social support seemed to be for midwives who had lower perceptions of overwork, who tended to report significantly lower levels of strain and emotional exhaustion. The moderate correlation between overwork and a midwives' average workweek ( $r=.32, p<.001$; see Table 1$)$ suggests that midwives who have a higher perception of being overworked do indeed tend to work more. It may be that 
Stress and Burnout 70

higher overwork midwives simply do not have as much opportunity to take advantage of the social support available to them.

A similar situation occurs with regards to the interaction between organizational support and overwork on emotional exhaustion (Figures 7 and 8). The benefits of organizational support only become apparent at high levels of overwork, when we can expect midwives to also be working more, where the low organizational support midwives reported significantly more emotional exhaustion and cynicism. At lower reported levels of overwork midwives tended to report lower emotional exhaustion and cynicism regardless of organizational support. The implication is that at different levels of overwork, midwives benefit from different types of support. Midwives who have a higher perception of being overworked may not be as likely to offer support to other colleagues in their practice, which would make them less likely to have access to support themselves (Bowling et al., 2004; Bowling, Beehr, \& Swader, 2005). The lack of reciprocal support from colleagues would then accentuate the importance of support made available by the organization. In the case of Canadian midwifery, for example, the Association of Ontario Midwives aims to provide peer support to its members and administers a benefits package, among other things. Also, because the regulation of midwifery is still relatively recent, the presence of such organizations may be especially salient to midwives who may have worked for part of their careers without such representation and may even have had an active role in the creation of the very organizations that support them. 


\section{Workload}

The objective workload variables as well as midwives' perception of being overworked did not predict professional efficacy and therefore only partially supported Hypotheses $3 \mathrm{a}$ and $3 \mathrm{~b}$. Moreover, results showed that the effect of workload was not a simple matter of quantity but that the type of work was also important. Specifically, the number of difficult births attended by a midwife was a significant predictor of most outcomes where the number of births per year was not. Because tending a difficult birth is a strenuous discrete even that occurs sporadically, it seems more likely that the effect of difficult births on work-life balance occurs through the spillover of negative affect (Small \& Riley, 1990; Williams \& Alliger, 1994). As a measure of objective workload, midwives' average workweek in hours was related to strain, emotional exhaustion, cynicism, and work-life balance. The midwives who participated in the survey estimated working an average of 49.24 hours per week $(S D=13.27)$, which is somewhat higher than the national average (31.2 hours per week; Statistics Canada, 2008). In this case the relationship of workload to outcomes seems simple: midwives who work more are more likely to have more stress and a poorer experience of work-life balance.

However, midwives' perceptions of overwork accounted for significant incremental variance in all the outcome variables with the exception of professional efficacy after controlling for the effects of objective workload variables. The importance of the overwork variable as a predictor suggests that the quantity of work (i.e., work week hours) or the quality of work (i.e., the number of difficult births) are not sufficient to describe the effect of workload on the outcome variables. To have a more complete picture we must incorporate midwives appraisal of their workload as manageable and 
fair (see Overwork scale, Appendix B), which harkens back to conceptualizations of stress as a result of a person's appraisal of potentially taxing environmental conditions (Lazarus \& Folkman, 1984, p. 19).

Role conflict

The hypothesis that role conflict would significantly predict strain, burnout, and work-life balance was supported (Hypothesis 4a). I had proposed that role conflicts would probably be best defined as a mismatch in control based on the mismatch theory of burnout (Maslach et al., 2001). According to Maslach et al. (2001), a mismatch in control should be most related to professional efficacy, which does not appear to be the case with this measure of role conflict. Maslach and Leiter (1997) described the mismatch in control as leading individuals to become disconnected from the outcomes of their work. It may simply be the case that the detachment from the outcome they propose, which presumably ties control mismatches to a poor experience of professional efficacy, is unlikely to occur in the case of midwifery (where the outcome, a new birth, is both vivid and exceptional). Midwives may then experience mismatches in control as chronic day to day stressors which may explain the stronger relationships with emotional exhaustion and cynicism.

\section{Compensation}

The rewards imbalance (Siegrist, 1996) aspect of career concerns was assessed with an item asking midwives if they felt they were adequately remunerated. The results partially supported the hypothesis that career concerns would predict strain, burnout, and work-life balance: midwives' adequacy of compensation did not predict cynicism (Hypothesis 5a). With regards to the effect on work-life balance, midwives' reported 
adequacy of compensation may have an effect as a chronic daily stressor which potentially results in spillover as with other stressors (Small \& Riley, 1990; Williams \& Alliger, 1994). However, it is also possible that the lifestyle adjustments that midwives need to make also simply put extra financial stress on midwives and their families. For example one midwife commented with regards to working on-call that "It is too hard to cope with the financial stresses of constant child care needs etc." It may be that the reward imbalance experienced by midwives who feel they are not adequately compensated can at least partly be addressed in terms of a support (i.e. family support and practice support) offered by the organization (tying in to organizational support) rather than outright financial incentives.

Time off-call

The hypothesis that the number of days midwives are off-call would predict strain, burnout, and work-life balance was not supported (Hypothesis 6a). This nonsignificant result was surprising given the amount of anecdotal evidence (e.g., Hird, 2002) and the number of comments about the stressful impact of working on-call for extended periods, the difficulty of finding time off-call, and the value of time off-call to having a balance lifestyle (Hird, 2002, p. 113). For example, one midwife responding to the survey commented: "I get concerned that we think living on-call 24/7, sleeping erratic hours, eating on the run, managing our caseload plus the business of the practice etc. is normal. It's not, and almost every midwife I've ever known in this province deals with some kind of anxiety, depression, or work-related trauma on a regular basis." Another survey respondent added: "The unpredictability of the workload, and the inability to plan life, and be sure of a night off takes an extreme emotional and physical 
toll." Both comments truly highlight the stress of being on-call and the reciprocal importance of having time off-call. Moreover, research does suggest that working oncall indeed has real psychological and physiological consequences (Nicol \& Botteril, 2004).

The lack of relationship between outcome variables and the number of days offcall midwives have per month may be an issue of range restriction. In our sample, midwives had an average of 7.36 days per month where they were not on-call $(S D=$ 5.25). In other words, the average sampled Canadian midwife spends three quarters of her life on-call, which seems to be inordinately high. It is possible that the overall variation in the amount of time Canadian midwives are not on-call occurs at far too low a range for there to be any noticeable relationship with outcome variables.

However, the decision to assess the number of days midwives are off-call rather than the number of days that midwives are on-call may have inadvertently introduced measurement error. The decision was made with the expectation that a day where a midwife is not on-call, be it a regular work day or a day off, would be considerably less stressful than a given work day or day off where a midwife can expect to be called away at any time. Evidently midwives' scheduling stressors are more complex, and a broader measure would be indicated in future research (e.g., time on/off call while at work, while not at work, time on/off-call as a second midwife, length of recuperation period, consecutive days on-call, etc.). Moreover, it was not clear in the present measure if respondents accounted days off-call to include both days where they were working but otherwise off-call and days not working and also off-call. Finally, it is also possible that 
wording of asking about time off-call was counterintuitive and was misread by some survey respondents thereby causing some measurement error.

\section{Location of practice}

There was no difference based on midwives' location of practice (urban or rural) and therefore there was no support for the hypothesis that differences would be mediated by the quality of midwives' relationships with health care professionals (Hypothesis 7a) or by midwives' access to resources (Hypothesis 7b). Moreover, there was no difference in the quality of midwives' relationships with health care professionals based on location of practice and the zero-order correlations (Table 1) show that midwives' relationships with health care professionals are only weakly associated with the outcome variables. Still, the results did support the assertion (Ramsey, 2002; Kornelsen, 2003b) that there are disparities between urban and rural midwives with regards to their access to resources, specifically with regards to rural midwives' access to the latest tests.

\section{Implications}

The important role of the most hypothesized workplace stressors, notwithstanding the surprising results regarding the number of days midwives are off call, provides support for the validity of a common organizing framework of occupational stressors (Sauter et al., 1990) with a profession that is highly complex such as midwifery. Moreover, the results of this study have important implications for Canadian midwives, providing them with valuable information about the importance of workplace stressors to the experience of negative outcomes such as strain and burnout as well as more positive outcomes such was work-life balance. 
The results also have practical implications looking forward for Canadian midwifery. The importance of job control in predicting strain, burnout, and work-life balance for Canadian midwives ensures that midwives will have a tested vector for improving outcomes. In fact, perceived job control is one of the few important workplace stressors where there is both theoretical and practical evidence of explicitly tying positive changes in observed outcomes to improvements in job control. For example, quasi-experimental research using participative action research shows that the effects workplace control-enhancing interventions (i.e., improved mental health, improved health, and lower absenteeism) were mediated by perceived job control (Bond \& Bunce, 2001; Bond, Flaxman, \& Bunce; 2008). Although the research in question was performed with administrative and office work populations, there is every reason to believe that participatory action research can succeed with the caring professions (e.g., Munn-Giddings, Hart, \& Ramon, 2005).

Improving social support in the workplace is also possible if slightly less straightforward. Past research interventions have succeeded in improving overall relationships in the workplace but had little impact on the social support from colleagues (Heaney, 1991) and other research has had success in improving other workplace dimensions at the apparent cost of social support (Lavoie-Tremblay et al., 2005). Recent research evidence suggests that social support in the workplace is a matter of reciprocity: those more likely to offer social support are also more likely to receive it (Bowling et al., 2004; Bowling, Beehr, \& Swader, 2005). Although improving reciprocity may be the path to improving social support from coworkers, it is not clear how one generates increased reciprocity in the workplaces. Bowling et al. (2004) suggest a common link 
Stress and Burnout 77

between reciprocity and organizational citizenship behaviours (OCBs), therefore, it may be sensible to consider improving elements that are common antecedents to OCBs such as organizational fairness (also an antecedent of perceived organizational support; Organ \& Ryan, 1995; Rhoades \& Eisenberger, 2002).

Improving midwives' perceptions of organizational support should be somewhat more straightforward. A recent meta-analysis of organizational support research suggests three main antecedents of perceived organizational support: 1) fairness; 2) supervisor support; 3) organizational rewards and job conditions (Rhoades \& Eisenberger, 2002). The third category, rewards and job conditions, is most relevant to our discussion because it encompasses recognition and pay, autonomy (i.e., perceived job control), and role stressors (including role conflict), all of which have been identified as relevant stressors in the midwifery literature and significant stressors in this study.

Interventions aimed at reducing the impact of workload variables, perceived or objective are relatively straightforward. Midwives in the interview portion of the study spoke of the value of adding administrative support to a group practice as a means of taking the pressure off of administrative demand. Also, the content of the overwork scale (Appendix B) which was drawn directly from comments made by midwives in the interview portion of the study, suggests a number of possible avenues though which to positively impact midwives perceptions of overwork (e.g., unpaid work and distribution of work). Furthermore, the relationship between workload or overwork and negative outcomes is consistent enough (Kelloway \& Day, 2005) that a reduction in workload should be reasonably expected to have a positive effect in reducing negative outcomes. Moreover, Sauter et al. (1990) suggest that adequate provisions need to be made to allow 
for recovery from especially demanding tasks, a suggestion that may need to be given due consideration given the role of difficult births specifically in predicting strain and burnout.

Limitations and future research

Although the results of this study show evidence of relatively strong relationships between the workplace stressors with the outcomes, all the data came from a self-report measure, which creates the possibility that mono-method bias is inflating the results. However, the presence of a number of near zero and very low non-significant correlations (see Table 1) suggests that mono-method bias may not have been an important factor. Moreover, the inclusion of scales as well as more objective measures (e.g., average hours worked per week) also helps minimize the impact of mono-method bias on the results.

An additional limitation was that my measures of stress did not account for past histories with possible manifestations of occupational stress-related problems. A number of midwives commented that although they were feeling well at the time of the survey they had experienced depression, burnout, or other illnesses in the past that they attributed to their working conditions which is an aspect of their experience that could not be captured in the survey instrument. Having this additional information may have been helpful in supporting the relevance of certain stressors and added another relevant dimension to our description of midwives' experiences of stress and well-being. However, data pertaining to diagnosed illness may best be addressed in a longitudinal research effort where timeframes for diagnoses are part of the analyses. 
Finally, midwifery is a complex profession where midwives may sometimes work in offices, clinics, birthing centres, hospitals, and patients' homes. Furthermore, midwifery is implemented in such a way that concerns over promotions, repetitive tasks, organizational commitment and a number of other organizational variables are not experienced in the same way as in other professions (e.g. accounting or sales). As such, a number of the measures used in this study had to be altered in order to make them more valid for use with midwifery. The alterations certainly enhanced the face validity and content validity of the measures in the study, but may have also resulted in subtle changes in how constructs relate to actual theory. However, the zero-order relationships between the scales used in this study do fall in expected patterns, which indicate that the alterations made to the scales retained the integrity of the constructs.

Some of the results are divergent from what would be expected according to the mismatch theory of burnout (Maslach et al., 2001). A number of the stressors that theory suggests will be more related to professional efficacy were instead more related to emotional exhaustion (e.g. perceived job control and role conflicts). Maslach and Leiter (1997) describe inefficacy as including feelings that one's accomplishments are trivial and a loss of confidence in one's ability to make a difference. Connecting those feelings with the process of midwifery, from pre-natal care to births through post-natal care seems unlikely because the outcome, a birth, is very poignant. In that sense it may be easier to understand why the midwives appear to have such a high experience of professional efficacy (see Table 1). However, it is not clear to what extent Canadian midwives' experiences of professional efficacy are a result of midwifery as a profession or of the way midwifery is implemented and practiced in Canada. Moreover, research 
suggests that professional efficacy has different patterns of relationships to organizational variable depending on the nature of the caring profession (Allen \& Mellor, 2002). Therefore, future research on burnout with Canadian midwives may be invaluable to broaden our understanding of the dynamics of the subscales of burnout.

Although the present study assessed the quality of midwives relationships with other health care professionals and other midwives, the specific issue of workplace incivility and bullying was not directly addressed. Although the literature emerging from the UK does suggest that bulling can be an issue in health care settings (Paice, Aitken, Houghton, \& Firth-Cozens, 2004; Quine, 2002) and within midwifery (Gillen, 2002), it is not clear if these issues are endemic to the National Health Service (UK) or if they would be equally relevant for Canadian midwives. Midwives and subject matter experts who participated in the semi-structured interviews for the present study did speak of tense relations with doctors and other midwives, but their comments were not reflective of outright bullying behaviour. Future research should examine identifying incivility and bullying in Canadian midwifery and quantifying its effects on midwives.

Also, the pattern of interactions between the support variables and overwork on strain, emotional exhaustion, and cynicism, suggests that midwives either call on different types of support under different work situations, or that different types of support are not as effective under different situations. However, the relationship between the average length of midwives' workweek and their perception of overwork suggests that at high overwork midwives tend to be working more. Such an increase in workload could lead to reduced opportunities for reciprocity in the workplace which may then reduce opportunities for the exchange of support (Bowling et al., 2004; Bowling, Beehr, 
\& Swader, 2005) perhaps prompting midwives to rely on the support from their organization. Future research could assess this relationship through experimental design in order to address concerns over causality between strain and social support (Viswesvaran et al., 1999).

The inconclusive results with regards to midwives' work scheduling are somewhat surprising given the amount of anecdotal and research evidence (e.g., Nicol \& Botteril, 2004) that suggests that working on-call tends to have real consequences and that time off-call can be especially hard to come by and especially important to a balanced lifestyle (e.g. Hird, 2002). The midwives who participated in this study reported relatively few days off-call $7.36(S D=5.25)$. Although there is a good research base on non-standard work arrangements, there is very little research pertaining specifically to on-call work (Nicol \& Botteril, 2004). The results of the present study indicate that the relationship of on-call work to stress is more complex than expected. Future research clearly needs to explore the mechanisms that tie on-call work to stress especially with regards to this null result.

\section{Conclusion}

Overall, this study provides valuable information about the importance of occupational stressors relevant to midwives' experiences of strain, burnout, and worklife balance. Results show that job control, social support, organizational support, workload, compensation, workplace relationships, and role conflict are all important to the experiences of occupational stress of Canadian midwives. Moreover, perceived job control predicts incremental variance in outcomes beyond other stressors and partial evidence of moderation by job control suggests that improving perceived job control 
will be beneficial in improving outcomes related to other stressors such as relationships with health care professionals. The results regarding burnout and workplace stressors highlight the uniqueness of midwifery as a profession and provide notable directions for future research. Overall the results of this study serve researchers and Canadian midwives by providing them with valuable information on which to help improve midwives' health and serve to direct future inquiry about non-standard work schedules (i.e. on-call work), burnout, and support in the workplace. 


\section{References}

Adebayo, D. O. (2006). Workload, social support, and work-school conflict among Nigerian nontraditional students. Journal of Career Development, 33, 125-141.

Aguinis, H., \& Stone-Romero, E. F. (1997). Methodological artefacts in moderated multiple regression and their effects on statistical power. Journal of Applied Psychology, 82, 192-206.

Aiken, L. S., \& West, S. G. (1991) Multiple Regression: Testing and Interpreting Interactions. Newbury Park, CA: Sage Publications.

Allen, J., \& Mellor, D. (2002). Work context, personal control, and burnout among nurses. Western Journal of Nursing Research, 24, 905-917.

Amelink-Verburg, M. P., Verloove-Vanhorick, S. P., Hakkenberg, R. M. A., Veldhuijzen. I. M. E., Bennebroek Gravenhorst, J., \& Buitendijk, S. E. (2008). Evaluation of 280000 cases in dutch midwifery practices: A descriptive study. BJOG An International Journal of Obstetrics and Gynecology, 115, 570-578.

Anderson, R. E., \& Davis, A. A. (1999). The cost effectiveness of home birth. Journal of Nurse-Midwifery, 44, 30-35.

Appleberg, K., Romanov, K., Heikkilä, K., Honkasalo, M., \& Koskenvuo, M. (1996). Interpersonal conflict as a predictor of work disability: A follow-up study of 15,348 Finnish employees. Journal of Psychosomatic Research, 40, 157-167. Appleton, K., House, A., \& Dowell, A. (1998). A survey of job satisfaction, sources of stress, and psychological symptoms among general practitioners in Leeds. British Journal of General Practice, 48, 1059-1063. 
Bakker, R. H. C., Groenewegen, P. P., Jabaaij, L., Meijer, W., Sixma, H., \& de Veer, A. 'Burnout' among Dutch midwives (1996). Midwifery, 12, 174-181.

Bakker, A. B., Demerouti, E., \& Schaufeli, W. B. (2002). Validation of the Maslach Burnout Inventory - General Survey: An internet study. Anxiety, Stress, and Coping, 15, 245-260.

Bakker, A. B., Demerouti, E., \& Euwema, M. C. (2005). Job resources buffer the impact of job demands on burnout. Journal of Occupational Health Psychology, 10, 170180.

Barnes-Farrell, J. L., Davies-Schrils, K., McGonagle, A., Walsh, B., Di Milia, L., Fisher, F. M., et al. (2008). What aspects of shiftwork influence off-shift well-being of healthcare workers. Applied Ergonomics, 39, 589-596.

Baron, R. M., \& Kenny, D. A. (1986). The moderator-mediator variable distinction in social psychological research: Conceptual, strategic, and statistical considerations. Journal of Personality and Social Psychology, 51, 1173-1182.

Bartone, P. T., Ursano, R. J., Wright, K. M., \& Ingraham, L. H. (1989). The impact of a military air disaster on the health of assistance workers: A prospective study. Journal of Nervous and Mental Disease, 177, 317-327.

Blais, R., \& Joubert, P. (2000). Evaluation of the midwifery pilot projects in Quebec: An overview. Canadian Journal of Public Health, 91, 1-4.

Bond, F. W., \& Bunce, D. (2001). Job control mediates change in a work reorganization intervention for stress reduction. Journal of Occupational Health Psychology, 6, 290-302. 
Bond, F. W., Flaxman, P. E., \& Bunce, D. (2008). The influence of psychological flexibility on work redesign: Mediated moderation of a work reorganization intervention. Journal of Applied Psychology, 93, 645-654.

Bourgeault, I. L., Benoit, C., \& Davis-Floyd, R. (2004). Reconceiving midwifery in Canada. In Bourgeault, I. L., Benoit, C., \& Davis-Floyd, R. (Eds.). Reconceiving Midwifery (pp. 3-13). Montreal, Canada: McGill-Queen's University Press.

Bowling, N. A., Beehr, T. A., Johnson, A. L., Semmer, N. K., Hendricks, E. A., \& Webster, H. A. (2004). Explaining potential antecedents of workplace social support: Reciprocity or attractiveness? Journal of Occupational Health Psychology, 9, 339-350.

Bowling, N. A., Beehr, T. A., \& Swader, W. M. (2005). Giving and receiving social support at work: The roles of personality and reciprocity. Journal of Vocational Behavior, 67, 476-489.

Bussey, C. G., Bell, J. F., \& Lydon-rochelle, M. T. (2007). Certified nurse midwifeattended births: Trends in Washington state, 1995-2004. Journal of Midwifery and Women's Health, 52, 444-450.

Campbell, O. M. R., \& Graham, W. J. (2006). Strategies for reducing maternal mortality: Getting on with what works. Lancet, 368, 1284-1299.

Canadian Institute for Health Information. (2004). Giving birth in Canada: Providers of maternity and infant care. Ottawa, ON: Author.

Canadian Institute for Health Information. (2006). Giving birth in Canada: The costs. Ottawa, ON: Author. 
Canadian Midwifery Regulators Consortium. (2007). Legal status of midwifery in Canada-August 2007. Retrieved September 17, 2007, from http://cmrcccosf.ca/node/19

Cannon, M., Morrow, H., Knight, E., \& Day, A. (2008). Development \& validation: Work \& life integration scale. [Abstract] Canadian Psychology Annual Convention Issue, 49, 112.

Carlisle, C., Baker, G. A., Riley, M., \& Dewey, M. (1994). Stress in midwifery: A comparison of midwives and nurses using the Work Environment Scale. International Journal of Nursing Studies, 31, 13-22.

Collin, J., Blais, R., White, D., Demers, A., \& Desbiens, F. (2000). Integration of midwives into the Quebec health care system. Canadian Journal of Public Health, $91,16-20$.

Coyle, D., Edwards, D., Hannigan, B., Fothergill, A., \& Burnard, P. (2005). A systematic review of stress among mental health social workers. International Social Work, 48, 201-211.

Currie, S., Azfar, P., \& Fowler, R. C. (2007). A bold new beginning for midwifery in Afganistan. Midwifery, 23, 226-234.

Day, A. L., \& Livingstone, H. A. (2001). Chronic and acute stressors among military personnel: Do coping styles buffer their negative impact on health? Journal of Occupational Health Psychology, 6, 348-360.

Day, A. L., Therrien, D. L., \& Carroll, S. A. (2005). Predicting psychological health: Assessing the incremental validity of emotional intelligence beyond personality, 
Type A behaviour, and daily hassles. European Journal of Personality, 19, 519536.

de Croon, E. M., Sluiter, J., Blonk, R. W. B., Broersen, J. P. J., \& Frings-Dresen, M. H. W. (2004). Stressful work, psychological job strain, and turnover: A 2-year prospective cohort study of truck drivers. Journal of Applied Psychology, 89, 442454.

Deery, R. (2005). An action-research study exploring midwives' support needs and the affect of group clinical supervision. Midwifery, 21, 161-176.

Demir, A., Ulusoy, M., \& Ulusoy, M. F. (2003). Investigations of factors influencing burnout levels in the professional and private lives of nurses. International Journal of Nursing Studies, 40, 807-827.

DeVries, R. (2001). Midwifery in the Netherlands: Vestige or vanguard? Medical Anthropology, 20, 277-311.

Dex, S., \& Bond, S. (2005). Measuring work-life balance and its covariates. Work Employment Society, 19, 627-637.

Donnison, J. (n.d.) Office of midwife: Some historical background. UK Centre for the Historu of Nursing and Midwifery. Retrieved July 30, 2008, from http://www.nursing.manchester.ac.uk/ukchnm/midwives/officeofmidwife.pdf

Dwyer, D. J., \& Ganster, D. C. (1991). The effects of job demands and control on employee attendance and satisfaction. Journal or Organizational Behavior, 12, 595-608. 
Edwards, D., Burnard, P., Coyle, D., Fothergill, A., \& Hannigan, B. (2000). Stress and burnout in community mental health nursing: A review of the literature. Journal of Psychiatric and Mental Health Nursing, 7, 7-14.

Eisenberger, R., Huntington, R., Hutchison, S., \& Sowa, D. (1986). Perceived organizational support. Journal of Applied Psychology, 71, 500-507.

Elsass, P., \& Veiga, J. F. (1997). Job control and job strain: A test of three models. Journal of Occupational Health Psychology, 2, 195-211.

Evans, M. G. (1985). A monte-carlo study of the effects of correlated method variance in moderated multiple regression analysis. Organizational Behavior and Human Decision Processes, 36, 305-323.

Frenet, C., Guay, F., \& Senécal, C. (2004). Adjusting to job demands: The role of work self-determination and job control in predicting burnout. Journal of Vocational Behavior, 65, 39-56.

Frese, M. (1999). Social support as a moderator between work stressors and psychological dysfunctioning: A longitudinal study with objective measures. Journal of Occupational Health Psychology, 4, 179-192.

Frone, M. R. (2000). Interpersonal conflict at work and psychological outcomes: Testing a model among young workers. Journal of Occupational Health Psychology, 5 , 246-255.

Ganster, D. C., Fox, M. L., \& Dwyer, D. J. (2001). Explaining employees' health care costs: A prospective examination of stressful job demands, personal control, and physiological reactivity. Journal of Applied Psychology, 86, 954-964. 
Gillen, P. (2002). Bullies at work: Midwives' memories. RCM Midwives Journal, 5, 290-293. Retrieved August 30, 2008, from http://www.rcm.org.uk/magazines/from-the-rcm/bullies-at-work-midwivesmemories/?locale=en

Guest, D. E. (2002). Perspectives on the study of work-life balance. Social Science Information, 41, 255-279.

Greenhaus, J. H., \& Beutell, N. J. (1985). Sources of conflict between work and family roles. Academy of Management Review, 10, 76-88.

Greenhaus, J. H., Collins, K. M., \& Shaw, J. (2003). The relation between work-family balance and quality of life. Journal of Vocational Behavior, 63, 510-531.

Harworth-Brockman, M. (2002). Midwifery in Manitoba: Access, supply, and demand. Building our contribution to maternity care: Proceedings from the working symposium (pp. 31-36). Vancouver, BC: British Columbia Centre of Excellence for Women's Helath.

Haymes, M. (2007). It is time for a national birthing strategy. Canadian Women's Health Network Magazine. Retrieved September 12, 2007, from http://www.cwhn.ca/network-reseau/9-34/9-34pg11.html

Heaney, C. A. (1991). Enhancing social support at the workplace: Assessing the effects of the caregiver support program. Health Education \& Behavior, 18, 477-494.

Herschderfer, K., \& Kateman, H. (2005). Summary of: Current practice in Europe and Australia. Multidisciplinary Collaborative Primary Maternity Care Project. Retrieved September 28, 2007, from http://www.mcp2.ca/english/documents/Summary-IntlReport.pdf 
Stress and Burnout 90

Hird, C. (2002). Burning on: Lifestyle challenges of a practicing midwife. Building our contribution to maternity care: Proceedings from the working symposium (pp. 111-115). Vancouver, BC: British Columbia Centre of Excellence for Women's Health.

House, R. J., Schuler, R. S., \& Levanoni, E. (1983). Role conflict and ambiguity scales: Reality or artifacts? Journal of Applied Psychology, 68, 334-337.

Human Resources and Social Development Canada. (2008). Health - Infant mortality. Retrieved May 19th, 2008, from http://www4.hrsdc.gc.ca/indicator.jsp?lang=en\&indicatorid=2

Jamal, M. (2004). Burnout, stress and health of employees on non-standard work schedules: a study of Canadian workers. Stress and Health, 20, 113-119.

Johansson, G. (2002). Work-life balance: The case of Sweden in the 1990s. Social Science Information, 41, 303-317.

Johnson, K. C., \& Davis, B. (2005). Outcomes of planned home births with certified professional midwives: Large prospective study in North America. BMJ, 330, 1416-1423.

Johnson, J. V., \& Hall, E. M. (1988). Job strain, work place social support, and cardiovascular disease: A cross-sectional study of a random sample of the Swedish working population. American Journal of Public Health, 78 1335-1342.

Karasek, R. A. (1979). Job demands, job decision latitude and mental strain: Implications for job redesign. Administrative Science Quarterly, 24, 285-311.

Kelloway, E. K., \& Day, A. L. (2005). Building health workplaces: What we know so far. Canadian Journal of Behavioural Science, 37, 223-235. 
Kirkham, M., \& Stapleton, H. (2000). Midwives' support needs as childbirth changes. Journal of Advanced Nursing, 32, 465-472.

Klein, M. C. (2000, January/February). The Quebec midwifery experiment: Lessons for Canada. Canadian Journal of Public Health, 91, 5-6.

Knox, L. (2002). Practicing in a shared care model. Building our contribution to maternity care: Proceedings from the working symposium (pp. 106-110). Vancouver, BC: British Columbia Centre of Excellence for Women's Health.

Kodz, J., Davis, S,. Lain, D., Strebler, M., Rick, J., Bates, P., et al., (2003). Working long hours: A review of the evidence. The Institute for Employment Studies. London, UK: Department of Trade and Industry.

Kornelsen, J. (2002). Midwifery in Canada: Directions for research. Vancouver, BC, May 9-11 proceedings. Vancouver, BC: Women's Health Reports.

Kornelsen, J. (2003a). Midwifery: Building out contributions to maternity care. Vancouver, BC, May 1-2, 2002 proceedings. Vancouver, BC: Women's Health Reports.

Kornelsen, J. (2003b). Solving the maternity care crisis. British Columbia Centre of Excellence for Women's Health Policy Series. Retrieved November 15, 2006, from http://www.bccewh.bc.ca/policy_briefs/Midwifery_Brief/midwifbrief\%20v4.pdf Kornelsen, J., \& Carty, E. (2004). Challenges to midwifery integration: Interprofessional relationships in British Columbia. In Bourgeault, I. L., Benoit, C., \& Davis-Floyd, R. (Eds.). Reconceiving Midwifery (pp. 111-130). Montreal, Canada: McGillQueen's University Press. 
Lavoie-Tremblay, M., Bourbonnais, R., Viens, C., Vezina, M., Durand, P.J., \& Rochette, L. (2005). Improving the psychosocial work environment. Journal of Advanced Nursing, 49, 655-664.

Lazarus, R. S., \& Folkman, S. (1984). Stress, appraisal, \& coping. New York, NY: Springer Publishing Co.

Leibau, A. (2002). Is it possible for a midwife to practice part-time? Building our contribution to maternity care: Proceedings from the working symposium (pp. 3738). Vancouver, BC: British Columbia Centre of Excellence for Women's Health.

Liu, C., Spector, P. E., \& Jex, S. (2005). The relation of job control with job strains: A comparison of multiple data sources. Journal of Occupational and Organizational Psychology, 78, 325-336.

Maslach, C. (2003). Job burnout: New directions in research and intervention. Current Directions in Psychological Science, 12, 189-192.

Maslach, C., \& Jackson, S. E. (1981). The measurement of experienced burnout. Journal of Occupational Behaviour, 2, 99-113.

Maslach, C., Jackson, S. E., \& Leiter, M. P. (1996). Maslach Burnout Inventory. (3 ${ }^{\text {rd }}$ ed.). Palo Alto, CA: Consulting Psychologists Press.

Maslach, C., \& Leiter, M. P. (1997). The truth about burnout: How organizations cause personal stress and what to do about it. San Francisco, CA: Jossey-Bass.

Maslach, C., Schaufeli, W. B., \& Leiter, M. P. (2001). Job burnout. Annual Review of Psychology, 52, 397-422.

McClelland, G. H., \& Judd, C. M. (1993). Statistical difficulties of detecting interactions and moderator effects. Psychological Bulletin, 114, 376-390. 
Munn-Giddings, C., Hard, C., \& Ramon, S. (2005). A participatory approach to the promotion of well-being in the workplace: Lessons from empirical research. International Review of Psychiatry, 17, 409-417.

Nicol, A., \& Botterill, J. S. (2004), On-call work and health: A review. Environmental Health: A Global Access Science Source, 3(15), 1-7.

Ontario Medical Association. (2006, October). OMA response to the Ontario Maternity Care Expert Panel Report. Ontario Medical Review, 73(9). Retrieved November 15, 2006, from http://www.oma.org/pcomm/omr/oct/06maintoc.htm

Organ, D. W., \& Ryan, K. (1995). A meta-analytic review of attitudinal and dispositional predictors of organizational citizenship behaviour. Personnel Psychology, 48, 775-802.

Paice, E., Aitken, M., Houghton, A., \& Firth-Cozens, J. (2004). Bullying among doctors in training: Cross sectional questionnaire survey. British Medical Journal, 329, 658-659. Retrieved August 30, 2008, from http://www.bmj.com/cgi/content/short/329/7467/658

Parker, P. A., \& Kulik, J. A. (1995). Burnout, self- and supervisor-rated job performance, and absenteeism among nurses. Journal of Behavioral Medicine, 18, 581-599.

Peeters, M. C. W., Montgomery, A. J., Bakker, A. B., \& Schaufeli, W. B. (2005). Balancing work and home: How job and home demands are related top burnout. International Journal of Stress Management, 12, 43-61.

Perinatal Partnership Program of Eastern and Southeastern Ontario. (2005). Perinatal services in Ontario: How are we doing? Retrieved July 08, 2008 from 
Stress and Burnout 94

http://www.pppeso.on.ca/english/Ontario\%20Perinatal\%20Report\%20PDF\%2020 05.pdf

Preacher, K. J., \& Leonardelli, G. J. (2001). Calculation of the Sobel test: An interactive calculation tool for mediation tests. Retrieved July 12, 2008, from http://www.people.ku.edu/ preacher/sobel/sobel.htm

Quine, L. (2002). Workplace bullying in junior doctors: Questionnaire survey. British Medical Journal, 324, 878-879. Retrieved August 30, 2008, from http://www.bmj.com/cgi/content/short/324/7342/878

Ramsey, M. (2002). Rural practice. Building our contribution to maternity care: Proceedings from the working symposium (pp. 99-105). Vancouver, BC: British Columbia Centre of Excellence for Women's Helath.

Rhoades, L., \& Eisenberger, R. (2002). Perceived organizational support: A review of the literature. Journal of Applied Psychology, 87, 698-714.

Rizzo, J. R., House, R. J., \& Lirtzman, S. I. (1970). Role conflict and ambiguity in complex organizations. Administrative Science Quarterly, 15, 150-163.

Sauter, S. L., Murphy, L. R., \& Hurrell, J. J. (1990). Prevention of work-related psychological disorders: A national strategy proposed by the National Institite for Occupational Safety and Health. American Psychologist, 45, 1146-1158.

Scheuermann, K. (1995). Midwifery in Germany: Its past and present. Journal of Nurse Midwifery, 40, 438-447.

Siegrist, J. (1996). Adverse health effects of high-effort/low-reward conditions. Journal of Occupational Health Psychology, 1, 27-41. 
Small, S. A., \& Riley, D. (1990). Towards a multidimensional assessment of work spillover into family life. Journal of Marriage and the Family, 52, 51-61.

Society of Obstetricians and Gynaecologists of Canada. (2006). SOGC pre-budget consultation. Retrieved September 12, 2007, from http://www.sogc.org/projects/pdf/pre-budget-consult-2006_e.pdf

Society of Obstetricians and Gynaecologists of Canada. (2007). A national birthing strategy. Retrieved September 12, 2007, from http://www.sogc.org/projects/pdf/BirthingStrategyVersionnbJune2107.pdf

Soderstrom, M., Dolbier, C, Leiferman, J., \& Steinhardt, M. (2000). The relationship of hardiness, coping strategies, and perceived stress to symptoms of illness. Journal of Behavioral Medicine, 23, 311-328.

Soper, D. S. (2008). The Free Statistics Calculators Website", Online Software, Retrieved August18, 2008, from http://www.danielsoper.com/statcalc/ Spector, P. E. (1989). Perceived control by employees: A meta-analysis of studies concerning autonomy and participation at work. Human Relations, 39, 1005-1016.

Spector, P. E. \& Jex, S. M. (1998). Development of four self-report measures of job stressors and strain: Interpersonal conflict at work scale, organizational constraints scale, quantitative workload inventory, and physical symptoms inventory. Journal of occupational health psychology, 3, 356-367.

Statistics Canada (2008). Weekly hours of hourly paid employees, average, by industry. (No. 72-002-XIB). Ottawa, ON: Author. Retrieved July 22, from http://www40.statcan.ca/101/cst01//abr81a.htm 
Tabachnick, B. G., \& Fidell, L. S. (Eds.). (2007). Using multivariate statistics. Boston, US: Pearson.

Tausig, M., \& Fenwick, R. (2001). Unbinding time: Alternate work schedules and worklife balance. Journal of Family and Economic Issues, 22, 101-119.

Tucker, P., Dahlgren, A., Akerstedt, T., \& Waterhouse, J. (2008). The impact of freetime activities on sleep, recovery, and well-being. Applied Ergonomics, 39, 653662.

Vadeboncoeur, H. (2004). Delaying legislation: The Quebec experiment. In Bourgeault, I. L., Benoit, C., \& Davis-Floyd, R. (Eds.). Reconceiving Midwifery (pp. 91-110) Montreal, Canada: McGill-Queen's University Press.

van der Doef, M., \& Maes, S. (1999). The job-demand-control(-support) model and psychological well-being: A review of 20 years of empirical research. Work \& Stress, 13, 87-114.

Viswesvaran, C., Sanchez, J. I., \& Fisher, J. (1999). The role of social support in the process of work stress: A meta-analysis. Journal of Vocational Behavior, 54, 314334.

Williams, D. (2005). Professional midwifery in the United-States: The American College of Nurse-Midwives turns 50. Journal of Midwifery \& Women's Health, 50, $1-2$.

Williams, K. J., \& Alliger, G. M. (1994). Role stressors, mood spillover, and perceptions of work-family conflict in employed parents. Academy of Management Journal, $37,837-868$. 
World Health Organization. (2006). Midwives: Making a difference in maternal health. Making Pregnancy Safer, 2, 1-8. Retrieved September 28, 2007, from http://www.who.int/entity/making_pregnancy_safer/publications/JAN06_Newslett er_v2.pdf

Zimmer, L. (2005). Community-based midwives and hospital-based nurses: Seeking the common ground for collegiality. The Midwifery Way: A National Forum Reflecting on the State of Midwifery Regulation in Canada (pp. K2-K9). Winnipeg, MB: Prairie Women's Health Centre of Excellence. 
Appendix A

Semi-Structured Interview Questions

Midwives

I understand that midwifery can be very demanding work. For the next few moments, I will be asking you specific questions about difficult days at work. Your responses will be recorded. However, the recording will be number coded and will not be linked to your personal identity. To help me keep your responses anonymous, I would like you to refrain from using proper names or names of places. However, if you accidentally include information that could identify you it will be purged from the recordings. The recordings, transcripts, and resulting data will be stored securely in Dr. Day's research lab.

Before we start I would like to give you the opportunity to talk to me about what you feel are current issues with regards to your practice of midwifery. I would also like to remind you that if at any point you feel uncomfortable answering the questions we can skip to the next question or simply end the interview.

1. Can you please tell me what you feel are some of the current issues related to your practice of midwifery?

2. Think of a work day in the past month that went particularly well.

Why did that day go particularly well?

What individual or personal factors, if any, made that day go well?

What organizational factors, if any, made that day go well?

3. Think of a work day in the past month that was particularly stressful.

Why was that particular day stressful? 
Can you pinpoint the source(s) of that stress?

What individual or personal factors helped you deal with that stress?

What organizational factors helped you deal with that stress or would help you deal with that stress were they present?

4. Specifically with regards to your work with your clients, think of a recent client interaction that went particularly well.

Why did it go particularly well?

What individual or personal factors, if any, made it go well?

What organizational factors, if any, made it go well?

5. Specifically with regards to your work with your clients, think of a recent client interaction that was difficult or stressful.

Why was that particular interaction stressful?

Can you pinpoint the source(s) of that stress?

What individual or personal factors helped you deal with that stress?

What organizational factors helped you deal with that stress or would help you deal with that stress were they present?

6. Specifically with regards to your interactions with other health professionals (nurses, doctors, other midwives), think of a recent interaction that went particularly well.

Why did it go particularly well?

What individual or personal factors, if any, made it go well?

What organizational factors, if any, made it go well? 
7. Specifically with regards to your interactions with other health professionals (nurses, doctors, other midwives), think of a recent interaction that was difficult or stressful.

Why was that particular interaction stressful?

Can you pinpoint the source(s) of that stress?

What individual or personal factors helped you deal with that stress?

What organizational factors helped you deal with that stress or would help you deal with that stress were they present?

8. Can you think of any other relevant sources of personal stress with regards to your work as a midwife that we have not yet discussed?

Why was that particular day/event/interaction stressful?

Can you pinpoint the source(s) of that stress?

What individual or personal factors helped you deal with that stress? What organizational factors helped you deal with that stress or would help you deal with that stress were they present?

9. Is there anything that you wish to add?

Results will be sent to your provincial association when the study is complete, however, feel free to contact me for updates.

Thank you very much for your assistance.

Subject matter experts

For the next few moments, I will be asking you specific questions about your experience with midwives. Your responses will be recorded. However, the recording will be number coded and will not be linked to your personal identity. To help me keep 
your responses anonymous, I would like you to refrain from using proper names or names of places. However, if you accidentally include information that could identify you it will be purged from the recordings. The recordings, transcripts, and resulting data will be stored securely in Dr. Day's research lab.

Before we start I would like to give you the opportunity to talk to me about what you feel are current issues with regards to the practice of midwifery. I would also like to remind you that if at any point you feel uncomfortable answering the questions we can skip to the next question or simply end the interview.

1. Can you please tell me what you feel are some of the current issues related to the practice of midwifery?

2. Specifically with regards to midwives' interactions with clients:

What factors would increase job stress for midwives?

What factors would decrease job stress for midwives?

What factors would increase health and well-being for midwives?

What factors would decrease health and well-being for midwives?

3. Specifically with regards to midwives' interactions with other health professionals (nurses, doctors, other midwives):

What factors would increase job stress for midwives?

What factors would decrease job stress for midwives?

What factors would increase health and well-being for midwives?

What factors would decrease health and well-being for midwives?

4. Can you think of any other relevant sources of personal stress with regards the practice of midwifery? 
5. Is there anything that you wish to add?

Results will be sent to your province's midwifery association when the study is complete, however, feel free to contact me for updates.

Thank you very much for your assistance. 
Appendix B

Measures

\section{Demographics}

Gender: Male 凶 Female Age:

Marital status: 凹 Single 凶 Married or Common Law 凹 Divorced

How many years have you worked as a midwife in Canada?

How many years have you worked as a midwife in other countries?

In which Canadian Province or territory do you currently practice?

\begin{tabular}{|c|c|c|c|c|}
\hline 区 Alberta & 凶 & Nova Scotia & 凶 & $\begin{array}{l}\text { Northwest } \\
\text { Territories }\end{array}$ \\
\hline 凶 British Columbia & 凶 & Ontario & 凶 & Yukon \\
\hline Manitoba & 凶 & Prince Edward Island & 凶 & Nunavut \\
\hline 凶 New Brunswick & 凶 & Quebec & & \\
\hline $\begin{array}{l}\text { 凶 Newfoundland and } \\
\text { Labrador }\end{array}$ & 凶 & Saskatchewan & & \\
\hline
\end{tabular}

Do you currently practice in a rural or urban setting?

区 Urban

凶 Rural

Are you required to work on-call?

凶Yes 凶No

If yes, how many days off-call are you allowed per month?

On average, how many hours do you work per week?

How many births did you attend over the last year?

How many home births have you attended in the past year?

How many medically difficult births have you experienced with your clients in the past year? (includes negative outcomes, unexpected complications, or other situations otherwise considered medical emergencies)

How many midwives (including yourself) work in your practice?

Where do you generally practice midwifery? (Select the most frequently used setting)
凶 Hospital

凶 Clinic

凶 Birthing Centre

凶 Client's Home

凶 Other, Specify: 
Job Control

Below are a number of questions about how much influence you may have over different aspects of your work as a midwife. Please use the following 5-point scale to indicate your responses.

\begin{tabular}{|c|c|c|c|c|}
\hline Very little & Little & $\begin{array}{c}\text { A moderate } \\
\text { amount }\end{array}$ & Much & Very Much \\
\hline 1 & 2 & 3 & 4 & 5 \\
\hline
\end{tabular}

1. How much can you generally predict the amount of work you will have to do on any given day?

2. How much control do you have personally over how much work you get done?

3. How much control do you have over the scheduling of your work?

4. How much control do you have over when you start and finish work?

5. How much control do you have over when you take vacations or days off?

6. How much control do you have over how you do your work?

7. How much can you control when and how much you interact with others at work?

8. How much control do you have over policies and procedures in your work unit?

9. How much control do you have over the sources of information you need to do your job?

10. How much are things that affect you at work predictable, even if you can't directly control them?

11. How much control do you have over the amount of resources (tools, materials) you get?

12. How much control do you have over the amount you earn as a midwife?

13. How much control do you have over how your work is evaluated?

14. In general, how much overall control do you have over work and workrelated matters? 
Role Conflict

Below are a number of statements about how you may feel about your work as a midwife. Please use the following 7-point scale to indicate your level of agreement or disagreement with the following statements.

\begin{tabular}{|c|c|c|c|c|c|c|}
\hline $\begin{array}{l}\text { Strongly } \\
\text { Dilsagree }\end{array}$ & Disagree & $\begin{array}{l}\text { Moderately } \\
\text { Disagree }\end{array}$ & $\begin{array}{l}\text { Neither } \\
\text { Agree Nor } \\
\text { Disagree } \\
\end{array}$ & $\begin{array}{l}\text { Moderately } \\
\text { Agree }\end{array}$ & Agree & $\begin{array}{c}\text { Strongly } \\
\text { Agree }\end{array}$ \\
\hline 1 & 2 & 3 & 4 & 5 & 6 & 7 \\
\hline
\end{tabular}

1. My responsibilities are clearly defined.

2. I work under policies or guidelines that are not clear.

3. I work with two or more groups who operate quite differently.

4. I am involved in situations in which there are conflicting requirements.

5. I am often asked to do things that are against my better judgement. 
Organizational support

Below are listed a number of statements about how you may feel about the midwifery organization (College, Association, etc.) that is most responsible for representing and supporting you in your province or territory. Please use the following 7-point scale to indicate your level of agreement or disagreement with the following statements.

\begin{tabular}{|c|c|c|c|c|c|c|}
\hline $\begin{array}{l}\text { Strongly } \\
\text { Disagree }\end{array}$ & Disagree & $\begin{array}{l}\text { Moderately } \\
\text { Disagree }\end{array}$ & $\begin{array}{l}\text { Neither } \\
\text { Agree Nor } \\
\text { Disagree }\end{array}$ & $\begin{array}{c}\text { Moderately } \\
\text { Agree }\end{array}$ & Agree & $\begin{array}{l}\text { Strongly } \\
\text { Agree }\end{array}$ \\
\hline 1 & 2 & 3 & 4 & 5 & 6 & 7 \\
\hline
\end{tabular}

1. The organization strongly considers my goals and values.

2. The organization would ignore any complaint from me.

3. The organization disregards my best interests when it makes decisions that affect me.

4. Help is available from the organization when I have a problem.

5. The organization really cares about my well being.

6. The organization is willing to extend itself in order to help me perform to the best of my ability. 
Social support

The following questions ask you to think about the support you receive from people around you. Using the 7-point scale below, please indicate how supportive are (a) your spouse, partner, or significant other; (b) your colleagues, and (c) your other family and friends.

\begin{tabular}{|c|c|c|c|c|c|c|}
\hline $\begin{array}{c}\text { Strongly } \\
\text { Disagree }\end{array}$ & Disagree & $\begin{array}{c}\text { Moderately } \\
\text { Disagree }\end{array}$ & $\begin{array}{c}\text { Neither } \\
\text { Agree Nor } \\
\text { Disagree }\end{array}$ & $\begin{array}{c}\text { Moderately } \\
\text { Agree }\end{array}$ & Agree & $\begin{array}{c}\text { Strongly } \\
\text { Agree }\end{array}$ \\
\hline 1 & 2 & 3 & 4 & 5 & 6 & 7 \\
\hline
\end{tabular}

Please rate separately for (a) Spouse, partner, or significant other; (b) your colleagues; and (c) your family $\&$ friends:

1. I can count on these people to listen to my problems.

2. I can rely on these people to provide advice or suggestions that I may need.

3. These people provide their time for me when I need it.

4. These people go out of their way to make my work life easier for me.

5. These people go out of their way to make my non-work life easier for me.

6. These people are concerned about my personal well-being. 
Resources

Below are a number of statements about your education in midwifery. Please use the following 7-point scale to indicate your level of agreement or disagreement with each statement.

\begin{tabular}{|c|c|c|c|c|c|c|}
\hline $\begin{array}{l}\text { Strongly } \\
\text { Disagree }\end{array}$ & Disagree & $\begin{array}{c}\text { Moderately } \\
\text { Disagree }\end{array}$ & $\begin{array}{l}\text { Neither } \\
\text { Agree Nor } \\
\text { Disagree }\end{array}$ & $\begin{array}{l}\text { Moderately } \\
\text { Agree }\end{array}$ & Agree & $\begin{array}{l}\text { Strongly } \\
\text { Agree }\end{array}$ \\
\hline 1 & 2 & 3 & 4 & 5 & 6 & 7 \\
\hline
\end{tabular}

1. I feel that my midwifery education has adequately prepared me to manage the administrative side of practicing as a midwife.

2. I feel that my midwifery education has adequately prepared me to interact with other professionals in a health care setting.

3. In general, I feel that my education as a midwife was appropriate to prepare me to practice as a midwife.

4. I have access to a peer review process to evaluate the quality of the care I provide.

5. I have access to insurance to protect myself as a midwife.

6. I am able to order medical procedures as they relate to my practice (e.g., blood work, ultrasounds, medical transfers).

7. I can consult directly with medical specialists as required by my practice.

8. The medical facilities with which I deal face staff shortages.

9. The medical facilities with which I deal offer the latest tests as required by my practice standards.

10. I personally have access to counselling services.

11. I have access to a means of protecting myself from legal action. 
Quality of relationships

Below are listed a number of statements about your work relationships as a midwife.

Please use the following 7-point scale to indicate your level of agreement or disagreement with the following statements.

\begin{tabular}{|c|c|c|c|c|c|c|}
\hline $\begin{array}{l}\text { Strongly } \\
\text { Disagree }\end{array}$ & Disagree & $\begin{array}{c}\text { Moderately } \\
\text { Disagree }\end{array}$ & $\begin{array}{l}\text { Neither } \\
\text { Agree Nor } \\
\text { Disagree }\end{array}$ & $\begin{array}{l}\text { Moderately } \\
\text { Agree }\end{array}$ & Agree & $\begin{array}{l}\text { Strongly } \\
\text { Agree }\end{array}$ \\
\hline 1 & 2 & 3 & 4 & 5 & 6 & 7 \\
\hline
\end{tabular}

1. The health-care professionals with whom I work are mistrustful of midwives.

2. My working relationships with other health-care professionals are collaborative.

3. My working relationships with other health-care professionals are characterized by mutual respect.

4. I have few interpersonal conflicts with the health-care professionals with whom I have a working relationship.

5. My working relationships with other midwives are collaborative.

6. My working relationships with other midwives are characterized by mutual respect.

7. I have few interpersonal conflicts with the midwives with whom I have a working relationship.

8. My clients have a positive view of midwives.

9. My clients trust midwives.

10. I have few interpersonal conflicts with my clients. 
Overwork

Below are a number of statements about how you may feel about your work as a midwife. Please use the following 7-point scale to indicate your level of agreement or disagreement with the following statements.

\begin{tabular}{|c|c|c|c|c|c|c|}
\hline $\begin{array}{c}\text { Strongly } \\
\text { Disagree }\end{array}$ & Disagree & $\begin{array}{c}\text { Moderately } \\
\text { Disagree }\end{array}$ & $\begin{array}{c}\text { Neither } \\
\text { Agree Nor } \\
\text { Disagree }\end{array}$ & $\begin{array}{c}\text { Moderately } \\
\text { Agree }\end{array}$ & Agree & Strongly \\
Agree
\end{tabular}

1. In general, I feel that my client load is manageable.

2. I often have to do extra unpaid work.

3. I often work unreasonably long periods.

4. It is very difficult for me to get time off from my work as a midwife.

5. I feel that my workload is fair relative to that of the midwives with whom I work. 
Burnout

The MBI-GS is not a publicly available measure and therefore not reproduced herein. To consult the measure see Maslach et al. (1996). 
Work-Life Balance

Below are listed a number of statements about your personal experience as a midwife.

Please use the following 7-point scale to indicate your level of agreement or disagreement with the following statements.

\begin{tabular}{|c|c|c|c|c|c|c|}
\hline $\begin{array}{c}\text { Strongly } \\
\text { Disagree }\end{array}$ & Disagree & $\begin{array}{c}\text { Moderately } \\
\text { Disagree }\end{array}$ & $\begin{array}{c}\text { Neither } \\
\text { Agree Nor } \\
\text { Disagree }\end{array}$ & $\begin{array}{c}\text { Moderately } \\
\text { Agree }\end{array}$ & $\begin{array}{c}\text { Agree } \\
\text { Agree }\end{array}$ \\
\hline $\mathbf{1}$ & $\mathbf{2}$ & $\mathbf{3}$ & $\mathbf{4}$ & $\mathbf{5}$ & $\mathbf{6}$ & $\mathbf{7}$ \\
\hline
\end{tabular}

1. I successfully manage the demands of both my work and my personal life.

2. I am happy with the way I divide my time among work, family, and my personal life.

3. I can manage my time such that I am able to incorporate personally satisfying activities into my schedule.

4. People close to me tell me that I have a good balance between work and life. 
Strain

The following is a list of physiological complaints that people sometimes have. Using 5point scale below, please indicate how often you have experienced each of these complaints in the past month.

\begin{tabular}{|c|c|c|c|c|c|}
\hline Never & Almost Never & Sometimes & Fairly Often & $\begin{array}{c}\text { Almost } \\
\text { Always }\end{array}$ & Always \\
\hline 0 & 1 & 2 & 3 & 4 & 5 \\
\hline
\end{tabular}

1. General aches or pains

2. Upset stomach

3. Headaches

4. Skin rashes or itching

5. Trouble sleeping

6. Crying

7. Lack of appetite

8. Feeling life is pointless

9. Dizziness or faintness

10. Common cold or flu

11. Overly tired/lack of energy

12. Sweating hands, feeling wet \& clammy

13. Nervousness or tenseness

14. Muscle twitching or trembling

15. Rapid heartbeat (while not exercising or working hard)

16. Feeling down or blue or depressed

17. Difficulty concentrating

18. Loss of interest in things, such as TV news, \& friends

19. Taking medication to sleep or calm down

20. Shortness of breath (while not exercising or working hard) 
Appendix C

Correlations Between Demographic Variables and Outcome Measures

$\begin{array}{lllllll}M & S D & 1 & 2 & 3 & 4 & 5\end{array}$

\section{Outcomes}

1. Strain

2. Emotional Exhaustion

3. Cynicism

4. Professional Efficacy

5. Work-Life Balance

\section{Demographics}

6. Age

7. Children currently living with

8. Years Worked in Canada

9. Years worked Other

10. Location of Practice

11. Size of practice

12. Single

13. Married or Common Law

14. Divorced

15. Practice, Hospital Setting

16. Practice, Clinic Setting

17. Practice, Birthing Centre

18. Practice, Client's Home $\begin{array}{lll}1.25 & 0.58 \quad(.89)\end{array}$

$2.89 \quad 1.31 \quad .65^{\mathrm{c}} \quad(.91)$

$\begin{array}{llll}1.77 & 1.39 & .56^{\mathrm{c}} & .70^{\mathrm{c}}\end{array}$

$\begin{array}{lllll}5.08 & 0.74 & -.24^{\mathrm{c}} & -.35^{\mathrm{c}} & -.43^{\mathrm{c}}\end{array}$

$\begin{array}{llllll}3.87 & 1.49 & -.49^{c} & -.63^{c} & -.51^{c} & .20^{b}\end{array}$ $\begin{array}{lllllll}40.38 & 9.79 & -.12 & -.18^{\mathrm{a}} & -.05 & .11 & .01\end{array}$

$\begin{array}{llllllll}1.39 & 1.16 & .06 & .16 & .16 & -.10 & -.08\end{array}$

$\begin{array}{lllllll}7.79 & 7.67 & -.03 & -.11 & .00 & .07 & .04\end{array}$

$\begin{array}{llllllll}1.70 & 4.50 & -.06 & -.09 & -.02 & -.02 & .01\end{array}$

$\begin{array}{lllllll}- & - & .09 & -.06 & .04 & .07 & .02\end{array}$

$\begin{array}{llllllll}5.78 & 3.02 & -.05 & -.02 & .01 & -.06 & .06\end{array}$

$\begin{array}{lllllll}- & - & .12 & .04 & .00 & -.02 & -.09\end{array}$

$\begin{array}{lllllll}- & - & -.12 & -.02 & .00 & -.01 & .07\end{array}$

$\begin{array}{lllllll}- & - & .01 & -.02 & .00 & .05 & .01\end{array}$

$\begin{array}{lllllll}- & - & .09 & .21^{\mathrm{b}} & .12 & -.12 & -.07\end{array}$

$\begin{array}{llllllll}- & - & - & .01 & -.04 & -.04 & .02 & -.04\end{array}$

$\begin{array}{lllllll}- & - & -.01 & -.15^{\mathrm{a}} & -.16^{\mathrm{a}} & -.03 & .14\end{array}$

$\begin{array}{llllllll}- & - & -.07 & -.05 & .00 & .07 & .08\end{array}$ ${ }^{\mathrm{a}} p \leq .05 .{ }^{\mathrm{b}} p \leq .01 .^{\mathrm{c}} p \leq .001$. 


\section{Saint Marys}

Halifax, Nova Scotia

Canada B3H $3 \mathrm{C} 3$

Patrick Power Library

tel $\quad 902.420 .5534$

$\operatorname{tax} \quad 902.420 .5561$

web www.smu.ca

\section{Research Ethics Board Certificate Notice}

The Saint Mary's University Research Ethics Board has issued REB certificates related to this thesis. The certificate number are 07-205 and 08-047.

A copy of the certificate is on file at:

Saint Mary's University, Archives

Patrick Power Library

Halifax, NS

B3H 3C3

Email: $\underline{\operatorname{archives} @ \text { smu.ca }}$

Phone: 902-420-5508

Fax: 902-420-5561

For more information on the issuing of REB certificates, you can contact the Research Ethics Board at 902-420-5728 / ethics@smu.ca 